\title{
NBSIR 73-126
}

\section{Structural Tests of Mechanical Connections For Concrete Panels}

L. E. Cattaneo and F. Y. Yokel

Center for Building Technology Institute for Applied Technology National Bureau of Standards

Washington, D. C. 20410

November 1972

Final Report

Prepared for Office of Research and Technology Department of Housing and Urban Development Washington, D. C. 20410 
NBSIR 73-126

\section{STRUCTURAL TESTS OF MECHANICAL CONNECTIONS FOR CONCRETE PANELS}

L. E. Cattaneo and F. Y. Yokel

Center for Building Technology

Institute for Applied Technology

National Bureau of Standards

Washington, D. C. 20234

November 1972

Final Report

Prepared for

Office of Research and Technology

Department of Housing and Urban Development

Washington, D. C. 20410

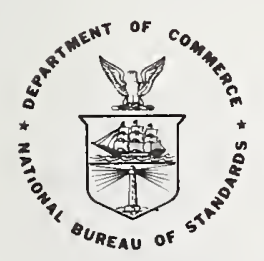

U. S. DEPARTMENT OF COMMERCE, Frederick B. Dent, Secretary

NATIONAL BUREAU OF STANDARDS, Richard W. Roberts, Director 



\section{Table of Contents}

Structural Tests of Mechanical Connections for Concrete Panels

Page

Abstract

SI Conversion Units

1.0 Introduction and objective.... . 1

2.0 Description of Building System . . 2

3.0 Scope . . . . . . . . . . . 3

4.0 specimens . . . . . . . . . . 5

4.1 Connectors .. . . . . . . . . . 5

4.2 Fabrication of Specimens . . . . . 6

5.0 Test Apparatus and Procedures . . 10

5.1 Bolt Tensioning . . . . . . . . . . 10

5.2 Specimen Loading. . . . . . . . . . . . . . 10

5.3 Displacement Measurements . . . . . . . . . . 11

5.4 Test Procedures . . . . . . . . . . . . . 11

6.0 Discussion of Test Results . . . 12

6.1 Type A Floor Connection Elements . . . . . . . 12

6.2 Type B Floor Connection Elements........ . 74

6.2.1 General Discussion .......... 14

6.2.2 Tension................... 16

6.2.3 Vertical (out-of-piane) shear: : : 17

6.2.4 Horizontal (in-plane) Shear...... 18

6.3 Type E Wall Connection Elements . . . . . . . 20

6.4 Type F Wall Connection Elements . . . . . . . 22

6.5 Type D Wall Connection Elements . . . . . 22

7.0 Summary . . . . . . . . . . . . 24

References . . . . . . . . . . . . . 27

Tables . . . . . . . . . . . . . . 28

Figures. . . . . . . . . . . . . . . . . . 34

Appendix - Test Resuits 

Structural Tests of Mechanical Connections

for

Concrete Panels

by

L. E. Cattaneo and F. Y. Yokel

Structures, Materials and Life Safety Division

Center for Building Technology

Institute for Applied Technology

\section{ABSTRACT}

Structural evaluation tests were performed on prototype steel insert connectors proposed for joining floor and wall panels of a precast concrete housing system included in Operation BREAKTHROUGH. Descriptions are given of 25 tests conducted with 5 different types of connectors. Specimen connections were laboratory-tested under simulated design loading conditions to evaluate their load capacity and ductility.

Key words: Concrete panels; connections; ductility; floor diaphragms; housing systems; insert connectors; Operation BREAKTHROUGH; precast concrete. 


\section{SI CONVERSION UNITS}

In view of present accepted practice in this country in this technological area, common U.S. units of measurement have been used throughout this paper. In recognition of the position of the USA as a signatory to the General Conference on Weights and Measures, which gave official status to the metric SI system of units in 1960, we assist readers interested in making use of the coherent system of SI units, by giving conversion factors applicable to U.S. units used in this report.

Length

$$
\begin{aligned}
& 1 \text { in }=0.0254 * \text { meter } \\
& 1 \mathrm{ft}=0.3048 * \text { meter }
\end{aligned}
$$

Area

$$
\begin{aligned}
& 1 \mathrm{in}^{2}=6.4516 * \times 10^{-4} \text { meter }{ }^{2} \\
& 1 \mathrm{ft}^{2}=0.09290 \text { meter }^{2}
\end{aligned}
$$

Force

$17 \mathrm{~b}(1 \mathrm{~b} f)=4.448$ newton

$1 \mathrm{kip}=4448$ newton

Pressure, Stress

1 ps $i=6895$ newton $/$ meter ${ }^{2}$

Mass/Volume

$1 \mathrm{lb} / \mathrm{ft}^{3}\left(1 \mathrm{bm} / \mathrm{ft}^{3}\right)=16.02 \mathrm{ki} 10 \mathrm{gram} / \mathrm{meter}^{3}$

Temperature ${ }^{\circ} \mathrm{C}=5 / 9$ (Temperature ${ }^{\circ} \mathrm{F}-32$ ) 
Structural Tests of Mechanical Connections

for

Concrete Panels

by

L. E. Cattaneo and F. Y. Yokel

1.0 Introduction and Objective

This report presents the results of tests performed to assist in the structural evaluation of a housing system selected by the Department of Housing and Urban Development for the Operation BREAKTHROUGH Program. The tests were conducted by the Center for Building Technology of the National Bureau of Standards as part of the technical support provided to DHUD.

The objective of the tests was to provide information necessary for evaluating the load capacity and ductility of a pre-cast concrete system using large panels.

An innovative feature of this system is the use of bolted steel connection elements of several standardized forms. The joint between two or more panels uses a sufficient number of connection elements to achieve the desired load capacity. Thus a single connection element may be considered to play a role similar to that of a single bolt in a bolted joint.

To insure adequate load capacity of the building structure it was essential to have reliable information on the load capacity of the connection elements. Because of the critical 
importance of this information and the complexity of the structural interaction, proof testing had to be used to verify the calculated strength of the connections and to obtain information on the characteristics of their resistance function.

\subsection{Description of Building System}

Figure 1.2.1 shows a simplified diagram of the structural system. The wall and floor panels are assembled at the site into structures which can range from 2-story townhouses to high-rise apartment buildings. Typical wall panels are approximately $30 \mathrm{ft} \times 8 \mathrm{ft} \times 8$ in and contain vertical reinforcing bars (varying between Nos. 4 and 6) [1] l/ and welded wire fabric $(4 \times 4-W 4 \times$ W4 $)[2]$ in each face. The perimeters of the wall panels contain pairs of bars (varying between Nos. 5 and 8 ) and, in addition, the top and bottom edges contain ivo. 4 bar stirrups. Typical floor slabs are approximately $22 \mathrm{ft} \times 10 \mathrm{ft}$ $x 6$ in and contain welded wire fabric $(4 \times 8$ - w4 $x$ w4) in the top surface and $1 / 2-i n$ diameter prestressing strands in the bottom, spaced at about 6 in, on center, across the width. Elevator cores, stairwells, etc., assembled on-site from precast elements complete the component mix required in a typical building .

Joining of the structural panels is accomplished by means of steel insert connectors cast into the edges of the panels.

\section{IT}

Numbers in brackets indicate references 1 isted at the end of this report. 
High strength bolts and special washers complete the connections which are subsequently grouted. The locations of the various types of connections are shown generally in figure 1.2.1; details of the various connection elements and supplementary hardware are given in figures 1.2 .2 through 1.2 .8 . Photographs of the 5 types of insert connectors (identified in this report as $A, B, D, E$ and $F$ ) submitted for test are shown in figures 1.2.9 through 1.2.13. A close-up of a floorslab to floor-slab (Type B) connection is shown in figure 1.2.14. Figure 1.2.15 further $i 11$ ustrates (as it would appear with concrete removed) the relationship of a Type A floor insert to Types $E$ and $F$ wall inserts at the connection of a floor slab with exterior bearing wall panels. It should be noted that, in order to implement design changes, some inserts were modified between the time of receipt at the laboratory (photos in figs. 1.2.11 through 1.2.13) and the time of testing (drawings in figs. 1.2.4 through 1.2.6). These modifications are described in section 4.1 (Connectors).

\subsection{Scope}

This report documents tension tests and shear tests performed to determine the load capacity and ductility of 3 basic connection designs which make use of the 5 types of insert connectors. 
The three connections (and respective inserts) are:

a. Floor-slab to bearing-wall to floor-slab.

(Inserts: A to $D$ to $A$ )

b. Floor-slab to floor-slab (unsupported edges).

(Inserts: $B$ to $B$ )

c. Junction of bearing-wal1-top to wal1-bottom, with floor-slab to floor-slab.

(Inserts: $E$ to $F, A$ to $E$ to $A$ )

A total of 25 tests were performed (see table 3.0 ) and are presented in 7 groups which are listed below:

a. Tests 1, 2: In-plane tension on floor

connection element (Type A) used over bearing walls.

b. Tests 3, 4: In-plane tension on floor connection element (Type B) used in unsupported edges .

c. Tests 5, 6: Out-of-plane shear of floor-slab to floorslab connection (Type B)

d. Tests 7-13: In-plane shear of floor-slab to floorslab connection (Type B)

e. Tests 14-16: In-plane tension on wall top connection element (Type E)

f. Tests 17-19: In-plane tension on wall bottom connection element (Type F)

g. Tests 20-25: 0ut-of-plane shear of bearing wall top connection element (Type D). 


\subsection{Specimens}

\subsection{Connectors}

Insert connectors and ancillary hardware used in the tests were supplied by the housing system producer. Details of these parts as used in test specimens which simulated wall and floor panel connections are shown in figures 1.2 .2 through 1.2.8. It should be noted that some of the inserts as tested (shown in figs. 1.2.4 through 1.2.6) differ in some respects from the corresponding photographs (1.2.11 through 1.2.13) of the inserts as received. These modifications were made so that the insert connectors would conform to the design changes in effect at the time of testing. Those affected were:

a. Type D - Anchor bars were shortened from 24 in to $18 \mathrm{in.}$ (figs. 1.2.4, 1.2.11).

b. Type E - Two end-pairs of anchor bars were removed and base plate was shortened from $2 \mathrm{ft}-3$ in to $2 \mathrm{ft}$; remaining 6 anchor bars were shortened from $2 \mathrm{ft}-6$ in to $2 \mathrm{ft}$; spacing of bars was left at 6 in although new spacing is to be 8 in. (figs. 1.2.5, 1.2.12).

c. Type F - Same as for Type D (above); (figs. 1.2.6, $1.2 .13)$.

Furthermore, the Type A test inserts had been fabricated of 7/16-in thick rectangular tubing (instead of $1 / 2-i n$, as designed) because of unavailability of the $1 / 2-i n$ material. 
Al1 base welds of shear studs and bar anchors were examined visually for obvious defects that would interfere with their intended function. One Type A insert was discarded as a result of one bar anchor breaking off in handling during this inspection. Further examination of weld quality was conducted by performing cold bend tests [3] on all base welds of 3 Type $A$ and 6 Type $B$ insert connectors. These were chosen at random as a sample of stud welds and bar welds from among the 82 various insert connectors received. Using this cold bend test method, studs and bars on the samples were bent through an angle of $30^{\circ}$ by striking with a hand hammer and then back to the original position in the same manner. Only one weld failure occurred. One bar anchor (Type A insert) was broken off completely after several hammer blows. No other base weld which was tested showed any apparent sign of failure.

\subsection{Fabrication of Specimens}

Specimens of floor slabs and wall panels were fabricated in the testing laboratory in accordance with plans and specifications provided by, or modified in consultation with, the housing system producer. All floor and wall panel specimens were cast in a horizontal plane. Drawings, giving a general description of the specimen dimensions with size and location of reinforcement, are shown in figures 2.2.1 through 2.2.6. Figures 2.2.1 through 2.2.3 describe the specimens which were fabricated according to the original design; and figures 2.2.4 through 2.2.6, show specimens using the modified design. Specimens of 
the design shown in figures 2.2.4 and 2.2.5 used a modified reinforcing detail to better simulate the restraint of prestressing. Specimens of the design shown in figure 2.2 .6 were added to the test series to simulate a special condition requiring test evaluation; in these the insert (Type B) is situated close to a corner of a floor slab, 8 in from the side of a utility cut-out (see insert in figure 1.2 .1 connected to labeled example of a typical Type B). The reinforcement in the specimens shown in figures 2.2.4 through 2.2.6 was considered reasonably representative of prototype construction.

Main reinforcement used in the panel specimens consisted of No. 3, No. 4 and No. 5 bars of ASTM A-615-70 Grade 60 [1] deformed steel bars. Welded steel wire fabric specified for concrete reinforcement was of two sizes: $4 \times 4-W 4 \times$ W4 and $4 \times 8-W 4 \times$ W4 (ASTM A-185-70)[2].

Covers for protecting insert tube cavities and other blockouts during casting (for later access to connecting nuts and bolts) were formed of plywood (fig. 2.2.7).

Concrete for the specimens was mixed at the laboratory in an 8-cu yd commercial transit mixer in 2-or 3-cu yd batches, and consolidated in forms and molds with internal vibration. Al1 batches were made with type I cement and normal weight sand and gravel; the maximum aggregate size was $3 / 4$ in and the air content which was specified to be 3 percent, or less, did not exceed 3.7 percent. The properties of the concrete batches at the time of casting are given in table 4.2. The concrete batch 
number is also used as the last digit of the specimen identification number (Table 3.0). The concrete mixes were proportioned as recommended by the supplier to achieve the desired strengths and the specified slump of 2 in \pm 1 in. Concrete for specimens representing floor slabs was specified to have a compressive strength of 5000 psi at 28 days and contained 6 bags of cement, 1200 1b of sand and 1900 1b of gravel per cu yd (with allowance for moisture in the aggregate); wall panel specimens were specified to have a 28 -day compressive strength of 4000 psi and were made of a mix containing 5 bags of cement, $1280 \mathrm{lb}$ of sand and $1900 \mathrm{lb}$ of gravel per cu yd. Control cylinders ( 6 in $\times 12$ in) for compression testing according to ASTM Method C-39-71[4] were cast for all batches. All cylinder test specimens were consolidated in their molds by internal vibration. After removal from forms and molds all specimens were moist-cured at $73^{\circ} \mathrm{F}, 95 \% \mathrm{R} . \mathrm{H}$. until they reached the desired strength as indicated by cylinder tests. Specimens were then stored in the 1 aboratory at $73^{\circ} \mathrm{F}, 50 \%$ R.H. unti 1 tested. Concrete strength at the time of panel tests was determined by cylinder tests (table 3.0).

Where connections were made in order to perform tests on assemblages of bolt-connected specimens (or to simulate such connections by attachment of loading equipment), bolts were tensioned to the specified load value with a calibrated torque wrench (fig. 2.2.8). Type B floor-slab to floor-slab connections which used $3 / 4-i n \times 3$ 1/2-in ASTM A-325[5] bolts were 
tightened to a bolt tension of 100 percent of proof $10 \mathrm{ad}$ $(28,4001 b)$. Floor-slab to wall-panel to floor-slab connections (Type $A$ to $D$ to $A$ ) which used $3 / 4-$ in $\times 5$-in $A-325$ bolts were tightened to a bolt tension of 5 percent of proof load (1420 1b). Bearing wall top and bearing wall bottom connections (Types $E$ and $F$ ) which used 5/8-in A-325 stud bolts (or equivalent bolts for testing Type F) were tightened to a bolt tension of 5 percent of proof load $(960$ 1b). Joint spaces of $1 / 4$ in were achieved using steel shims (figs. 1.2.7, 1.2.8, 1.2.14). In the actual system these spaces are used to compensate for tolerances in typical connections.

Grouting of joints and block-outs (and insert tube cavities in some test specimens) was done with a proprietary product. It is described by the manufacturer to be a factorymixed, non-shrinking, non-corrosive grouting material which contains Type III portland cement, sand and additional proprietary aggregate. The grout was mixed in accordance with the manufacturer's directions to attain compressive strength in excess of that of the specimen concrete. It was placed by hand. At the time of testing the connection element, checks were made on the grout compressive strength using 2 -in cubes stored in the laboratory alongside the grouted test specimens (table 3.0). Grout cubes were prepared and tested according to ASTM Method C-109-70T[6].

Prior to testing, connection element specimens were whitewashed to increase visibility of test damage. 


\subsection{Test Apparatus and Procedures}

Much of the apparatus and test procedure were common to many tests and are described here in general; comments on individual test particulars are included in the Appendix (Test Results) under the enumerated tests.

\subsection{Bolt Tensioning}

In order to tension the connection bolts to the proper loads, a hand-indicator-torque wrench (fig. 2.2.8) was calibrated to determine the torque corresponding to the desired bolt tensions. This operation was performed on sample groups of 3 bolts for each combination of bolt size and load. Calibration loads were measured by a center-hole type of load cell clamped between the head and nut (with appropriate washers) of each sample bolt while torque was measured on the wrench dial indicator. Calibration was performed with an extension attached to the socket end of the wrench which, later, had to be used in order to gain access to connecting bolts within insert cavities (fig. 2.2.8).

\subsection{Specimen Loading}

Specimens were subjected to loads applied by hydraulic rams. Center-hole-design rams, with a pull-rod through the ram bearing on a yoke beam, (fig. 3.2.1) were used to apply static tensile loads. Specimens subjected to static compres- 
sion were loaded by rams reacting against structural frames attached to the structural laboratory tie-down test floor (fig. 3.2.2). Repeated shear (push and push-pul1) tests were performed in a closed reaction frame with rams controlled by electro-hydraulic servovalves actuated by a signal function generator (fig. 3.2.3). Pressure for static rams was supplied by manual pumps and that for repeated load tests by a motor driven hydraulic power supply. All loads were measured by load cells (center-hole type, where required) placed in line with the rams.

\subsection{Displacement Measurements}

Linear variable differential transformers (LVDT's) were used for the measurement of deformation in specimens and of displacement between parts of test assemblages. LVDT's were mounted on fixtures attached to specimens with hot-melt adhesive as shown in figure 3.2.1. For correlation of test photographs which illustrate displacement measurement with test load-displacement computer plots, it is to be noted that specimen movement causing LVDT core insertion into the coil produced a positive record of displacement; and extraction, a negative one.

\subsection{Test Procedures}

In general, manually pumped static loads were applied at a rate of approximately $20001 \mathrm{~b} / \mathrm{min}$ in increments of 1000 $1 \mathrm{~b}$ or $2000 \mathrm{lb}$ (depending on the expected maximum). Load increments were followed by brief pauses (of seconds duration) 
to record 2 to 5 load-displacement observations. Voltage signals from transducers were automatically measured and recorded on magnetic tape for computer processing to produce digital data and computer-plotted graphs. Tests were also monitored, for the purpose of progress control, by an $X-Y$ recorder actuated by one load cell and one LVDT.

Repeated load tests (Tests 12 and 13 only), which employed cyclic loading, subjected the specimens to sinusoidal load at a frequency of $0.1 \mathrm{~Hz}$. Load cell and LVDT signal outputs were recorded continuously on strip chart recorders.

\subsection{Discussion of Test Results 2 /}

\subsection{Type A Floor Connection Elements}

Type A elements connect floor panels to bearing wall panels. Two of these elements were tested in tension, their critical mode of loading (Tests 1 and 2).

In Test 1 (fig. 4.1.1) the element was embedded in a floor slab specimen using the revised design (fig. 2.2.4) which gave less restraint and was thought to be a more accurate simulation of actual conditions than the original specimen design. Typical resistance curves are shown in figures 4.1 .2 and 4.1 .3 which illustrate the load-displacement relationship for Test 1 . In Test 2 the original specimen design (fig. 2.2.1) was used.

For details on tests, reference is made to table 3.0 and the text in the Appendix. 
Another difference between the specimens was that the insert tube was filled with grout in Test 2 .

The large difference between the failure loads in these two tests (29.5 kip in Test 1 versus $38.7 \mathrm{kip}$ in Test 2 ) is probably attributable to differences in the reinforcement design.

Failure load is defined as the load at which the specimen ceases to fullfill its function which, in this particular case, would be the yield load. It should be distinguished from ultimate load, which is the maximum load the specimen could resist, and rupture load which occurred at a point beyond which the specimen lost the ability to resist load.

The hairpin bars in the Test 2 specimen, shown in figure 2.2.1, provided more restraint to the wing studs than the reinforcing bars used in the Test 1 specimen, shown in figure 2.2.4. The failure mode of these specimens (figs. 4.1.1 and 4.1.4) illustrates the important role of the wing studs and the potential effect of their confinement, since in both cases the concrete covering the wing studs failed. In figure 4.1.4 the specimen was "pulled away" after rupture of the tail anchors to better examine their condition. It can be seen in figure 1.2.2 that the concrete cover of these studs was only $11 / 2 \mathrm{in}$. Another factor that may have affected capacity was the grouting of the connector tube. However, although the Test 2 specimen was grouted, it is questionable whether this grout did increase its capacity since no deformation had been observed 
in the ungrouted tube of the Test 1 specimen. On the basis that the less confining reinforcement in the Test 1 specimen is considered a better simulation of the actual structure, the results of Test 1 are considered representative of the strength of the Type A connection element in tension.

The ductile behavior of both specimens (more than 1/4-in elongation after the failure load was reached is probably attributable to localized plastic deformation in the tail anchor bars. Tensile failure in the tail anchor bars was observed in both specimens.

\subsection{Type B Floor Connection Elements}

\subsubsection{General Discussion}

Type B elements are used to connect floor panels to each other. They are subjected to horizontal (in-plane) shear or tension when the floor acts as a diaphragm to transmit horizontal (wind and earthquake) loads; and to vertical (out-of-plane) shear when two adjacent floor panels are subjected to different live loads or when adjacent panels have to be forced into alignment during erection.

Type B elements use oversize bolt holes and depend on friction bolting to develop shear resistance (the proof load on the bolts is $28,4001 \mathrm{~b})$. Overcoming of this frictional resistance as identified by sudden marked initial slip defines shear failure of Type B connectors. The conclusions drawn from the results of this test program are based on two premises: 
the tightening of the bolts does not exert significant tension on the connection elements; (2) the proof load in the bolt is fully transmitted as compression through the bearing between two adjacent elements.

Lack of fit (contact) in this bearing prior to tensioning of the bolt could result in a situation where part of the tension force in the bolt is resisted by tension exerted on the slabs by the connectors. Only the remaining part of the bolt tension force would then be available to compress the bearing between the two connectors. As a result, the capacity of the connection element in all three modes of loading previously discussed would be reduced.

Such a situation was experienced in the first unsuccessful attempt to assemble a floor-joint specimen assemblage (of the type described in Appendix section A.1.4, Test 7). Contact between the floor slabs at points besides the inserts, in addition to insufficient shimming between the connection insert bearing surfaces, allowed the tensioning force to produce separation cracks between the concrete and the insert tubes.

The designer intended to use steel shims to compensate for any lack of fit. It was not one of the objectives of the investigation to determine the feasibility of achieving full bearing prior to tensioning of the bolt or to make specific recommendations for added safety margins required to allow for erection tolerances. 


\section{2 .2 Tension}

Tests 3 and 4 (figs. $4.1 .5,4.1 .6$, and 4.1 .7 ) were tension tests on Type B connection elements. The specimen in Test 3 used the revised slab specimen reinforcement design (fig. 2.2.5) while in Test 4 the original design (fig. 2.2.1) was used. Test 3 used no grout and in Test 4 the tube of the connector was filled with grout.

As in the case of the Type A connection elements, the specimen using the revised reinforcement design (Test 3 ) failed at a lower load (18.0 kip as compared to 30.0 kip for Test 4$)$. The failure of these specimens was ductile. In this case, the wing studs had substantial concrete cover. Grouting may have affected strength; however, the failure modes provide no evidence that this was the case (no distortion of the tube in the ungrouted specimen was observed).

Figure 4.1 .5 and 4.1 .7 illustrate the failure mode. There was a tensile failure in the tail stud as is illustrated by the typical load-displacement curve shown in figure 4.1.6. The wing studs were bent but did not rupture.

The failure load in Test 3 should be considered indicative of the load capacity of the connection element since the Test 3 specimen better simulated restraint of the anchor in the structure. 


\subsubsection{Vertical (out-of-plane) Shear}

Two specimens were tested (Tests 5 and 6 ). The Test 5 specimen (fig. 4.1.8) used the revised reinforcement detail (figure 2.2.5) and in the Test 6 specimen the original design (fig. 2.2.1) was used. While the Test 5 specimen was ungrouted, grout was used in the tubes and the joints of the Test 6 specimen. Another difference was in the test set-up. Test 5 used restrained support conditions, (fig. 4.1.8). In Test 6 the outer slabs were unrestrained (as shown in fig. 4.1.10) and could rotate. In the actual structures, individual floor slabs are only partially restrained from rotation and grouting of the joint might not be used. Test 5 is considered the simulation which provides an indication of the connection element strength with less risk.

Since failure occurred by slipping at the interface between two adjacent connectors, it is assumed that the confining reinforcement arrangement had no effect on load capacity. However, load capacity was probably affected by grouting and may have been affected by support conditions .

Figure 4.1 .9 shows the plot of slip versus load for Test 5 which is also similar to the response observed in Test 6 . It can be seen that a large displacement occurred after initial slip. This apparent yield is attributable to slipping of the connection elements. The subsequent load increase occurred when the bolt resisted additional slipping in shear. The plot does not show the entire range of the test in which the speci- 
men resisted an ultimate load of 24 kip. Extended failure damage, as i11ustrated in figures 4.1 .8 and 4.1 .10 , occurred by spalling of the concrete covering the connectors. This mode of failure was resisted by the welded wire fabric covering the connector.

In summary, Test 5 with a failure load of 14.5 kip is considered a more reasonable representation of prototype construction. Both specimens developed approximately equal maximum loads.

\subsubsection{Horizontal (in-plane) Shear}

The loading condition simulated by these tests is considered critical since the connection element participates in the transmission of wind and seismic loads to the shear walls.

The Test 7 specimen (fig. 4.1.11) contained the revised reinforcement design (fig. 2.2.5) and no grout. The Test 9 specimen contained the revised reinforcement design and grout in the connector tubes but not in the joints. Tests 10 and 11 used specimens similar to those in Tests 7 and 9 , respectively, except that the connector was located close to the corner of the slab simulating a critical design condition. Test 8 used the original design (fig. 2.2.1) and grouting of the tubes as well as the joints. Test 10 is considered the simulation which would be expected to provide the least strength. However, the variables in Tests $7,9,10$ and 11 apparently did not affect load resistance. 
A typical resistance curve is shown in figure 4.1 .12 which illustrates the load-displacement relationship for Test 7 . Up to 10.0 kip the load was resisted by the friction force.

Subsequently, large deformations were associated with additional loading. The 10-kip load is identified as the failure load. The ultimate load is $34.5 \mathrm{kip}$. Collapse occurred by shearing of the high-strength bolt, (see figures 4.1 .11 and 4.1 .13 ). No concrete failure was observed in Tests 7 through 9. In Tests 10 and 11, where the connector is located close to a corner, the concrete was sheared in addition to the connections failing by slip as shown in figures $4.1 .14,4.1 .15,4.1 .16$ and 4.1.17. In Test 11 the bolt was sheared in addition to the concrete failure, while the Test 10 specimen reached ultimate load by shearing of the concrete without fracture of the bolt. In spite of the differences in their failure modes the resistance curves, as well as the failure loads and maximum loads, are similar in Tests $7,9,10$ and 11 . Test 8 , which used grout in the tubes and joints, developed a much higher frictional resistance; however, the maximum load was similar to that of the other test specimens. Since the integrity of grout in joints like those in Test 8 can not be assured because of their small widths, and since grouting might not be used in all cases, it is concluded that the results of Tests $7,9,10$ and 11 give an indication of the load capacity of the connection element. Even though the failure loads of specimens $7,9,10$ and 11 are similar, it may be desirable to prevent the concrete 
failure observed in Tests 10 and 11 (see figs. 4.1.14 through 4.1 .17 ) by additional reinforcement designed to prevent diagonal tension cracks.

Another two tests were conducted with specimens similar to the one used in Test 7 applying repeated cycles of load (fig. 4.1.18). In Test 12,1000 cycles of 3.8 kip per connection were applied. This cyclic load was determined to represent 50 percent of the design windload acting on a connection whose load capacity (10 kip) would be fully utilized to resist extreme wind Toads .

In Test 13, five alternating cycles of 6.9 kip per connection were applied. The $6.9 \mathrm{kip}$ load was determined to represent the design seismic load acting on a connection whose load capacity would be fully utilized to resist extreme seismic load. In both cases the sinusoidal load had a frequency of $0.1 \mathrm{~Hz}$. No slip failure or distress was observed.

\subsection{Type E Wall Connection Elements}

Type E connection elements are used to provide structural continuity (transmit tensile forces) between two successive bearing wall panels. Type E connection elements are also designed to provide a wall-to-floor connection together with Type A connectors.

The critical loading of these connection elements is tension caused by uplift forces, or by gravity following the destruction of a bearing wall panel by catastrophic loads. In 
the latter case the connector would act to prevent progressive collapse $-3 /$ as a result of abnormal loads on the building.

Three identical specimens were tested under similar loading conditions in Tests 14, 15, and 16. Figure 4.2.1 shows the setup for Test 14. Tension was applied through nuts attached to the high strength stud bolts. Displacements were measured between the concrete panel and the base plate of the connector. Displacements observed in this test were very small and failure occurred by rupture of the bolts (fig. 4.2.2). In subsequent tests, displacement measurements were made of bolt elongation (as shown in fig. 4.2.3 for Test 15). Figure 4.2.4 shows the results of Test 15 and figure 4.2 .5 shows the setup for Test 16 in which both displacement of base plate and bolt elongation were measured. The failure in Test 16 is shown in figure 4.2 .6 . Typical measurements are plotted in figures 4.2 .7 and 4.2 .8 for bolt elongation in Test 16; and in figures 4.2 .9 and 4.2.10 for base plate displacement in the same test. The connection elements in all three tests developed tensile load capacities ranging from $55 \mathrm{kip}$ to $58 \mathrm{kip}$. In all three, failure by fracture occurred with very little elongation of the high strength bolts (approximately 0.04 in). In establishing allowable design loads for these connection elements allowance should be made for their lack of ductility.

3/The term "progressive collapse" is used to describe a chain reaction of failures in a structure initiated by failure of a localized portion of the structure. 


\subsection{Type F Wall Connection Elements}

Type $F$ elements connect to Type $E$ elements and therefore fulfill the same function in tension. Thus the capacity of the connection in tension must be controlled by the weaker of the two elements. Three tests were performed. In Test 17 (fig. 4.2.11) the connection element was not grouted. In Tests 18 and 19 (figs. 4.2.12 and 4.2.13) similar grouted specimens were used. In all cases failure occurred in the connecting bolts which actually simulated the mating bolts of a Type E element. Except for minor concrete cracking no other distress was observed. The lowest load capacity was observed in Test 17 where failure was caused by thread stripping in both nuts (fig. 4.2.11). Unless design provisions are made to prevent thread failure, the lower load capacity in this test controls the allowable tensile load on the joint composed of Types $E$ and $F$ elements.

\subsection{Type D Wall Connection Elements}

Type $D$ wall connection elements are used together with Type A floor elements to effect a connection between floor slabs and bearing wall panels. These elements were judged to be critical in the prevention of progressive collapse in locations where wall panels or portions of wall panels would be required to resist extreme lateral (out-of-plane) loads. Thus the capacity of these connections under shear acting normal to the plane of the wall had to be determined. 
A total of six tests were conducted on three specimens. Figure 4.2.14 shows the specimen used in Tests 20 and 21 . Initially, load was applied by both rams; however only one connection failed. Subsequently the other connection was loaded to failure. This procedure generated two tests for the first specimen. In subsequent specimens, tests were conducted sequentially on one end and then on the other.

In Test 20 the $10 a d$ reacted on large steel plates as shown in figure 4.2.14. It was determined from the failure mode (fig. 4.2.15) that this provided restraint to the concrete and thereby increased load resistance. Thus, the results of Tests 20 and 21 are high and do not represent a valid simulation. In subsequent tests the load was applied through smaller, less confining bearing plates as shown in figure 4.2 .16 for Test 22 . Load versus displacement is given for Test 22 in figure 4.2.17. Static load was applied in 4-kip increments and reduced to zero after each new increment. The trend in this plot is also typical of that for the other tests. Failure load in this test was determined at the point where significant distress was observed in the concrete surface of the wall. This distress coincided with a marked change in the slope of the loaddisplacement curve. Subsequently, large additional deformations occurred during gradual shear failure in the concrete. The ultimate load substantially exceeded the failure load. The load capacity of these connection elements provided information which is important when progressive collapse is considered. 
Figure 4.2.18 shows the failure mode in Test 23. Failure modes in Tests 24 and 25 are shown in Figures 4.2 .19 and 4.2.20, respectively. In each case considerable spalling of concrete can be observed.

Comparison of the test results indicates that except for Tests 20 and 21 (which are not considered valid simulations) failure loads and ultimate loads are reasonably consistent. Grout was used only in the specimens in Tests 20 through 23. Grouting had no apparent effect on load capacity or loaddisplacement characteristics.

\subsection{Summary}

These tests were conducted because of the critical nature of the function of the connection elements. Results were obtained to assist in determining the load capacity and ductility of a pre-cast concrete panel system. In tests of Type B connection elements in in-plane shear. Types $E$ and $F$ in tension, and Type $D$ in out-of-plane shear, several similar specimens were tested under similar loading conditions. In all other cases only a single test is considered representative of the design used. Even where several specimens were tested, the number of tests performed was not adequate to determine strength variability. Thus, none of these test results should be used as a basis for increasing design load capacities if they are above those determined by calculation. Additional testing would be necessary for this purpose. 
Table 7.1 lists the minimum capacities determined from those tests which are considered reasonable simulations of the most critical design conditions. In the case of connection elements Types $E$ and $F$, where the weaker of the two constitutes the weak link in the connection, only the lowest value from all the tests of Types $E$ and $F$ elements is listed.

In addition to the lowest test results, table 7.1 notes whether the failure was ductile. Ductile behavior would tend to allow the structure to fail only if several connection elements fail simultaneously. In the case of nonductile failure, a single element could act as a weak link. Thus, conservative margins of safety should be used for nonductile connection elements, notably Types $E$ and $F$. On the other hand the ductile behavior of the other connection elements could be exploited in earthquake resistant design.

In the case of Type $B$ elements the results shown in table 7.1 are qualified, since they are based on the assumption that a fit of the bearing interface is achieved prior to tensioning of the friction bolt. Lack of fit at the bearing interface of these connection elements could result in reduction of their load capacity.

For the case using Type B elements simulated in Tests 10 and 1.1 , an improved arrangement of reinforcement in the vicinity of the connection would prevent shear failure of the concrete near the corner of the slab. 
The minimum capacities 1 isted in table 7.1 are based on the assumption that tolerances in fabrication and erection are within the limits recommended by ACI Standard 314-65[7] and ACI Standard 318-71[8]. It was not one of the objectives of this investigation to determine the feasibility of compliance with this standard. 


\section{References}

1. American Society for Testing and Materials, Specification A-615-68 for Deformed Billet-Steel Bars for Concrete Reinforcement, Part 4 of Book of 1971 ASTM Standards, Philade1phia, Pa.

2. American Society for Testing and Materials, Specification A-185-70 for Welded Steel Wire Fabric for Concrete Reinforcement, Part 4 of Book of 1971 ATMS Standards, Philade1phia, Pa.

3. American Welding Society, Code for Welding in Building Construction (AWS D1.0-69, Section 432), 1969, New York, New York.

4. American Society for Testing and Materials, Test Method C-39-71 for Compressive Strength of Cylindrical Concrete Specimens, Part 10 of Book of 1971 ASTM. Standards, Phi1adetphia, Pa.

5. American Society for Testing and Materials, Specification A-325-70a for High-Strength Bolts for Structural Steel Joints, Including Suitable Nuts and Plain Hardened Washers, Part 4 of Book of 1971 ASTM Standards, Philadelphia, Pa.

6. American Society for Testing and Materials, Test Method C-109-70T for Compressive Strength of Hydraulic Cement Mortars (Using 2-in Cubes), Part 9 of Book of 1971 ASTM Standards, Philadelphia, Pa.

7. American Concrete Institute, Manual of Standard Practice for Detailing Reinforced Concrete Structures (ACI 315-65), 1965, Detroit, Michigan.

8. American Concrete Institute, Building Code Requirements for Reinforced Concrete (ACI-318-71), 1971, Detroit, Michigan. 


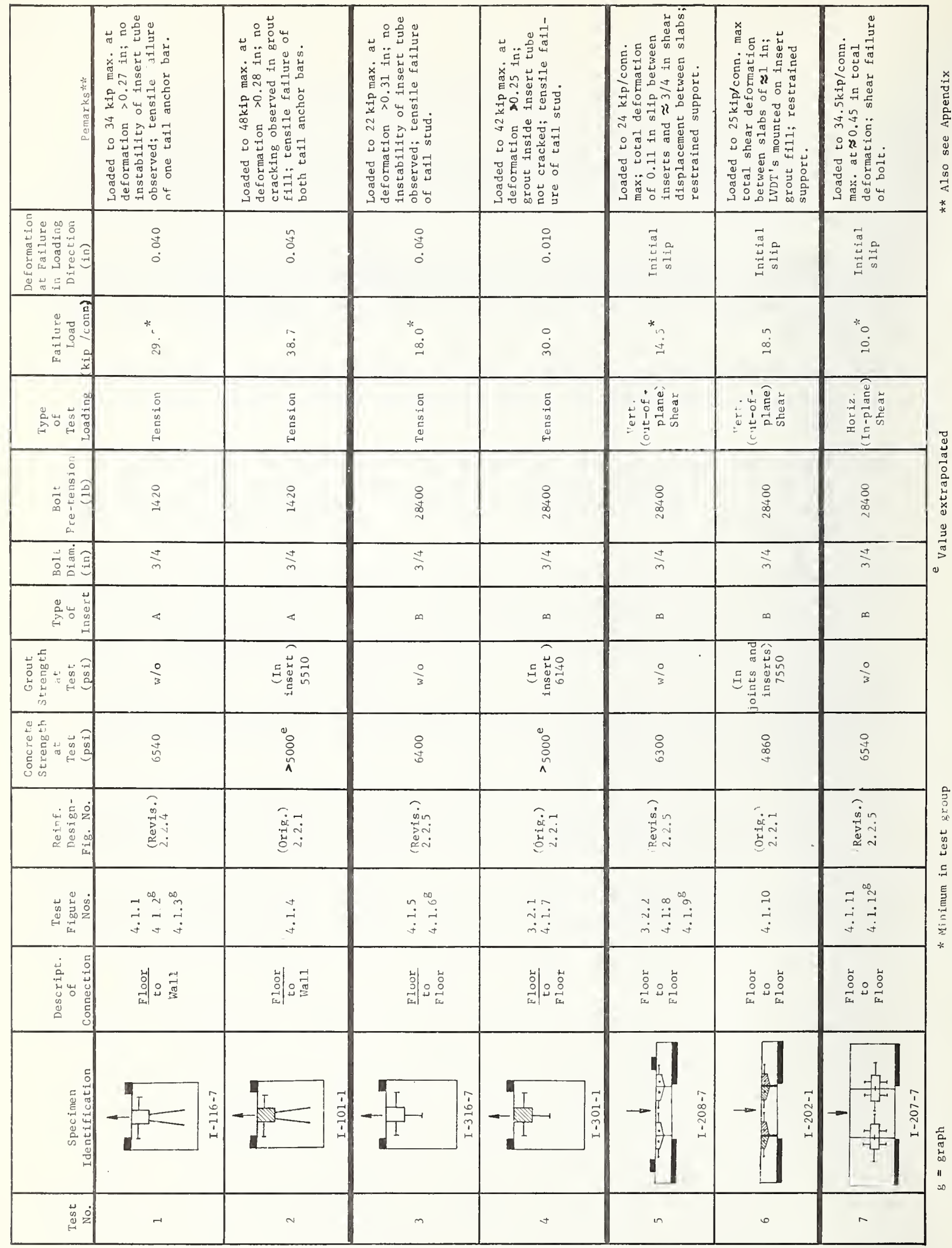









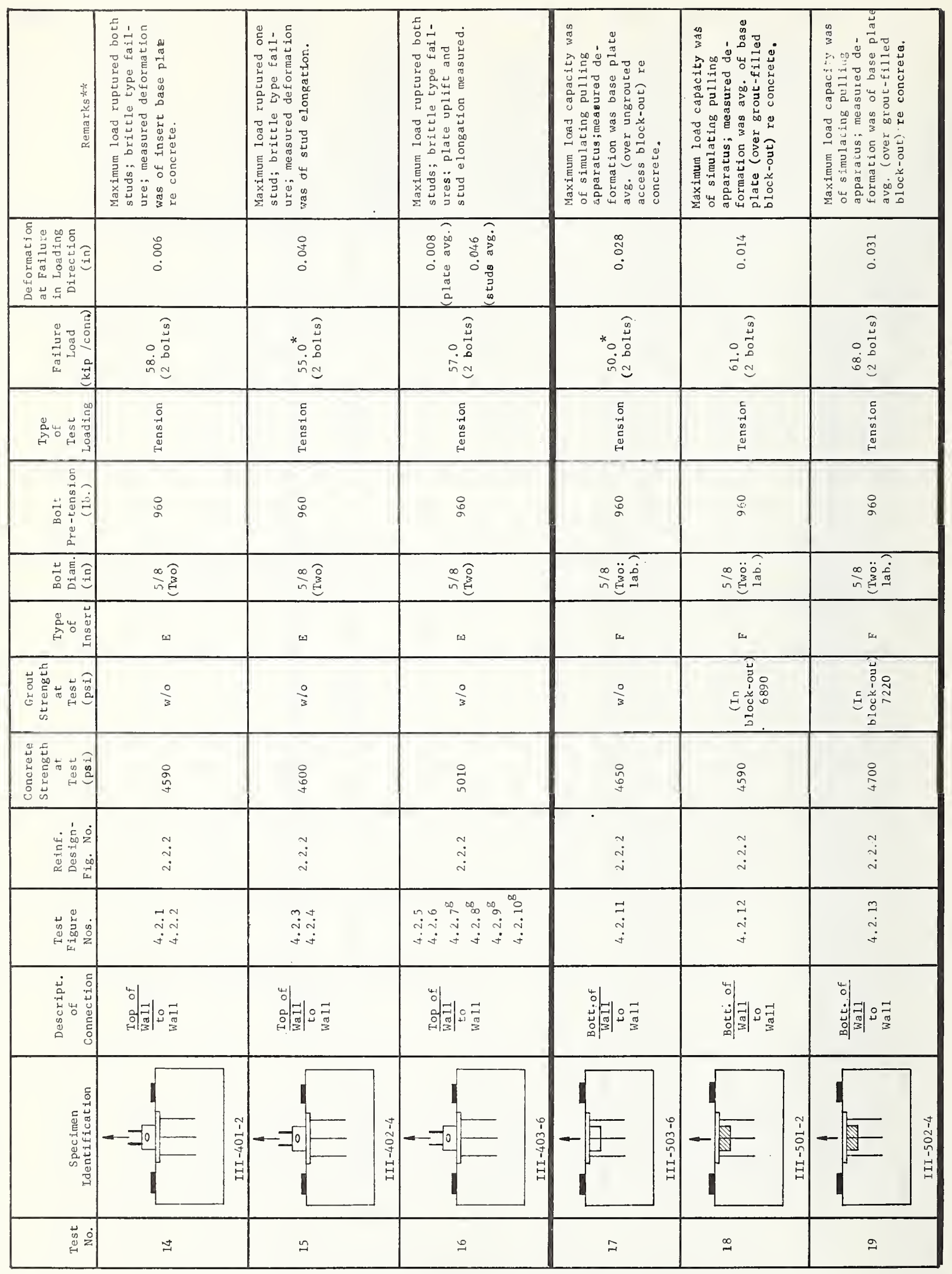




\begin{tabular}{|c|c|c|c|c|c|c|}
\hline 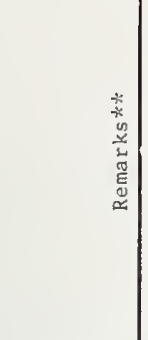 & 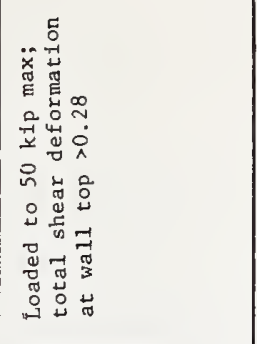 & 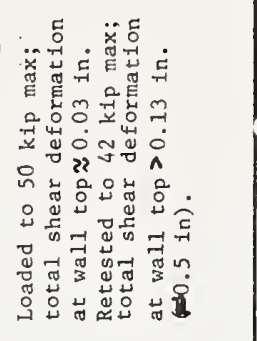 & 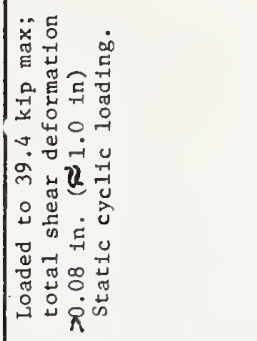 & 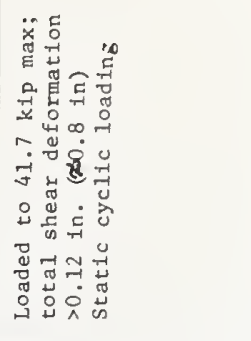 & 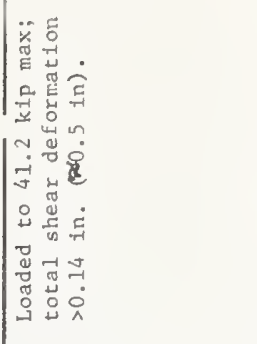 & 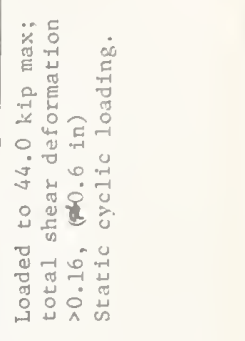 \\
\hline 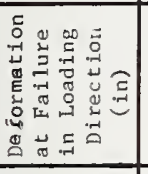 & : & $\stackrel{\leftrightarrow}{\circ}$ & $\begin{array}{l}\circ \\
\vdots \\
\circ\end{array}$ & $\begin{array}{l}\overrightarrow{1} \\
\vdots\end{array}$ & $\begin{array}{l}\overrightarrow{0} \\
\dot{0}\end{array}$ & $\begin{array}{l}\stackrel{0}{0} \\
\dot{0}\end{array}$ \\
\hline 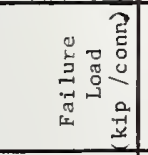 & $\begin{array}{l}\circ \\
\dot{0}\end{array}$ & $\dot{\circ}$ & $\begin{array}{l}*_{\infty} \\
\dot{\pi}\end{array}$ & $\dot{0}$ & $\stackrel{\circ}{\dot{v}}$ & $\dot{\imath}$ \\
\hline 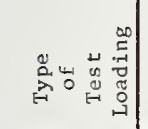 & 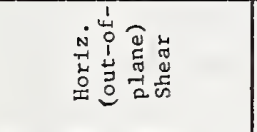 & 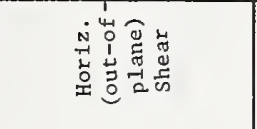 & 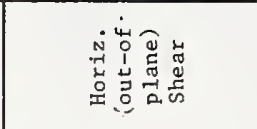 & 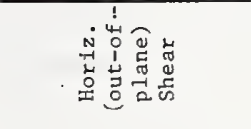 & 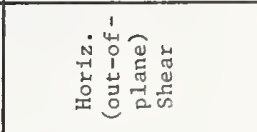 & 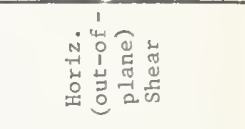 \\
\hline 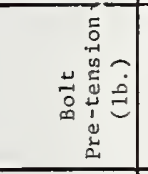 & 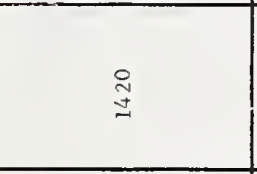 & 衤 & 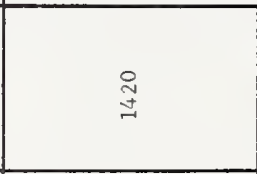 & 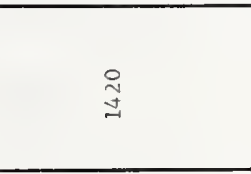 & 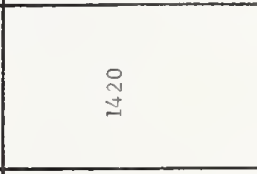 & $\stackrel{\text { I }}{\text { I }}$ \\
\hline 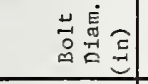 & $\frac{ \pm}{m}$ & $\frac{ \pm}{m}$ & $\frac{ \pm}{m}$ & $\stackrel{+}{m}$ & $\frac{ \pm}{m}$ & $\stackrel{ \pm}{m}$ \\
\hline $\begin{array}{ccc} & & - \\
\vdots \\
0\end{array}$ & $a$ & 0 & 0 & $a$ & $\theta$ & $\therefore$ \\
\hline 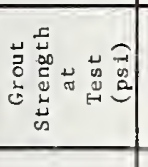 & 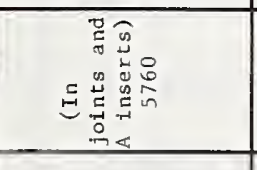 & 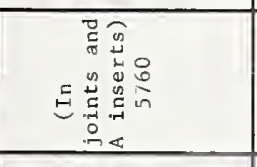 & 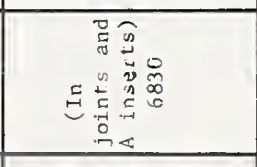 & 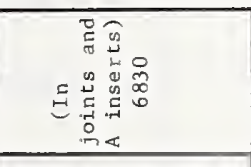 & $\frac{0}{3}$ & $\stackrel{\circ}{3}$ \\
\hline 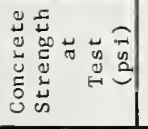 & 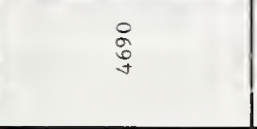 & 吕 & 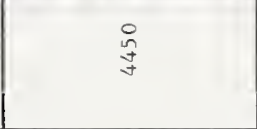 & 号 & 웅 & $\stackrel{\circ}{\circ}$ \\
\hline 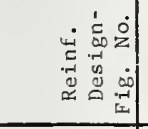 & $\stackrel{m}{i}$ & $\stackrel{m}{i}$ & $\underset{\substack{i \\
i}}{i}$ & $\stackrel{m}{i}$ & mi & ì \\
\hline 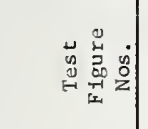 & 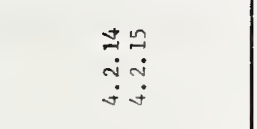 & $\vdots$ & 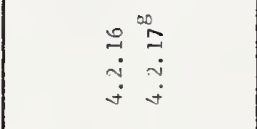 & $\begin{array}{l}\infty \\
\stackrel{\sim}{j} \\
\dot{j}\end{array}$ & 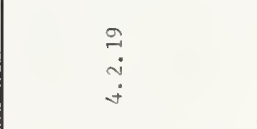 & $\begin{array}{l}\stackrel{\sim}{N} \\
\dot{\sim} \\
\dot{J}\end{array}$ \\
\hline 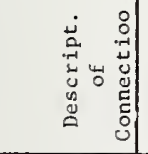 & 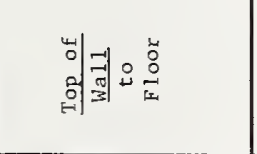 & 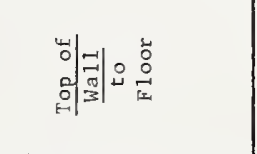 & 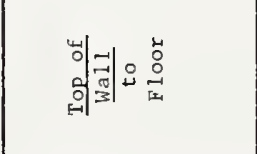 & 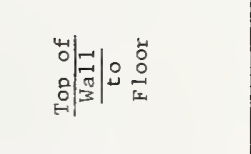 & 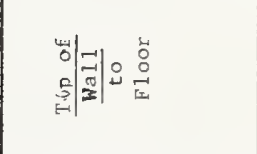 & 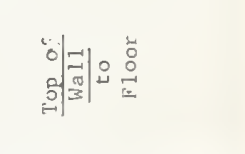 \\
\hline 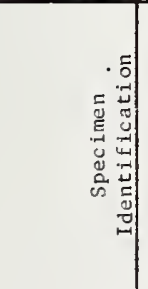 & 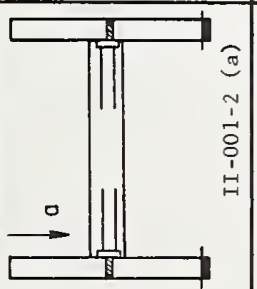 & 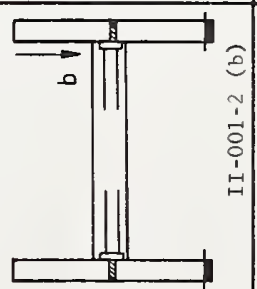 & 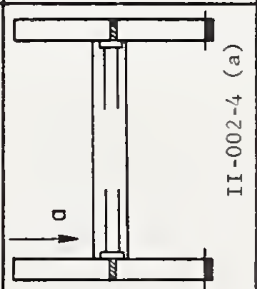 & 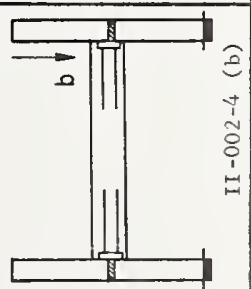 & 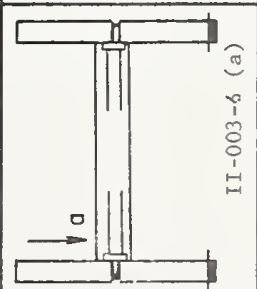 & 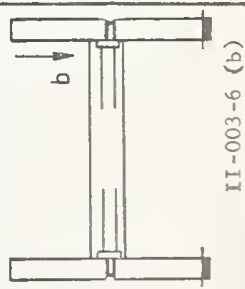 \\
\hline 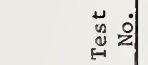 & i & $\overline{\mathbf{v}}$ & N & $\ddot{\nu}$ & 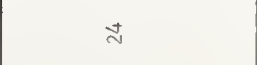 & $\vartheta$ \\
\hline
\end{tabular}


Table 4.2 Concrete Properties at Time of Placement

\begin{tabular}{|c|c|c|c|c|}
\hline $\begin{array}{c}\text { Batch } \\
\text { No. }\end{array}$ & $\begin{array}{c}\text { Specified } \\
\text { Strength } \\
\text { (psi) }\end{array}$ & $\begin{array}{c}\text { Slump } \\
\text { (in) }\end{array}$ & $\begin{array}{l}\text { Air } \\
\text { Content } \\
(\%)\end{array}$ & $\begin{array}{l}\text { Unit } \\
\text { Weight } \\
\left(\text { lb/ft }^{3}\right)\end{array}$ \\
\hline 1 & 5000 & 3 & $\begin{array}{l}\text { not } \\
\text { recorded }\end{array}$ & 142.7 \\
2 & 4000 & 2 & 3.4 & 145.1 \\
3 & 5000 & 2 & 3.7 & 145.5 \\
4 & 4000 & 2 & 2.8 & 145.5 \\
5 & 5000 & 3 & 1.3 & 147.8 \\
6 & 4000 & $21 / 4$ & 1.5 & 145.9 \\
7 & 5000 & $11 / 2$ & 2.2 & 149.0 \\
$7 a$ & 5000 & 1 & 1.5 & 149.5 \\
\hline
\end{tabular}


Table 7.1 Summary of Test Results

\begin{tabular}{|c|c|c|c|c|}
\hline $\begin{array}{l}\text { Connection } \\
\text { Element } \\
\text { (Type) }\end{array}$ & $\begin{array}{c}\text { Description } \\
\text { of } \\
\text { Connection }\end{array}$ & $\begin{array}{l}\text { Manner } \\
\text { of } \\
\text { Loading }\end{array}$ & $\begin{array}{l}\text { Minimum } \\
\text { Observed } \\
\text { Load-Capacity, } \\
\quad(\text { kip) }\end{array}$ & $\begin{array}{l}\text { Ductile } \\
\text { Behavior }\end{array}$ \\
\hline A & floor-to-wall & tension & 29.5 & Yes \\
\hline B & floor-to-floor & tension & 18.0 & Yes \\
\hline B & floor-to-floor & $\begin{array}{l}\text { out-of- } \\
\text { plane } \\
\text { shear }\end{array}$ & 14.5 & Yes \\
\hline B & floor-to-floor & $\begin{array}{l}\text { in-plane } \\
\text { shear }\end{array}$ & 10.0 & Yes \\
\hline$E \& F$ & wal1-to-wall & tension & 50.0 & iNo \\
\hline $\mathrm{D}$ & wal1-to-floor & $\begin{array}{l}\text { out-of - } \\
\text { plane } \\
\text { shear }\end{array}$ & 23.8 & Yes \\
\hline
\end{tabular}




\section{List of Figures}

Figure 1.2.1 Connections in panelized housing system.

Figure $\quad 1.2 .2$ Type $A$ insert details.

Figure 1.2 .3 Type $B$ insert details.

Figure $\quad 1.2 .4$ Type $D$ insert detai1s.

Figure 1.2 .5 Type $E$ insert details.

Figure $\quad 1.2 .6$ Type $F$ insert details.

Figure 1.2.7 Hardware for Type B insert.

Figure 1.2 .8 Hardware for Type A insert.

Figure $\quad 1.2 .9$ Type A insert.

Figure $\quad 1.2 .10$ Type B insert.

Figure 1.2.11 Type D insert (before modification).

Figure 1.2 .12 Type $E$ insert (before modification).

Figure 1.2.13 Type $F$ insert (before modification).

Figure 1.2.14 Floor-to-floor connection (Type B).

Figure 1.2.15 Floor-to-walls connection (skeletal)(Types $A$ to $E$ to $F)$.

Figure 2.2.1 Original design of floor test specimens (Types $A, B$ ).

Figure 2.2.2 Original design of wall-end test specimens (Types E,F).

Figure 2.2.3 Original design of double-top-ended wal1 test specimens (Type D).

Figure 2.2.4 Revised design of floor test specimens ( Type A).

Figure 2.2.5 Revised design of floor test specimens (Type B).

Figure 2.2.6 Revised design of floor test specimens near corner (Type B). 
Figure 2.2.7 Removal of block-out over floor insert connector.

Figure 2.2.8 Tensioning bolt of floor connection test as semb 1 age.

Figure $3.2 .1 \quad$ Typical static pull-out test set-up.

Figure 3.2 .2 Typical static compression test set-up.

Figure 3.2 .3 Typical repeated shear test set-up.

Figure 4.1.1 Front of Test 1 floor connection element (Type A).

Figure 4.1.2 Load-displacement graph for front of Test 1.

Figure 4.1.3 Load-displacement graph for rear of Test 1 .

Figure 4.1 .4 Test 2 floor connection element (Type A).

Figure 4.1 .5 Front of Test 3 floor connection element (Type B).

Figure 4.1.6 Load-displacement graph for front of Test 3.

Figure 4.1.7 Front of Test 4 floor connection element (Type B).

Figure 4.1.8 Front of Test 5 floor connection elements (Type B).

Figure 4.1.9 Load-displacement graph for left connection of Test 5 .

Figure 4.1 .10 Right connection of Test 6 floor connection elements (Type B).

Figure 4.1.11 Front of Test 7 floor connection elements (Type B).

Figure 4.1.12 Load-displacement graph for right connection of Test 7 .

Figure 4.1 .13 Test 9 floor connection elements (Type B).

Figure 4.1.14 Front of Test 10 floor connection elements (Type B, near corner).

Figure 4.1 .15 Rear of Test 10. 
Figure 4.1 .16 Front of Test 11 floor connection elements (Type B, near corner).

Figure 4.1 .17 Rear of Test 11 .

Figure 4.1 .18 Test 12 floor connection elements (Type B) (after test).

Figure 4.2.1 Front of Test 14 wall top connection element (Type E)(before test).

Figure $4.2 .2 \quad$ Ruptured stud bolts of Test 14.

Figure 4.2.3 Front of Test 15 wall top connection element (Type E).

Figure $\quad 4.2 .4 \quad$ Ruptured left stud bolt of Test 15.

Figure 4.2 .5 Front of Test 16 wall top connection element (Type E).

Figure $4.2 .6 \quad$ Ruptured stud bolts of Test 16.

Figure 4.2.7 Elongation of right stud bolt in Test 16 .

Figure 4.2.8 Elongation of left stud bolt in Test 16 .

Figure $\quad 4.2 .9$ Uplift of front edge of base plate in Test 16 .

Figure 4.2 .10 Uplift of rear edge of base plate in Test 16 .

Figure 4.2.11 Test 17 wall bottom connection element (Type F).

Figure 4.2 .12 Test 18 wall bottom connection element ( Type F).

Figure 4.2 .13 Test 19 wall bottom connection element (Type F).

Figure 4.2 .14 Tests 20,21 wall top connection elements (Type D)(before test).

Figure 4.2 .15 Test 20 wall top connection element (Type D).

Figure 4.2 .16 Test 22 wall top connection element (Type D).

Figure 4.2.17 Load-displacement graph of Test 22. 
Figure 4.2.18 Test 23 wall top connection element (Type D).

Figure 4.2 .19 Test 24 wall top connection element (Type D).

Figure 4.2 .20 Test 25 wall top connection element (Type D). 



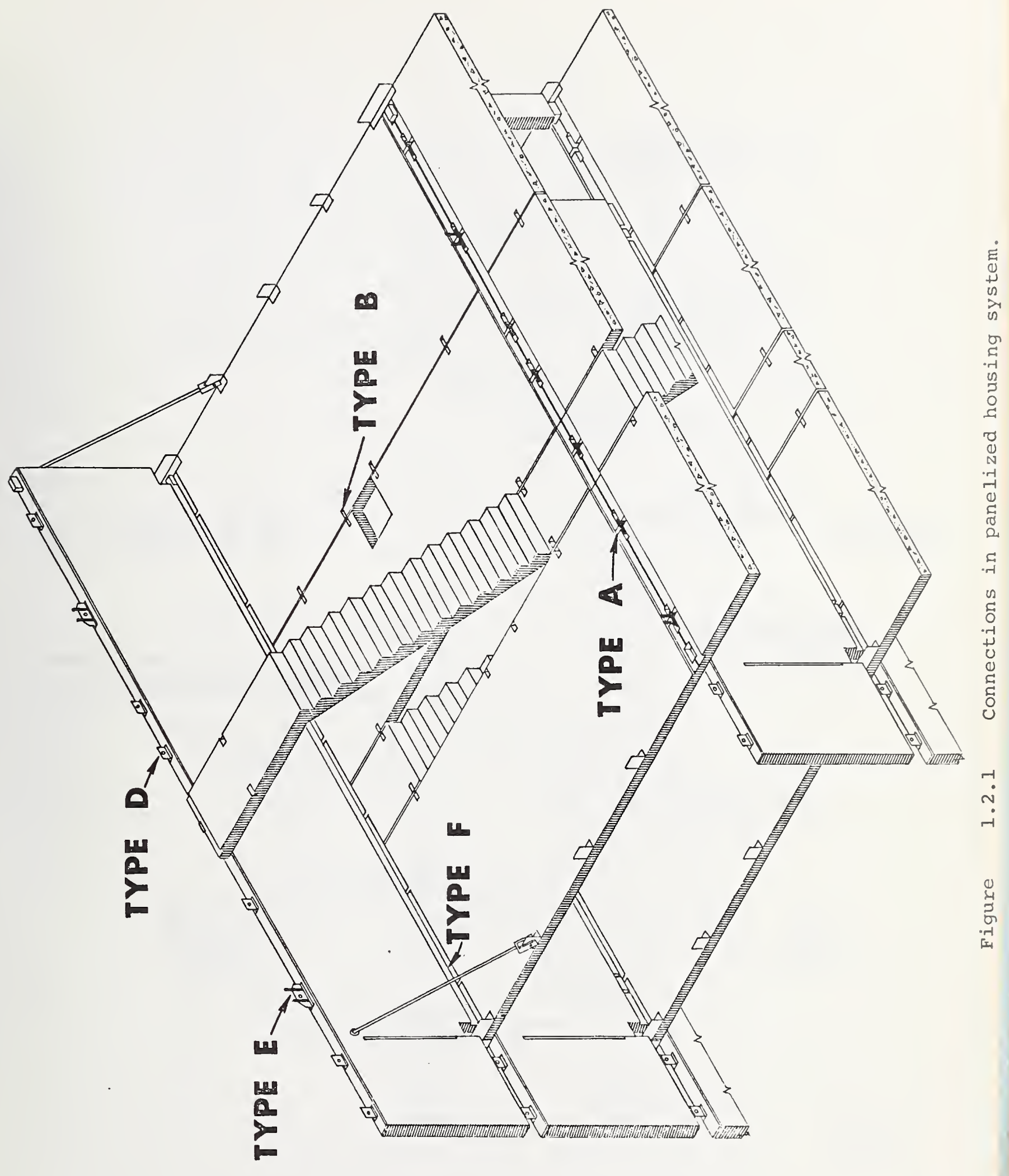




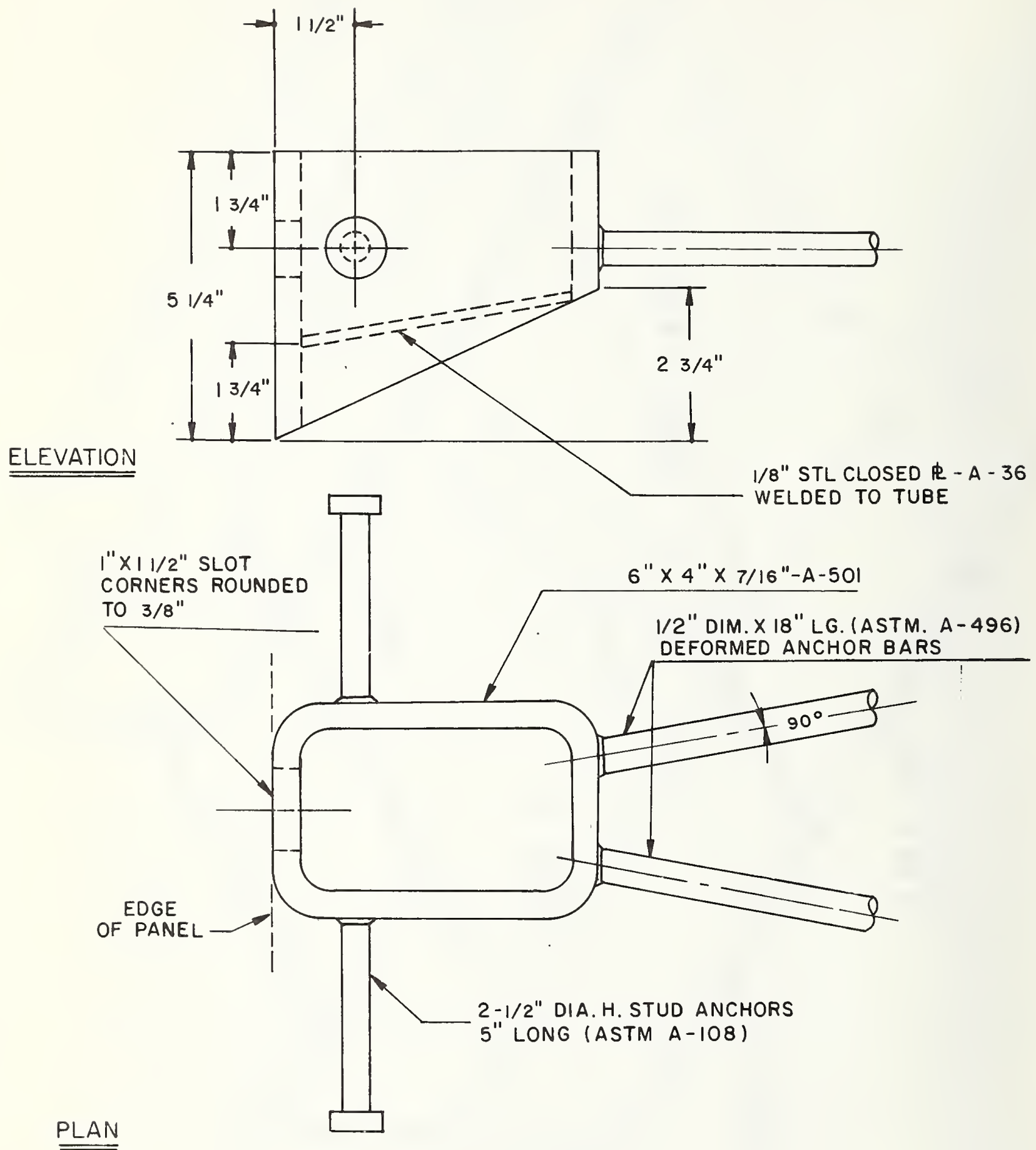

Figure 1.2.2 Type A insert details. 


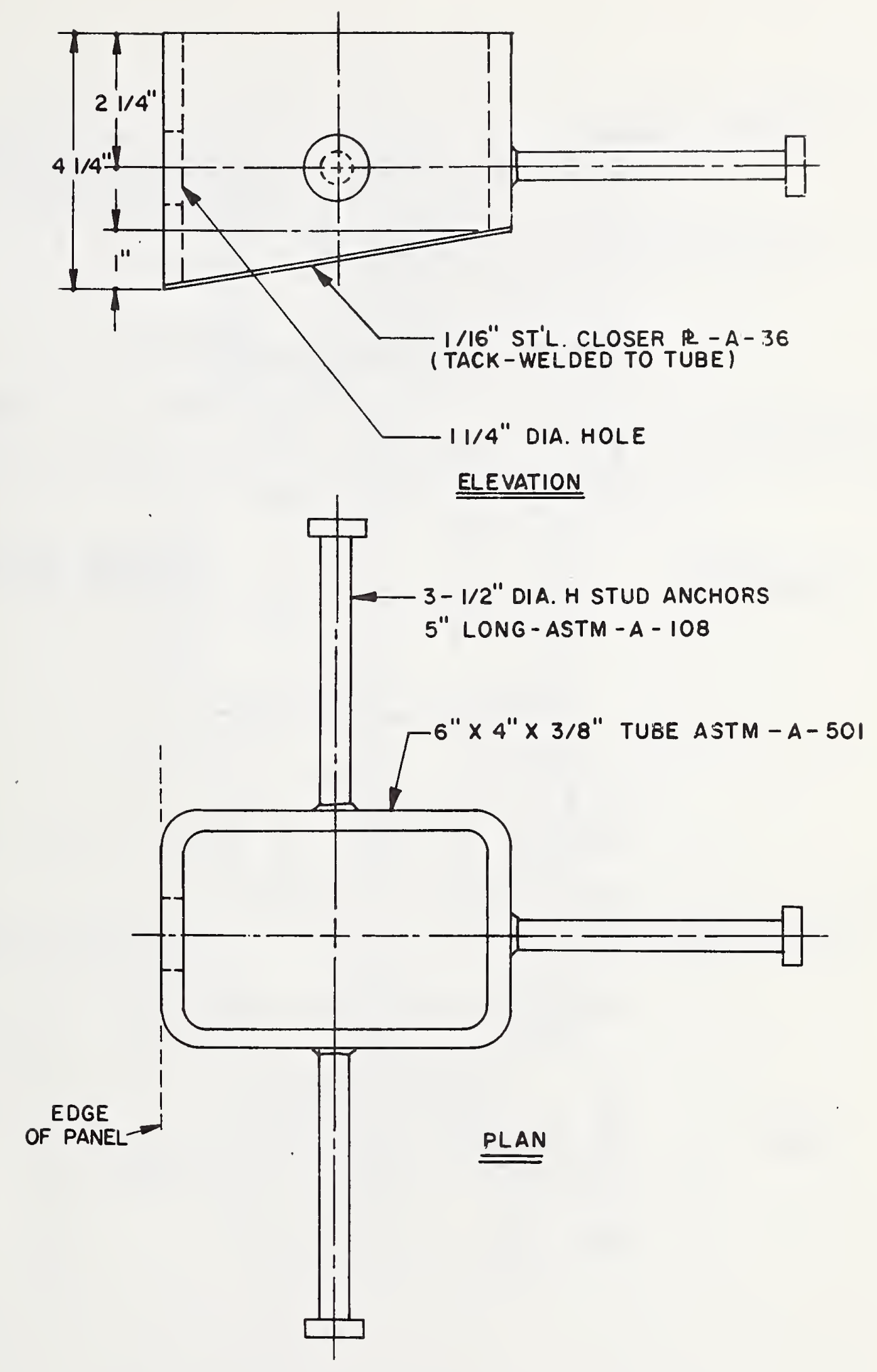

Figure 1.2.3 Type B insert details. 


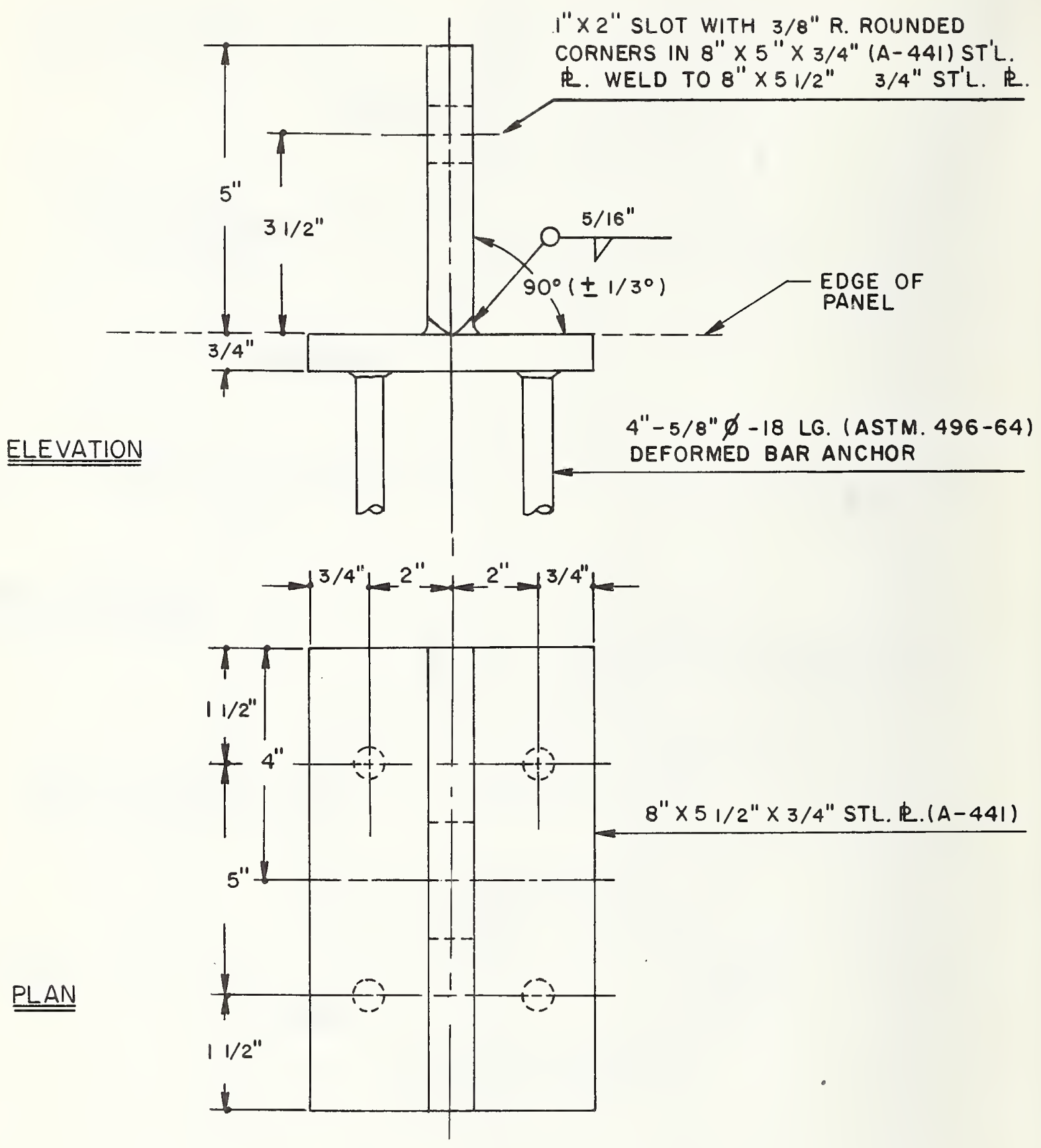

Figure 1.2.4 Type D insert details. 


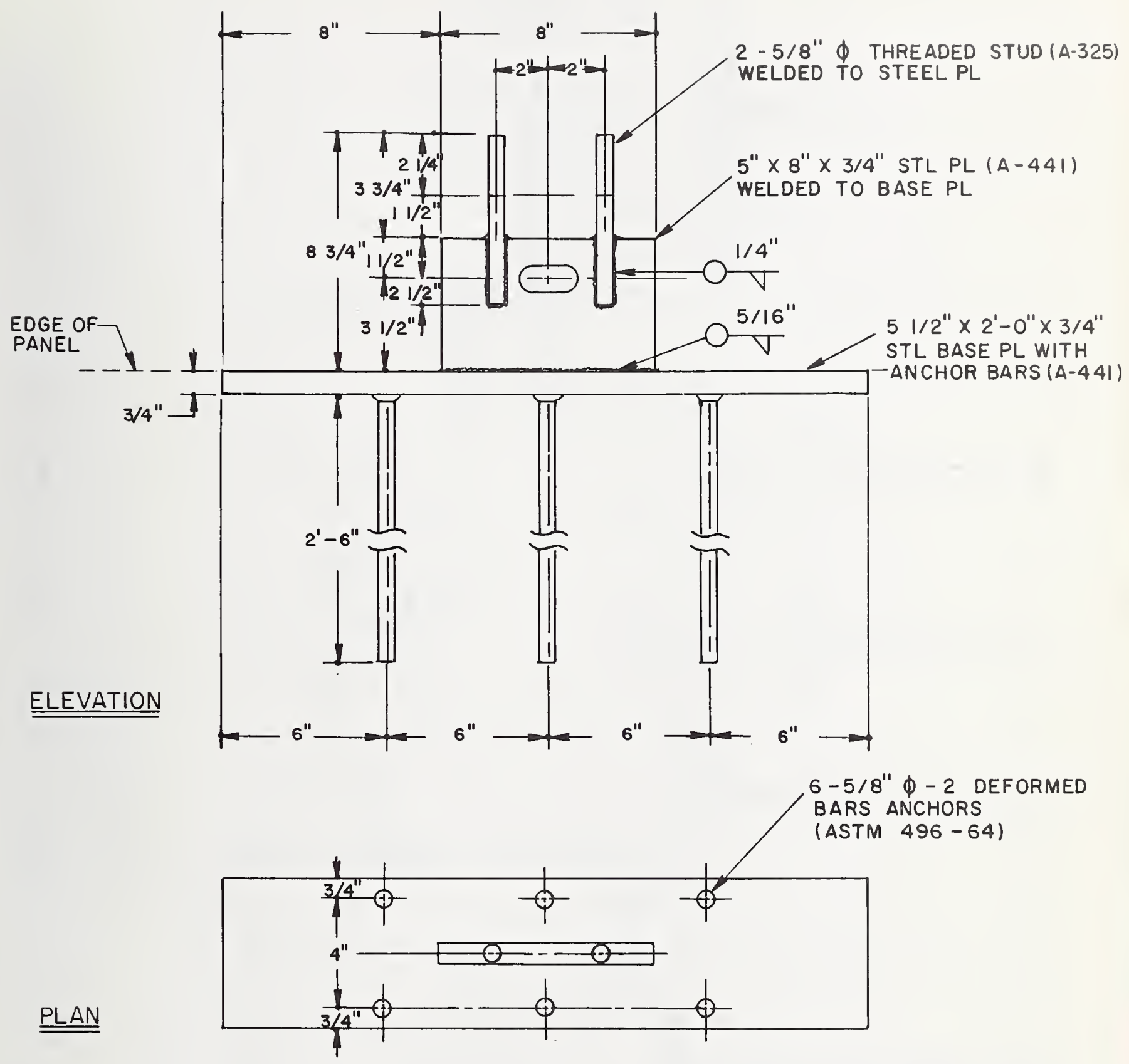

Figure 1.2.5 Type $E$ insert details. 


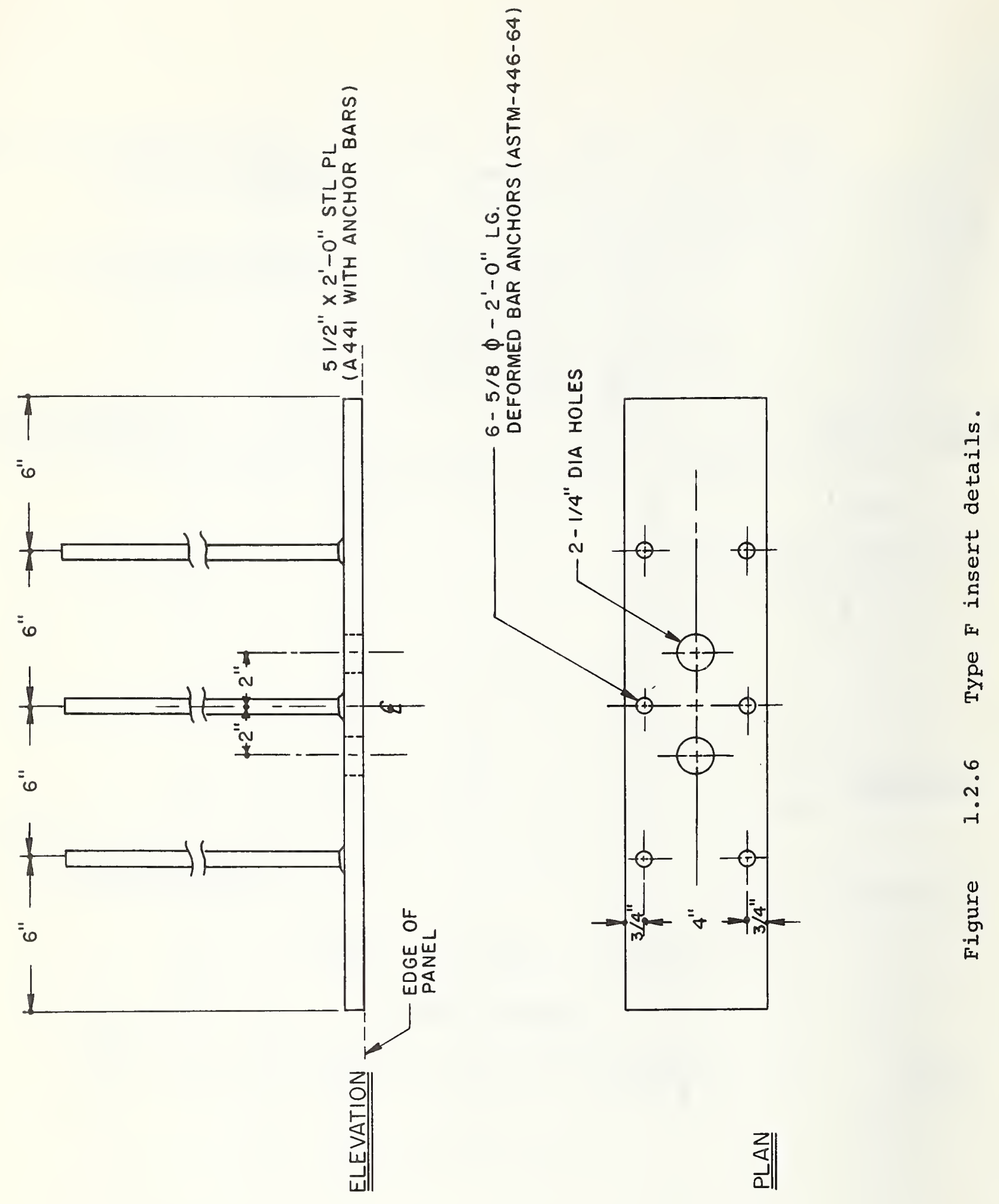



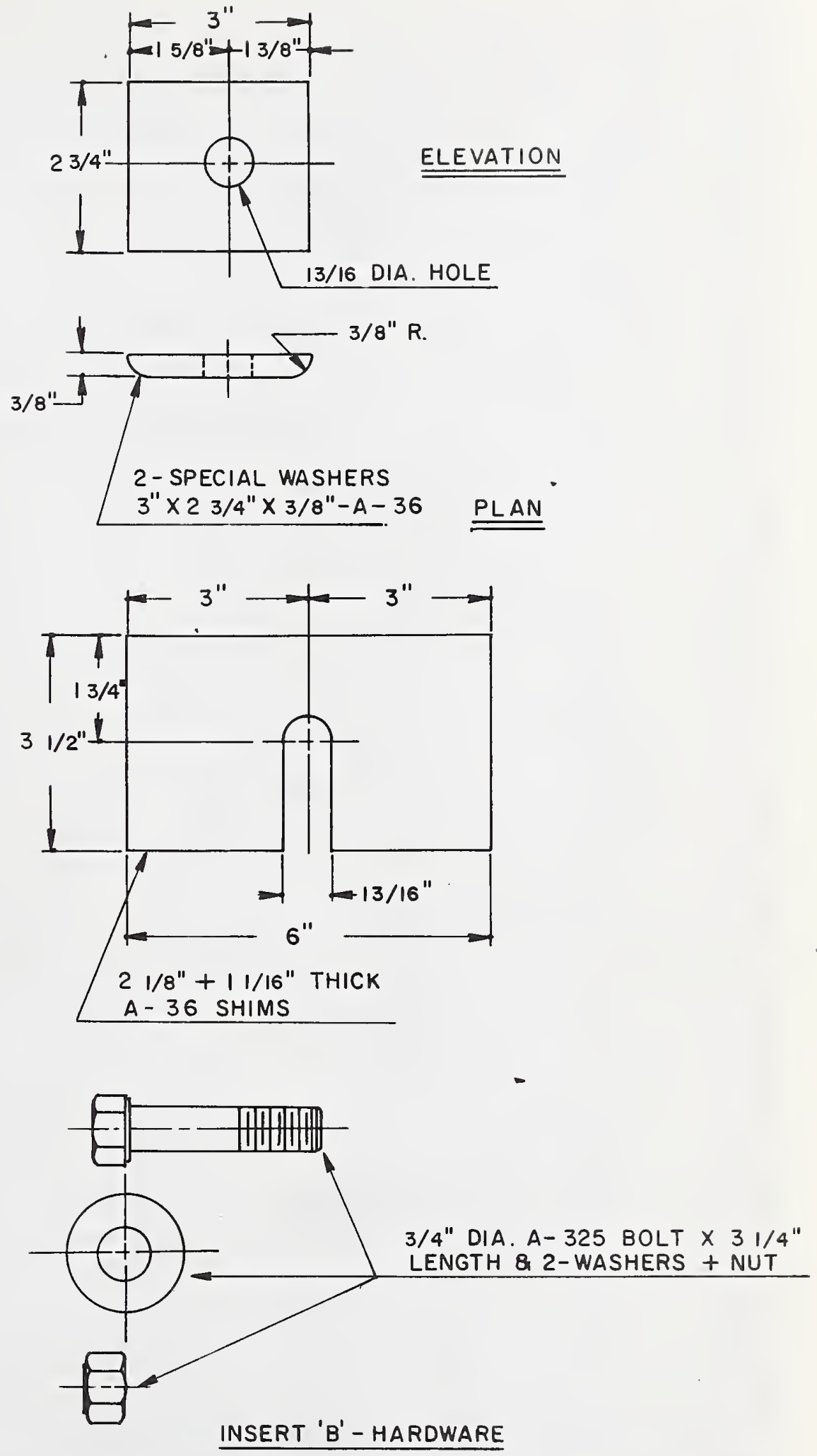

Figure 1.2.7 Hardware for Type B insert. 


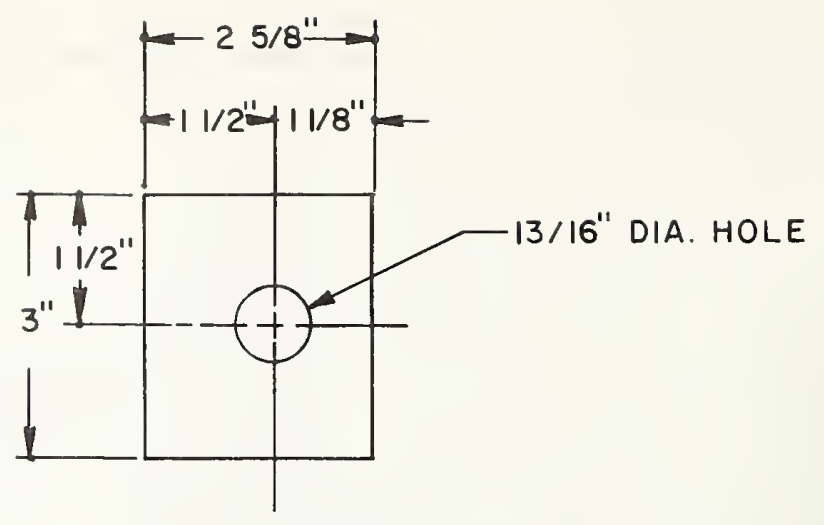

\section{ELEVATION}
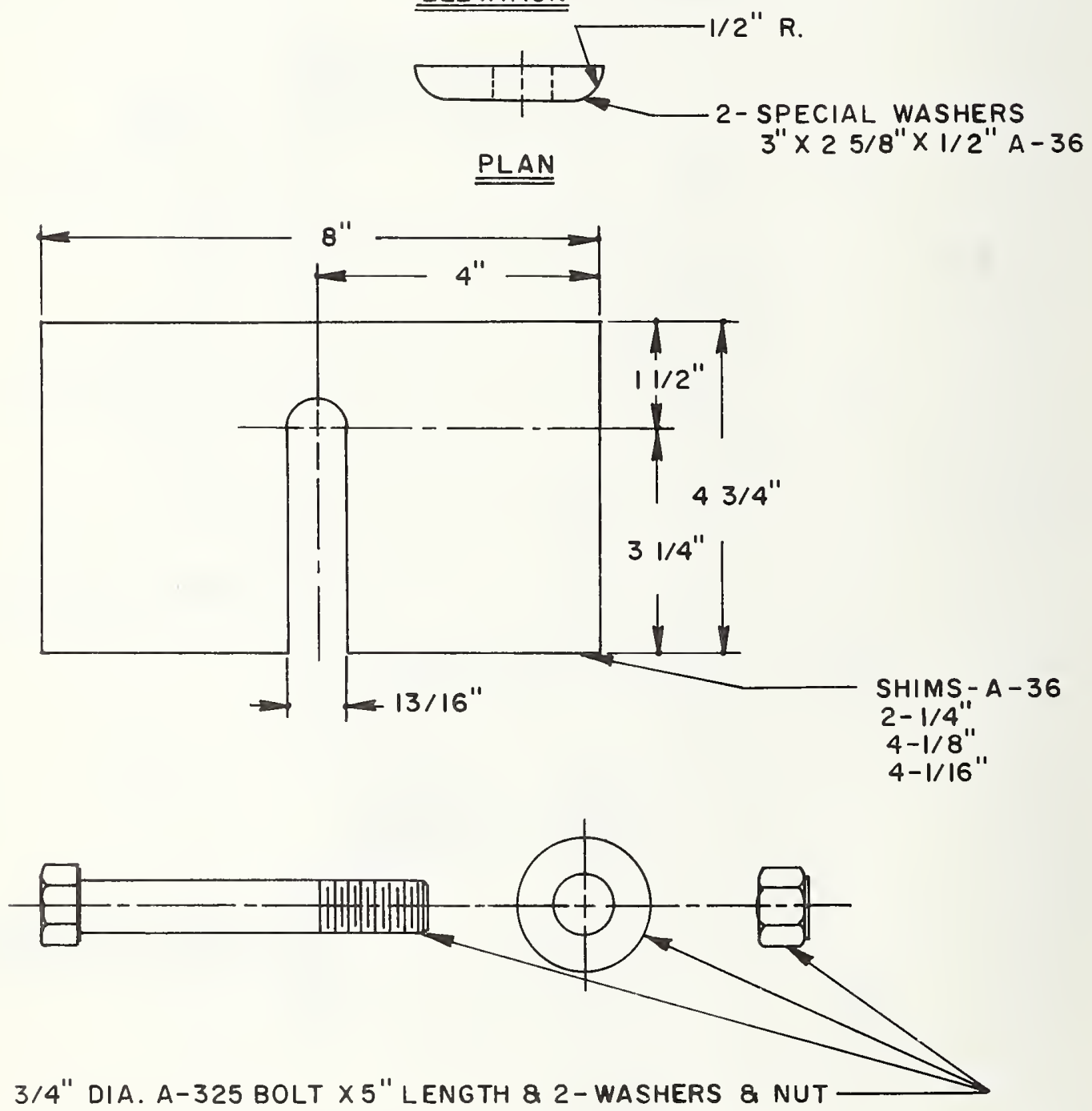

\section{INSERT 'A' - HARDWARE}

Figure $\quad 1.2 .8$ Hardware for Type A insert. 


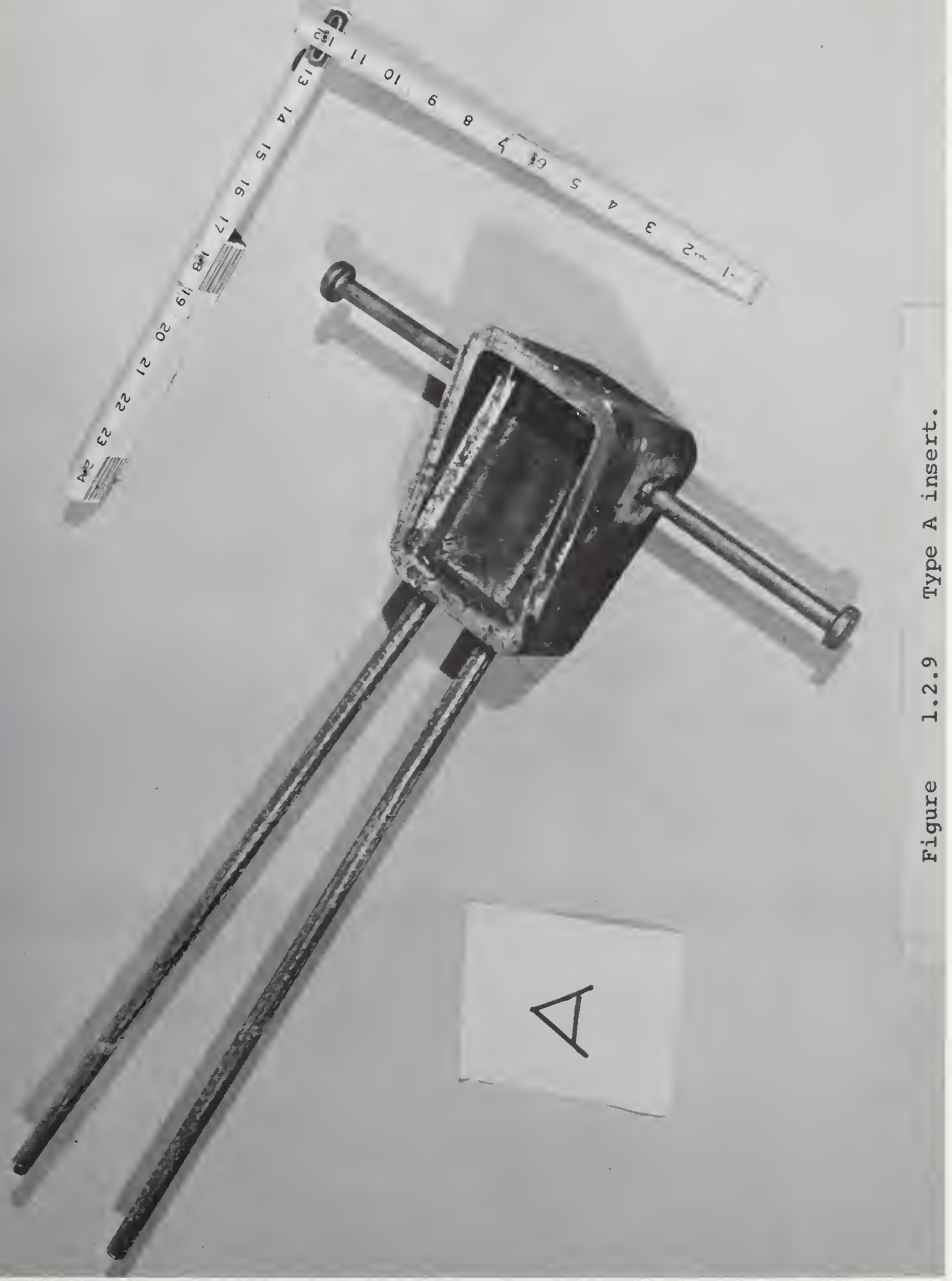





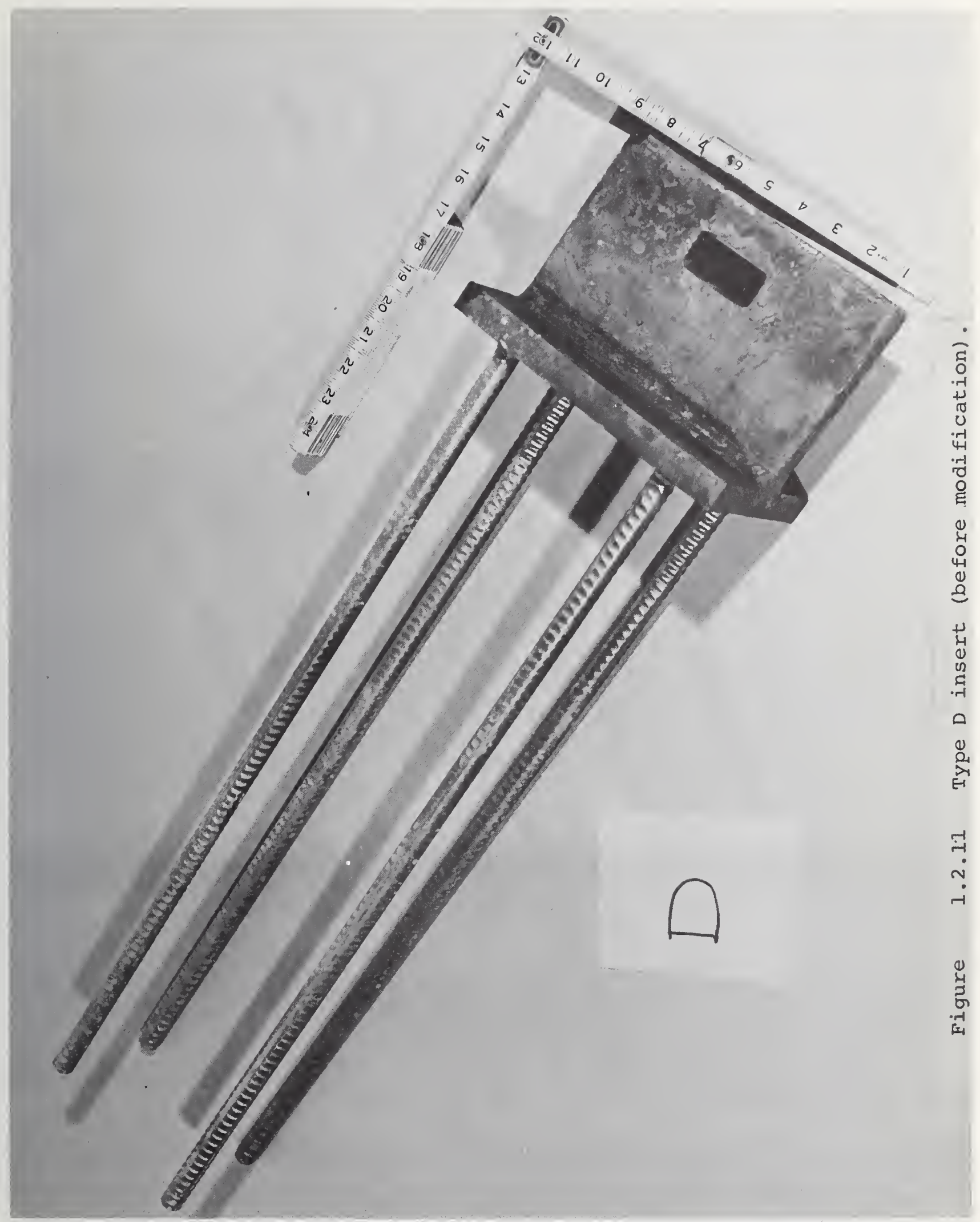




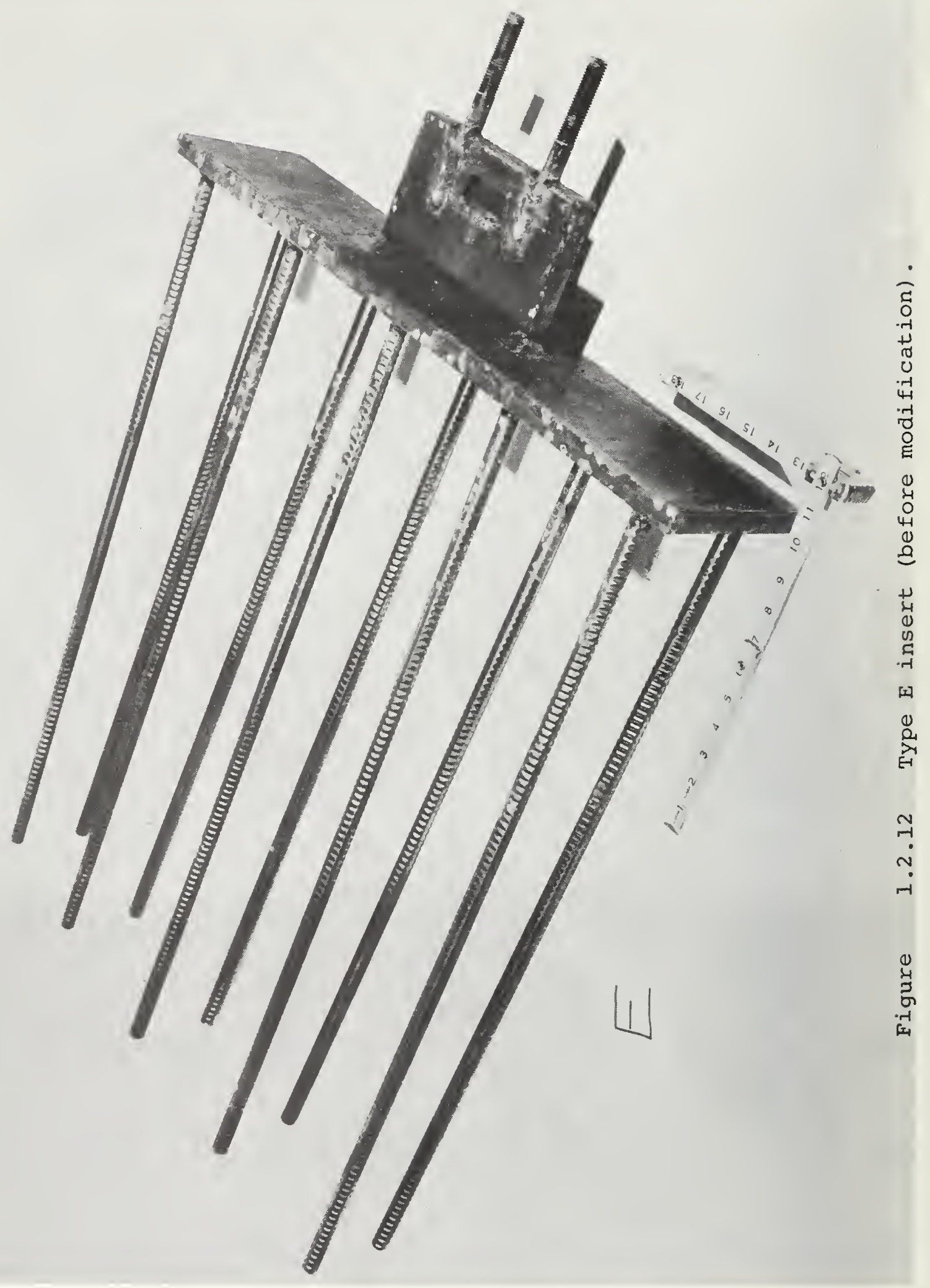




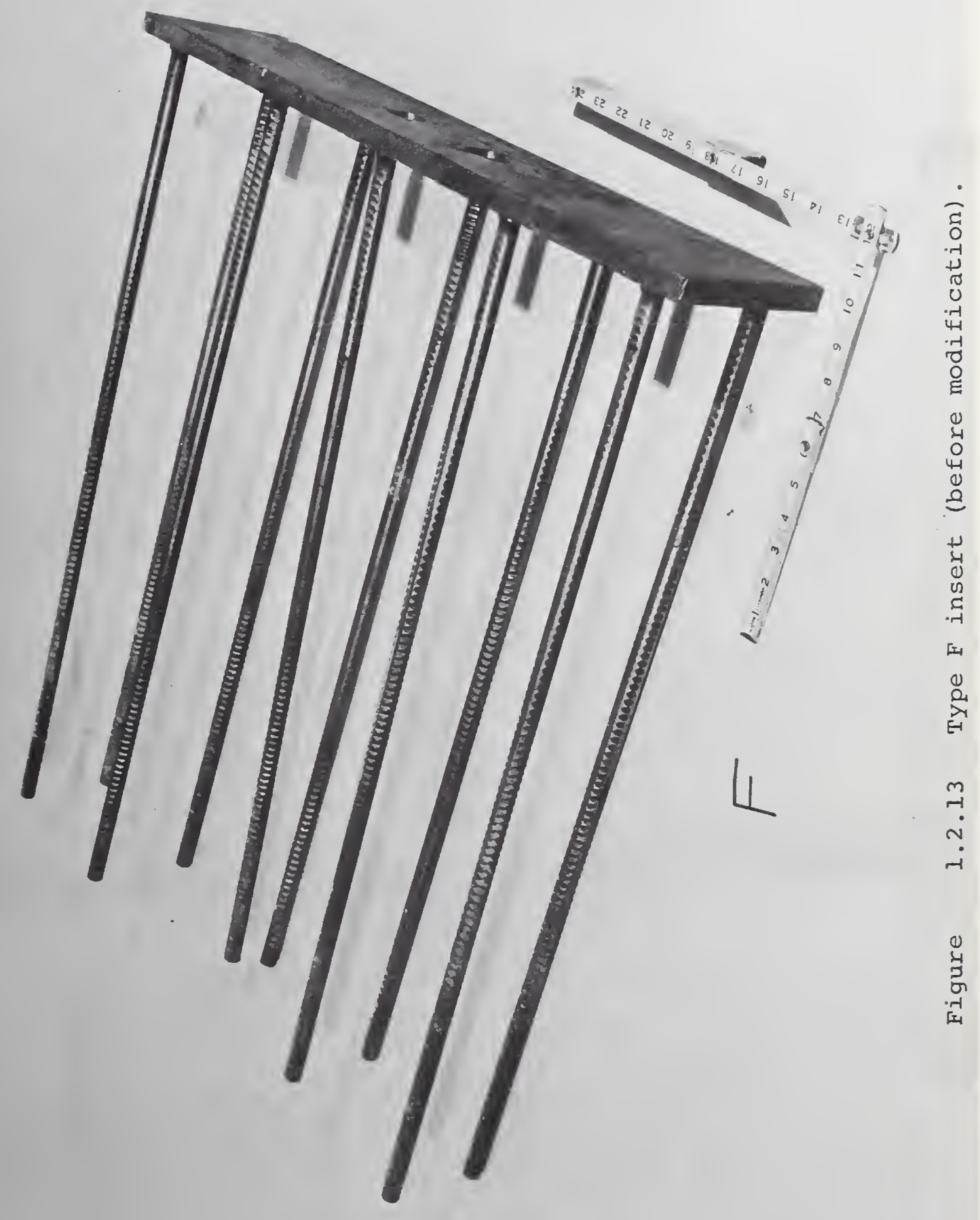




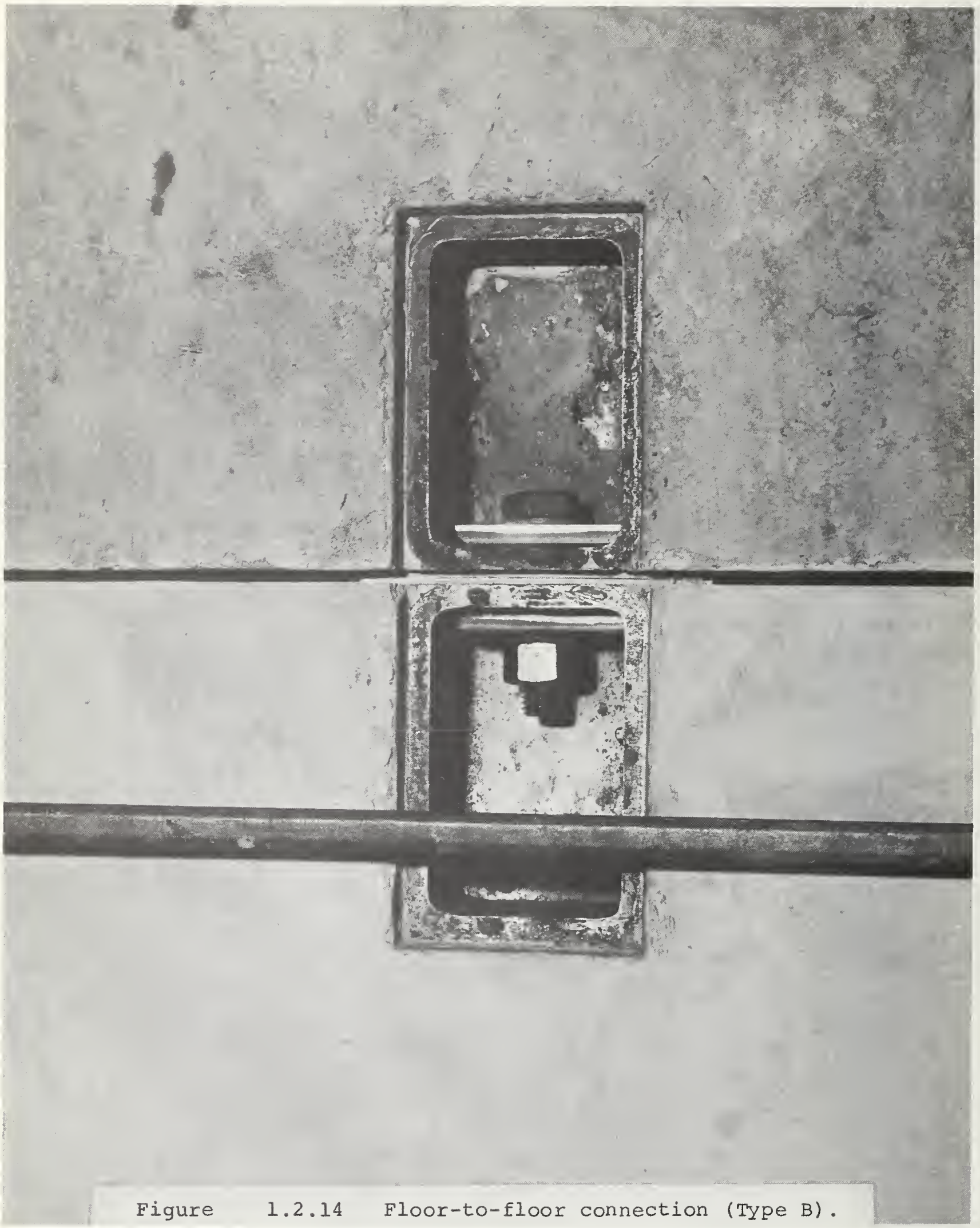




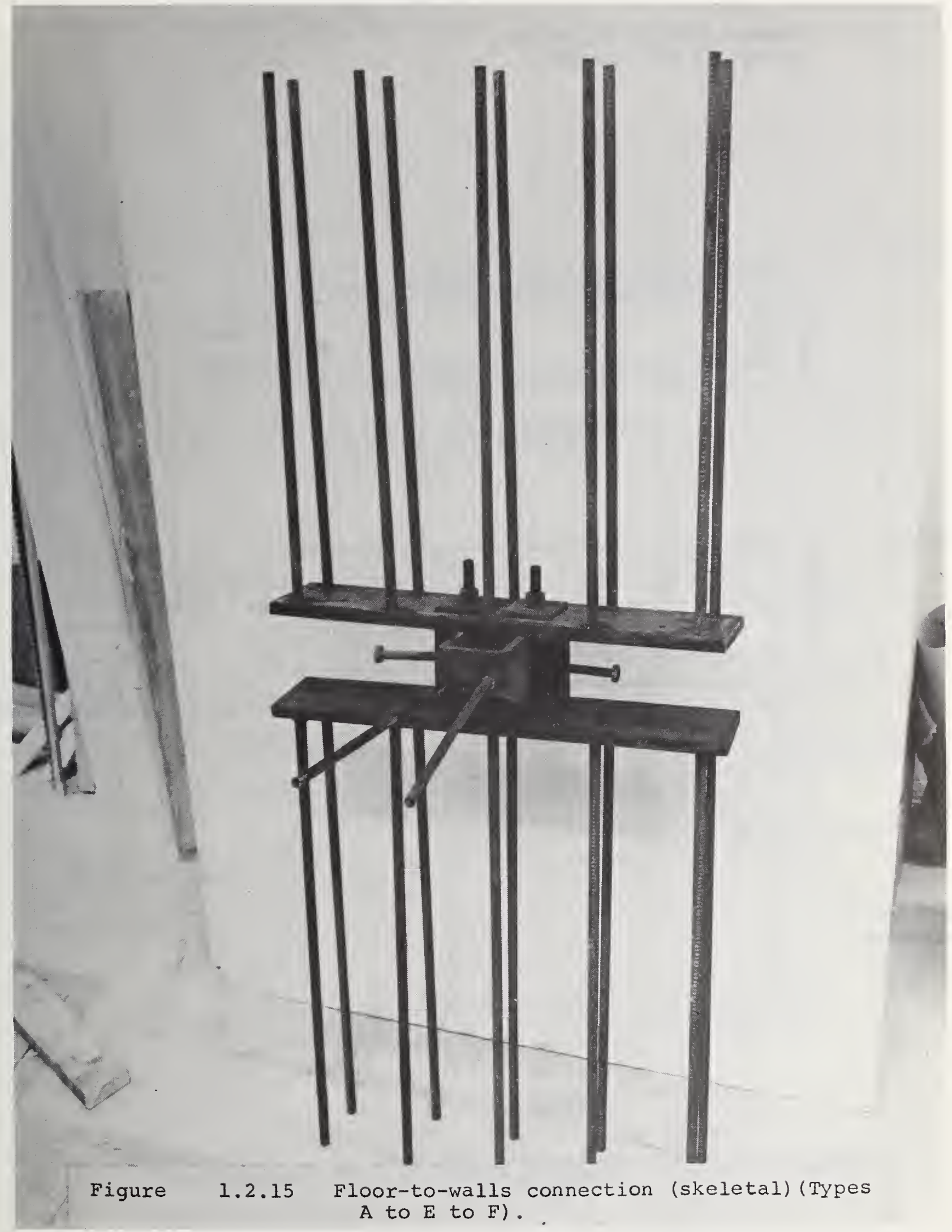


Concrete: 5000 psi @ 28 days

Re. Steel: A-615-Grade 60

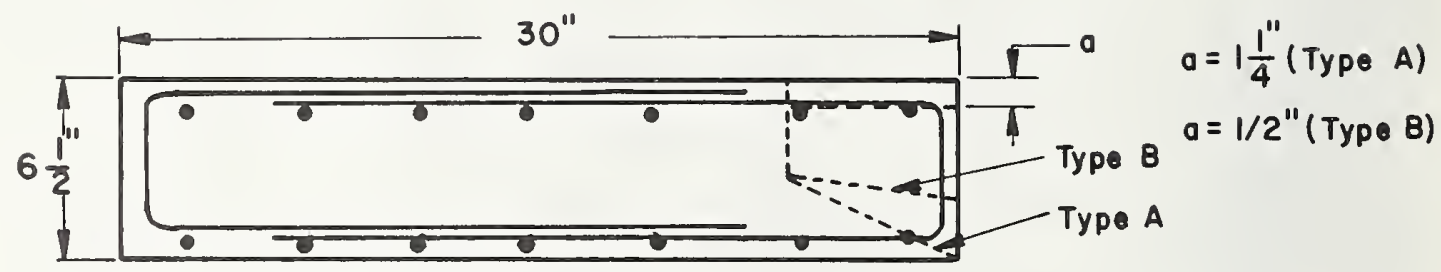

ELEVATION

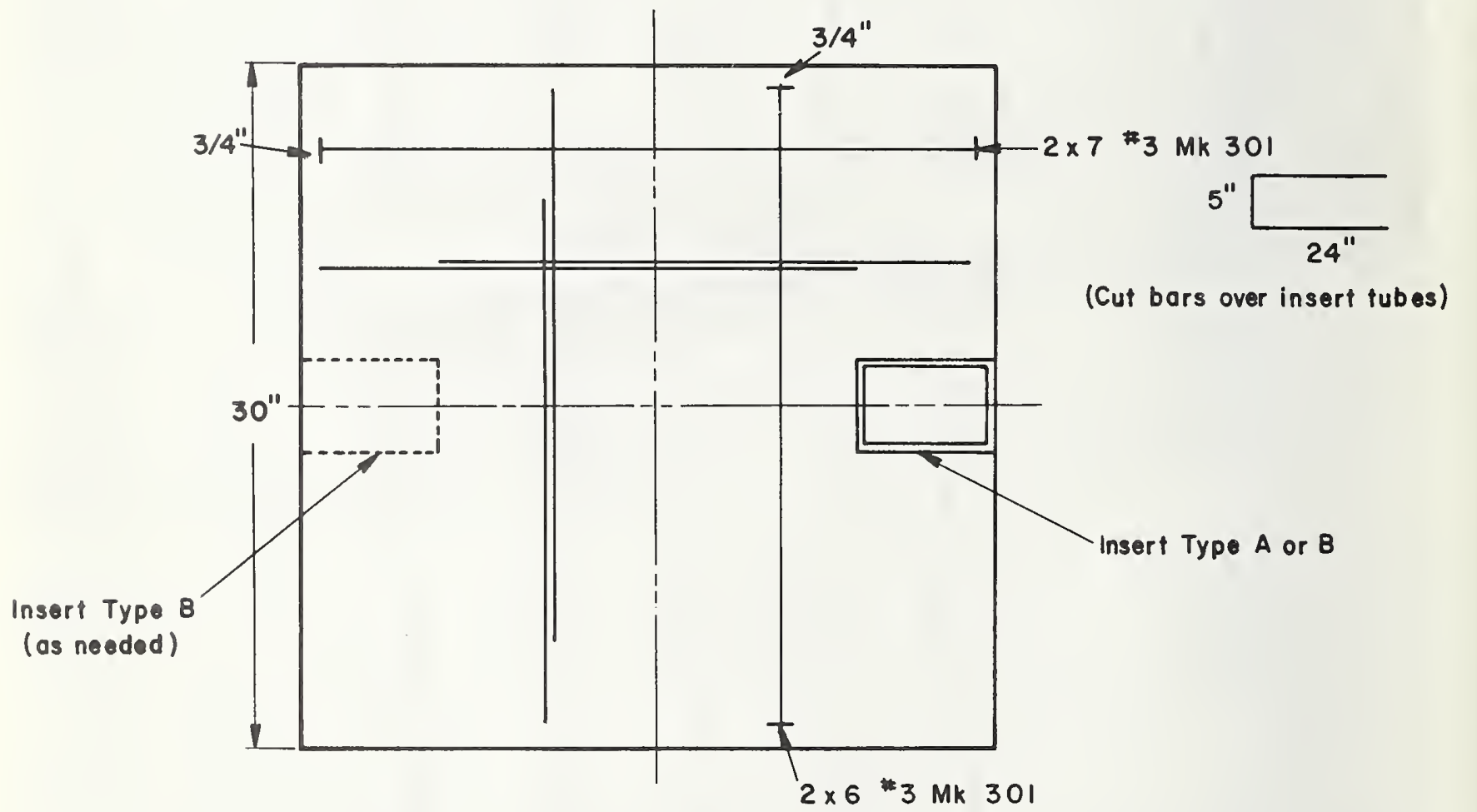

Figure 2.2.1 Original design of floor test specimens (Types A,B). 
Concrete: 4000 psl @ 28 days

Re. Steel: A-615-Grade 60

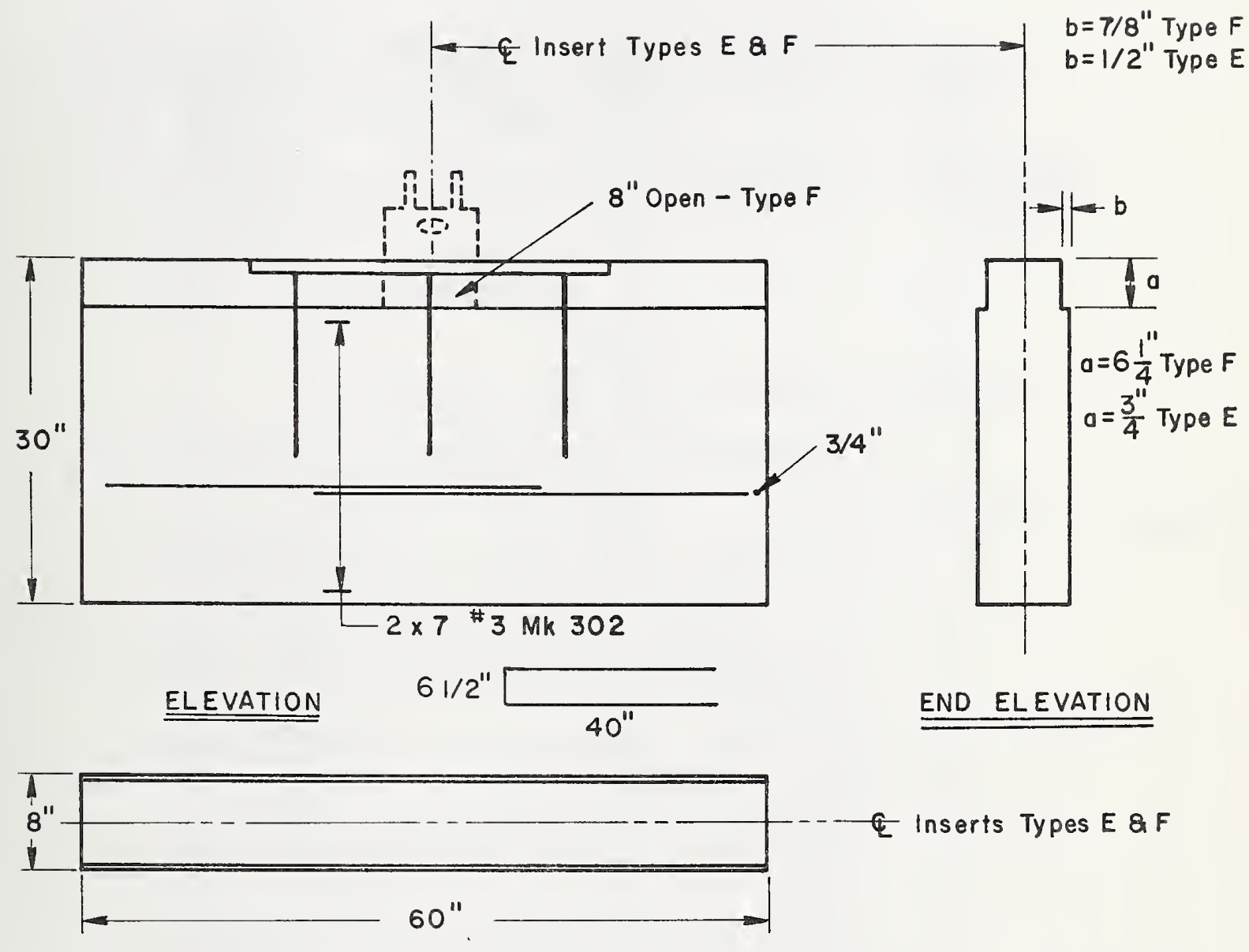

$\underline{P L A N}$

Figure 2.2.2 Original design of wall-end test specimens (Types $E, F$ ). 
Concrete: 4000 psi @ 28 days

Re. Steel: $A-615$ Grade 60

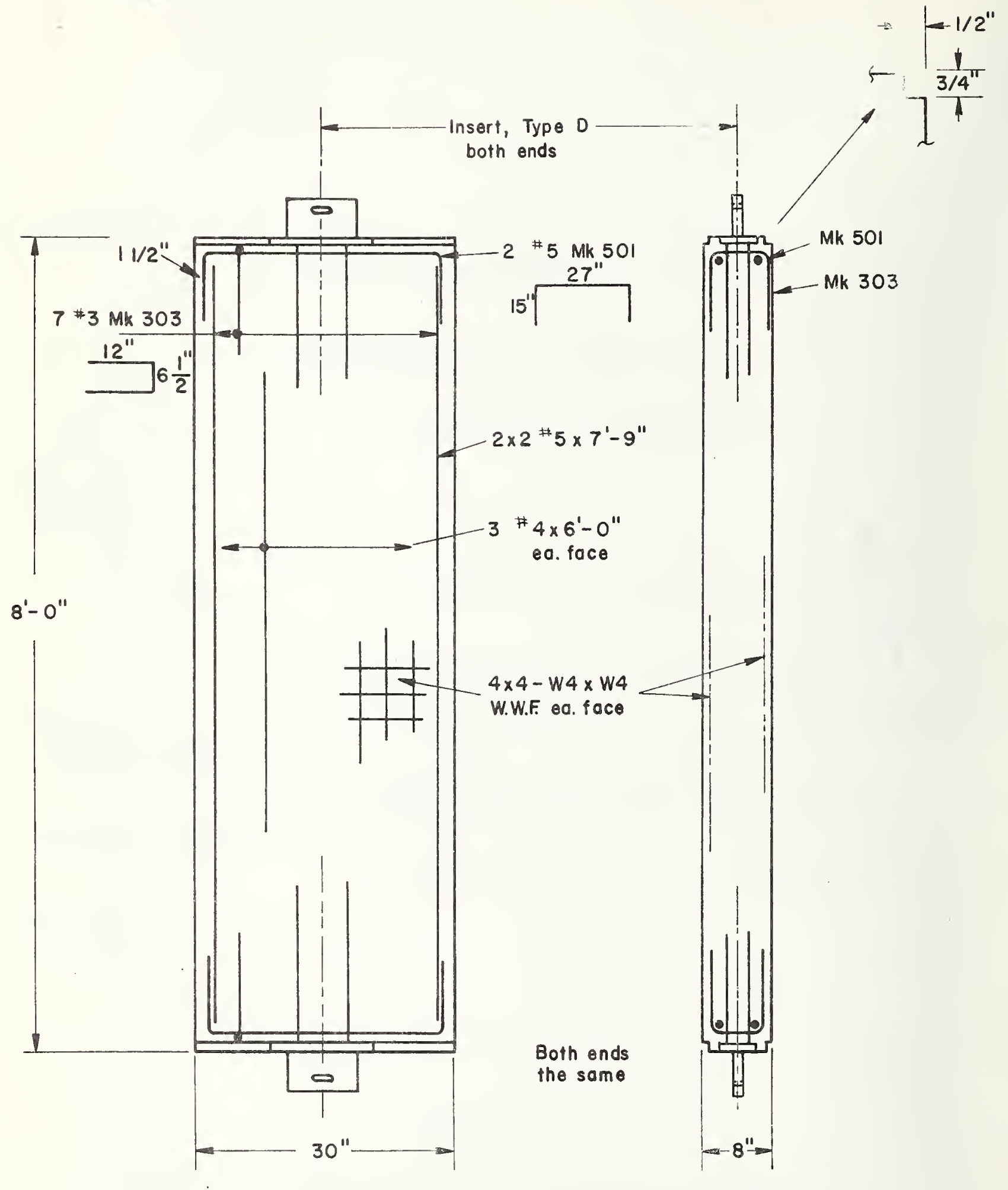

ELEVATION

END ELEVATION

Figure 2.2.3 Original design of double-top-ended wall test specimens (Type D). 
Concrete: 5000 psi@28 days

Re. Steel: $A-615$ - Grade 60
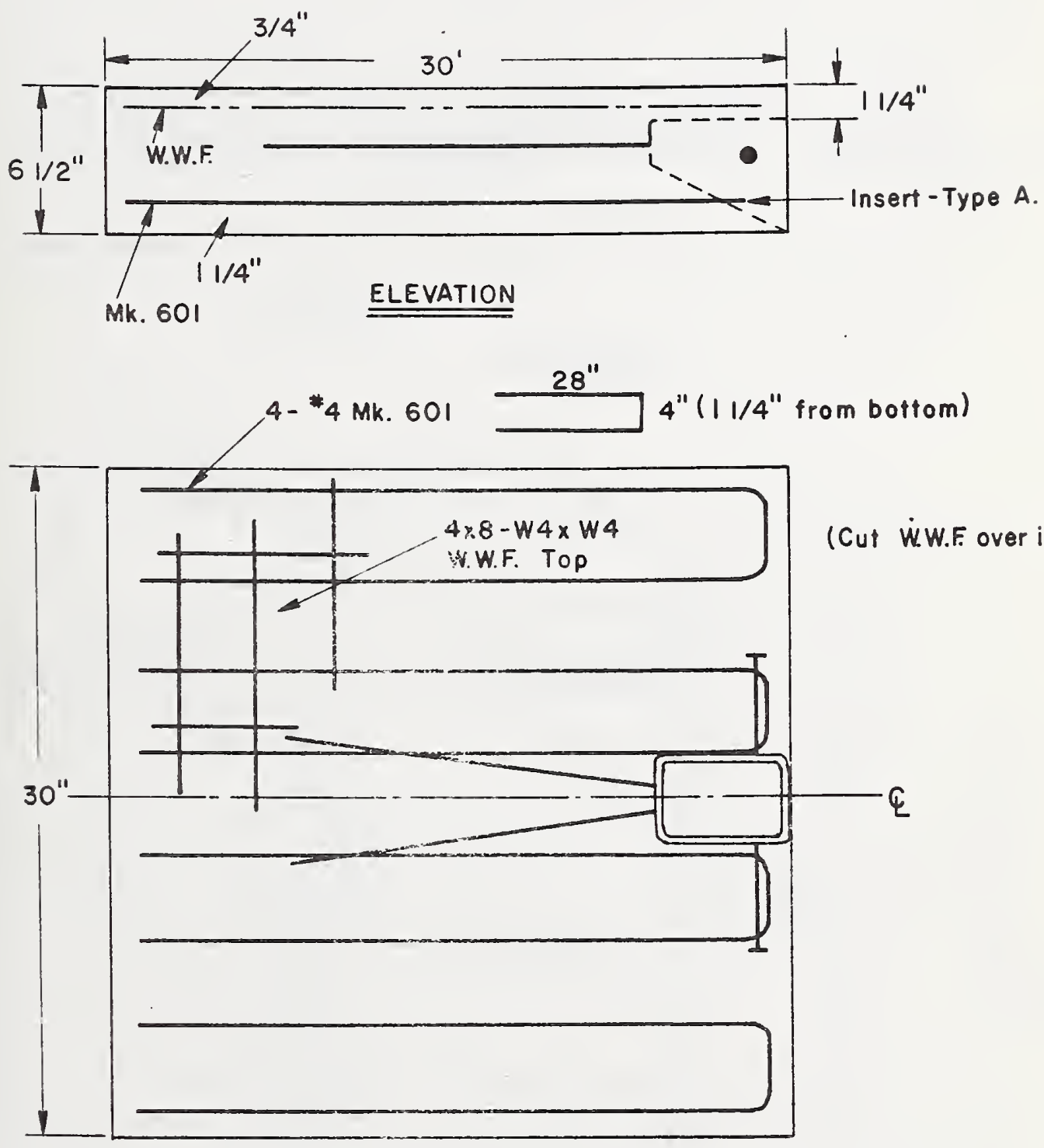

$P \leq A N$

Direction of floor span

Figure 2.2.4 Revised design of floor test specimens (Type A) . 
Concrete: 5000 psi @ 28 days

Re. Steel: A-615-Grode 60
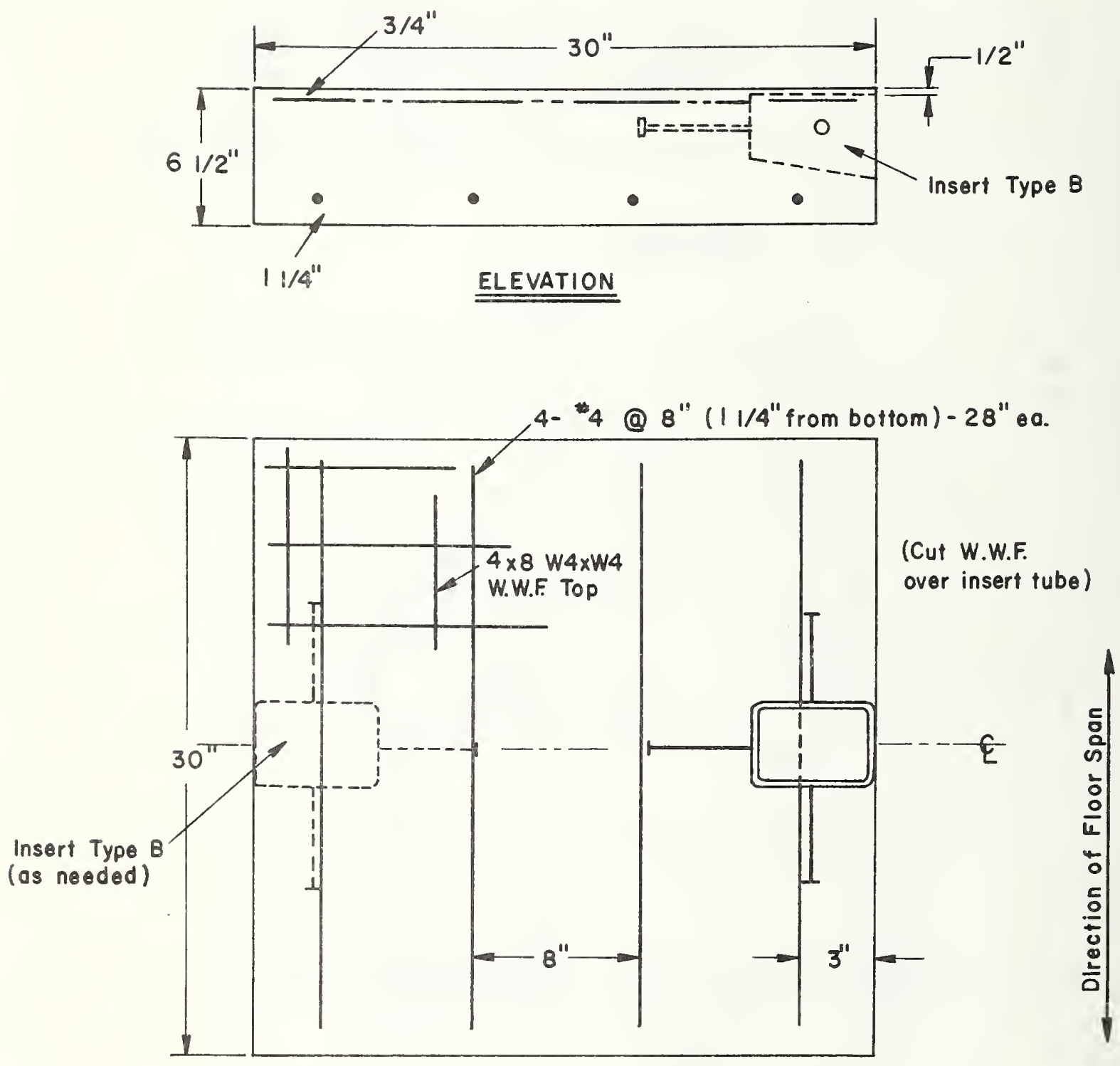

PLAN

Figure 2.2.5 Revised design of floor test specimens (Type B). 
Concrete: 5000 psi @ 28 days

Re. Steel: $A-615$-Grode 60
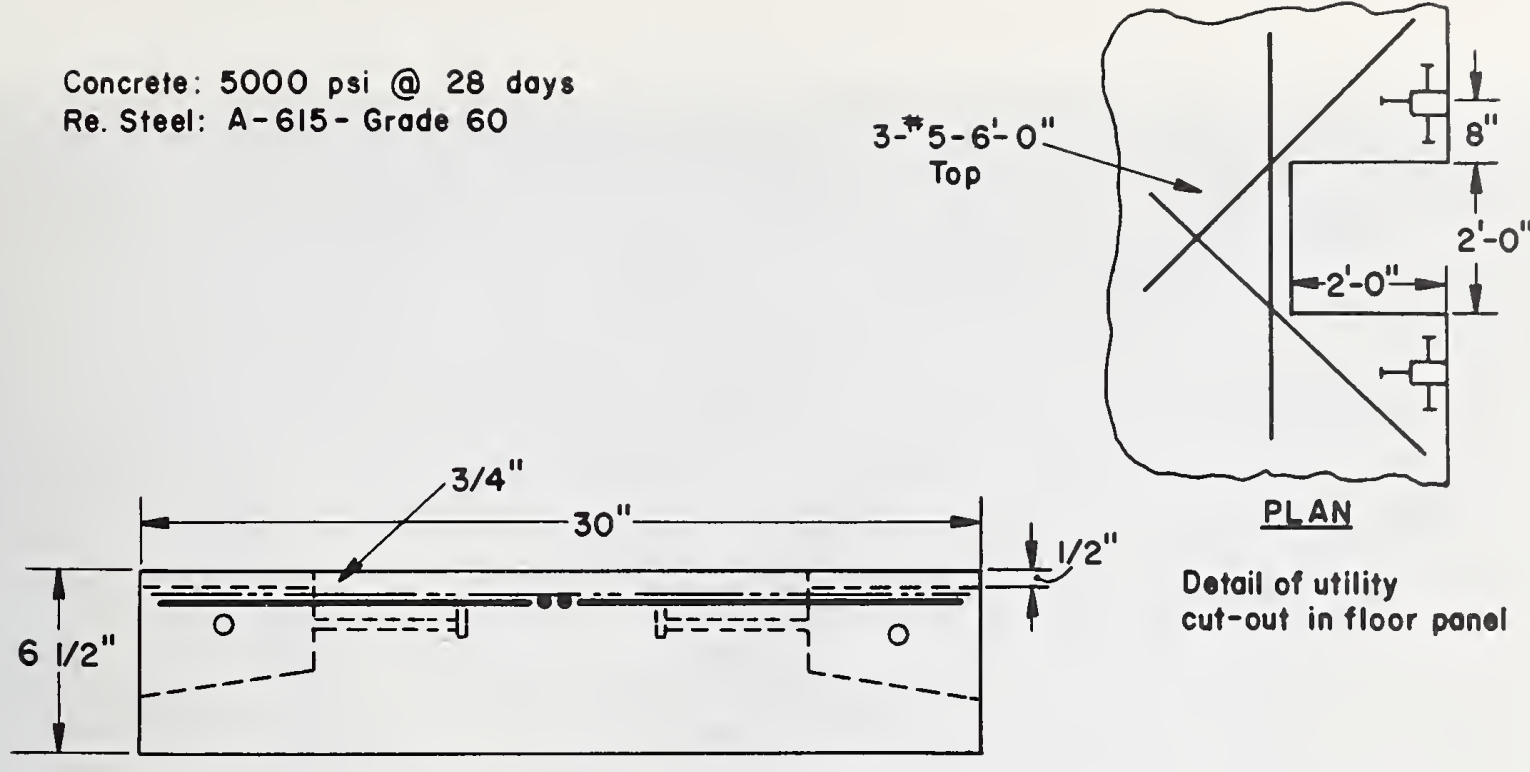

Detail of utility

cut-out in floor ponel

\section{ELEVATION}

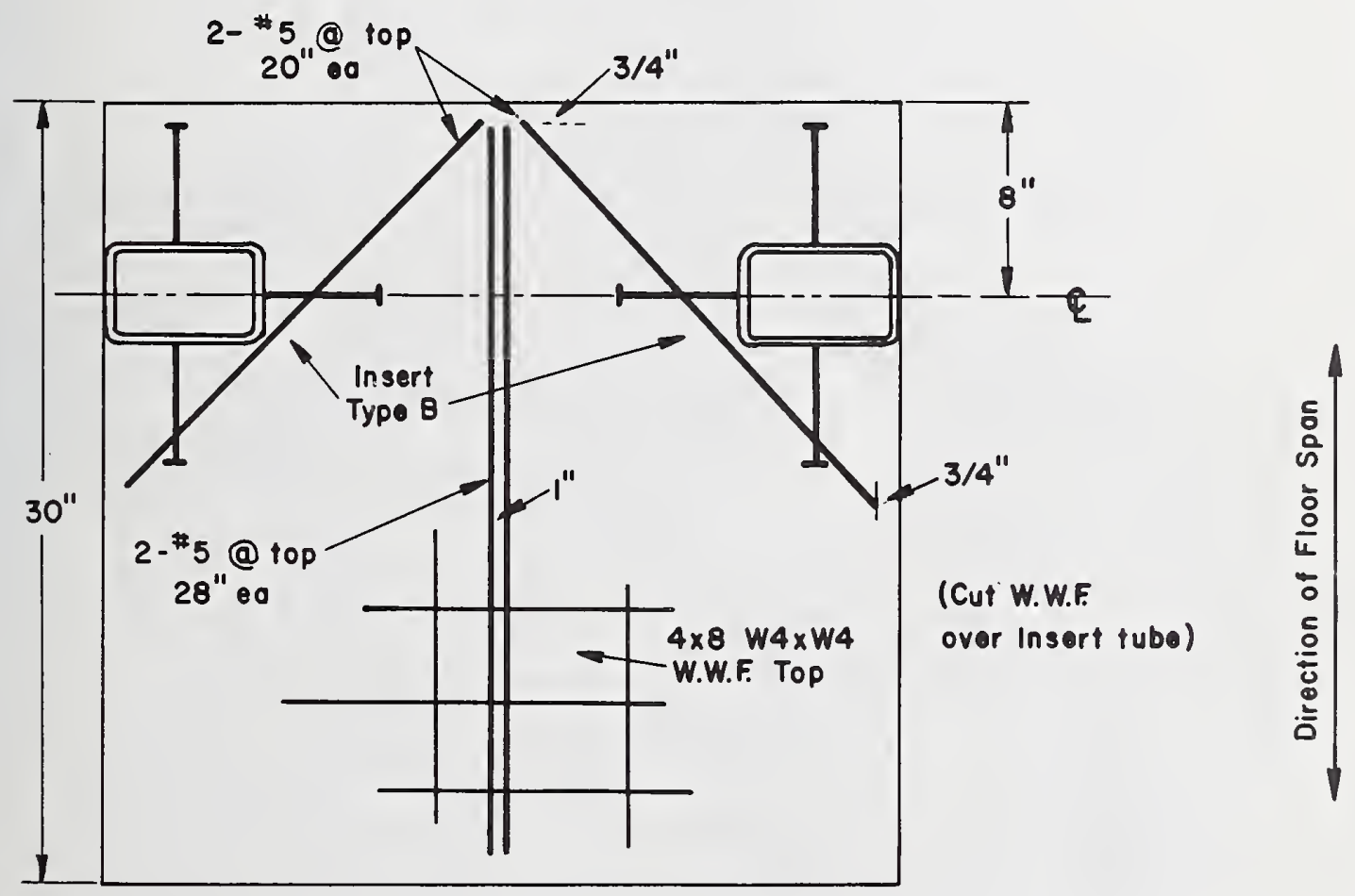

\section{PLAN}

Figure 2.2.6 Revised design of floor test specimens near corner (Type B). 


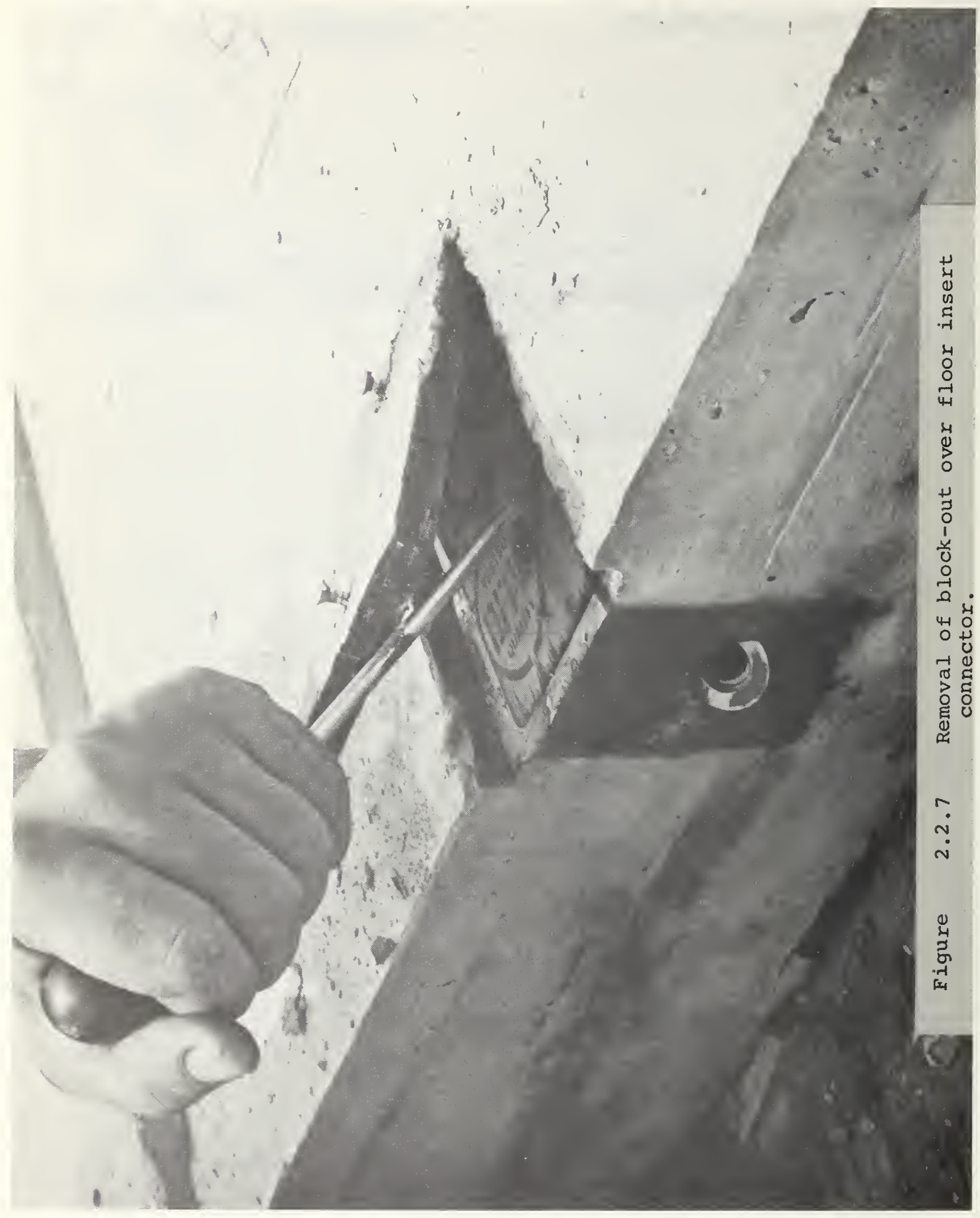




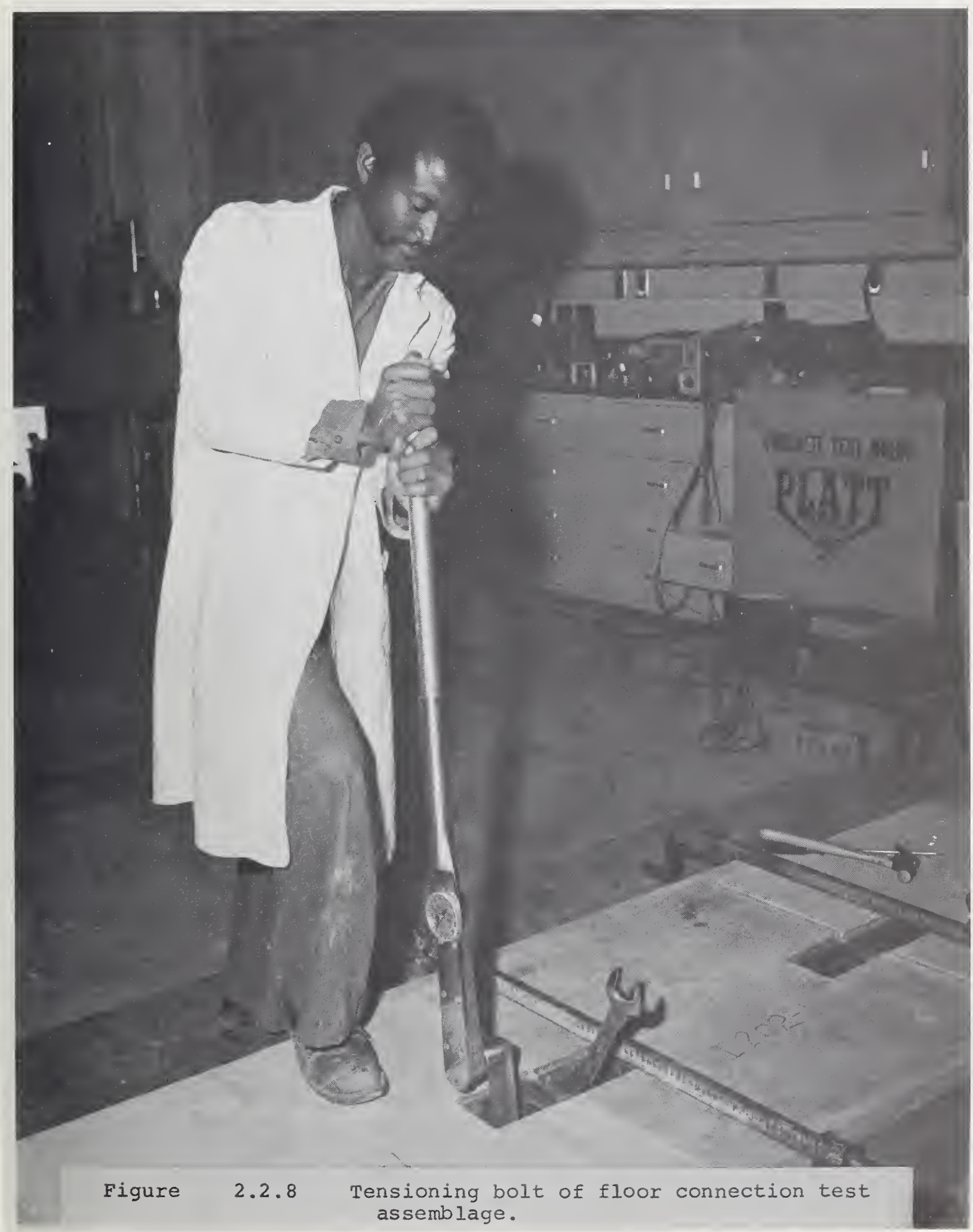




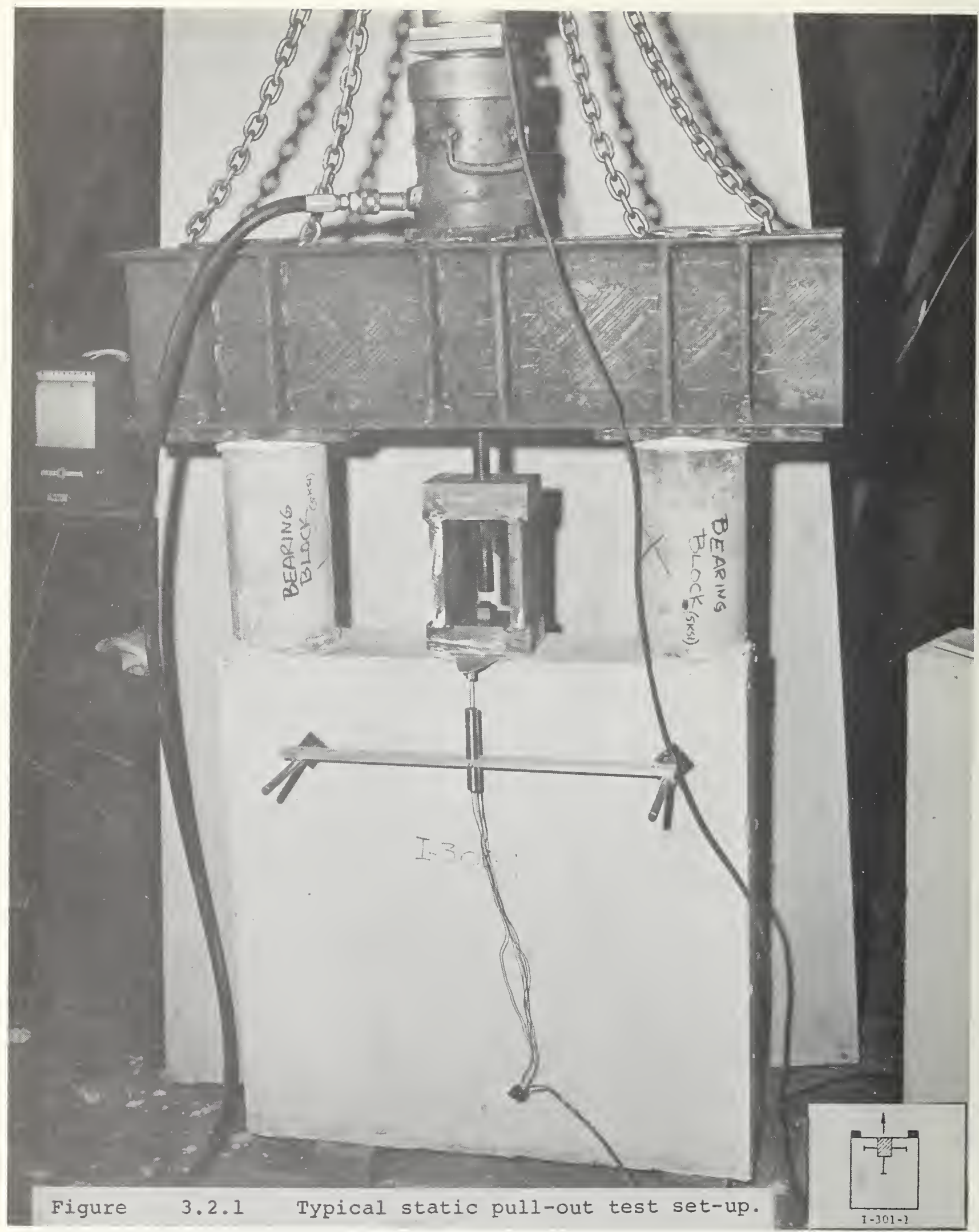




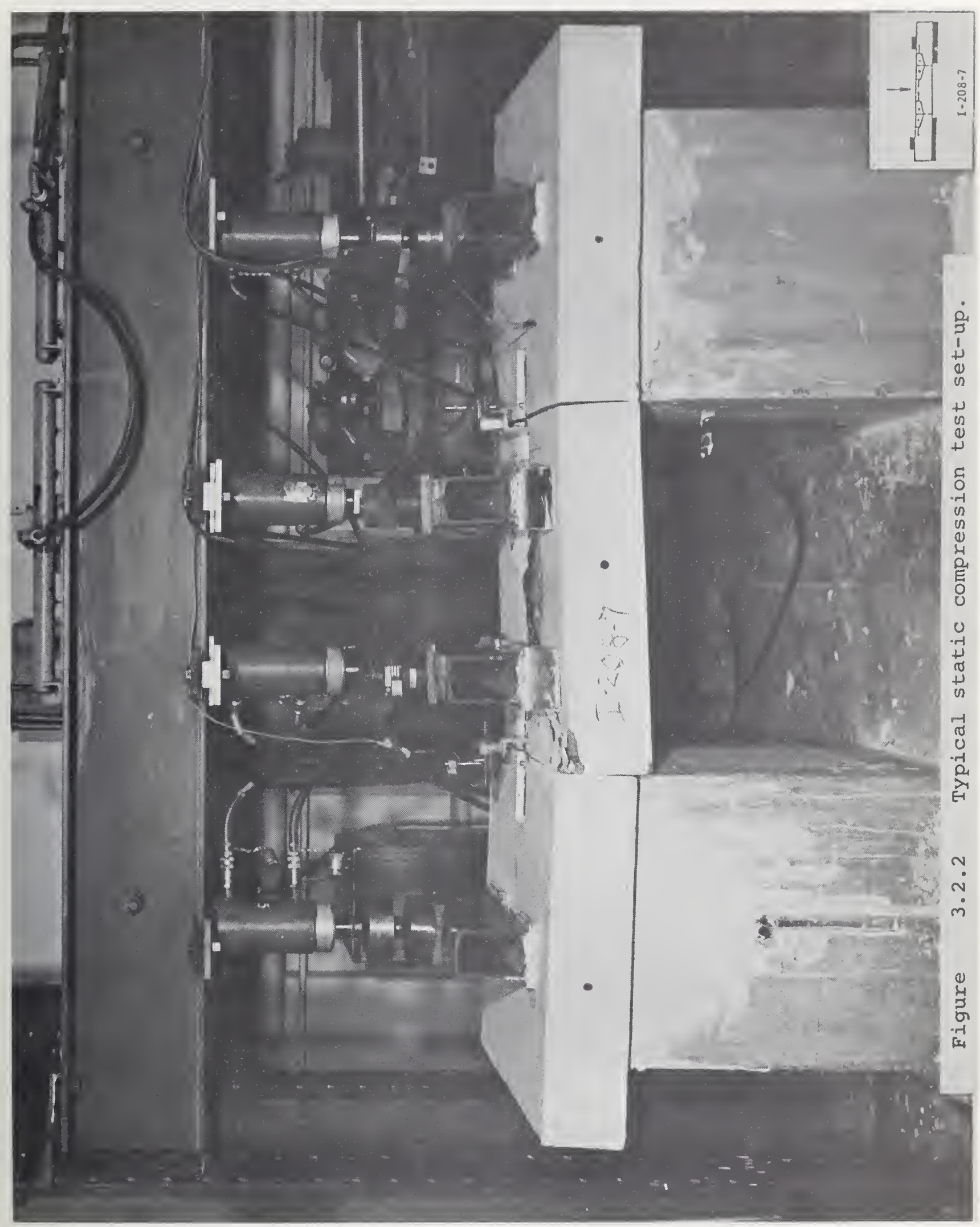




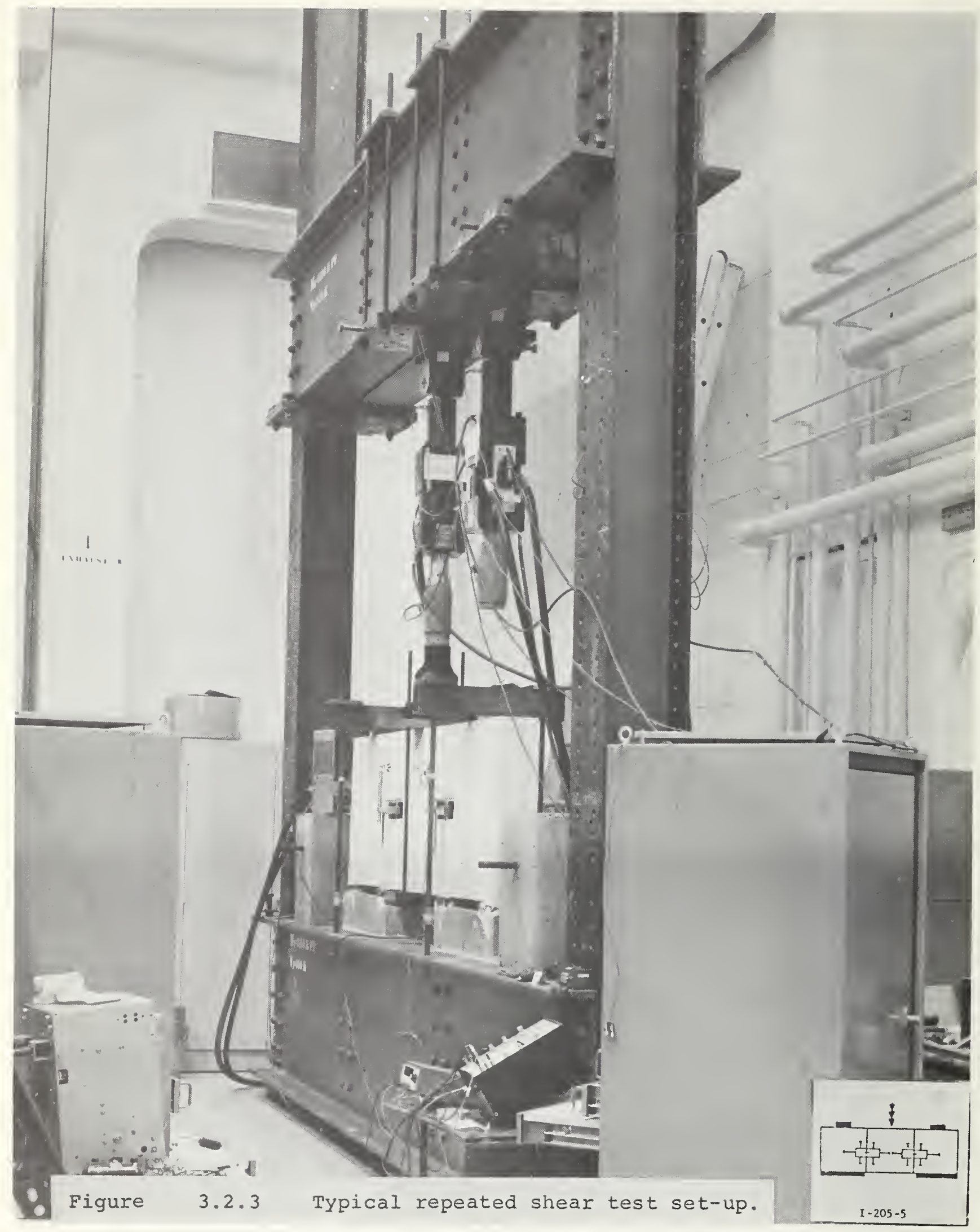




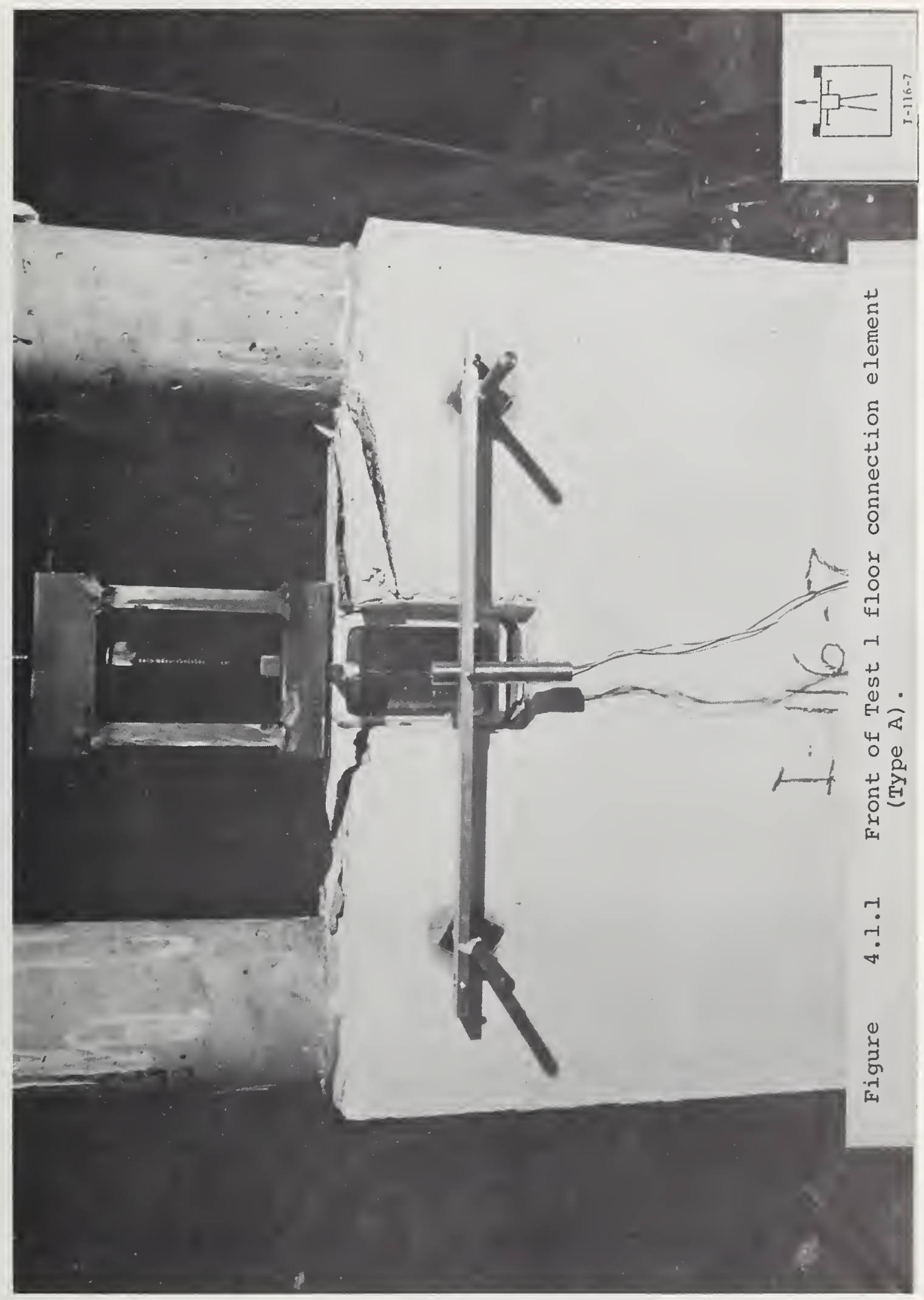


官

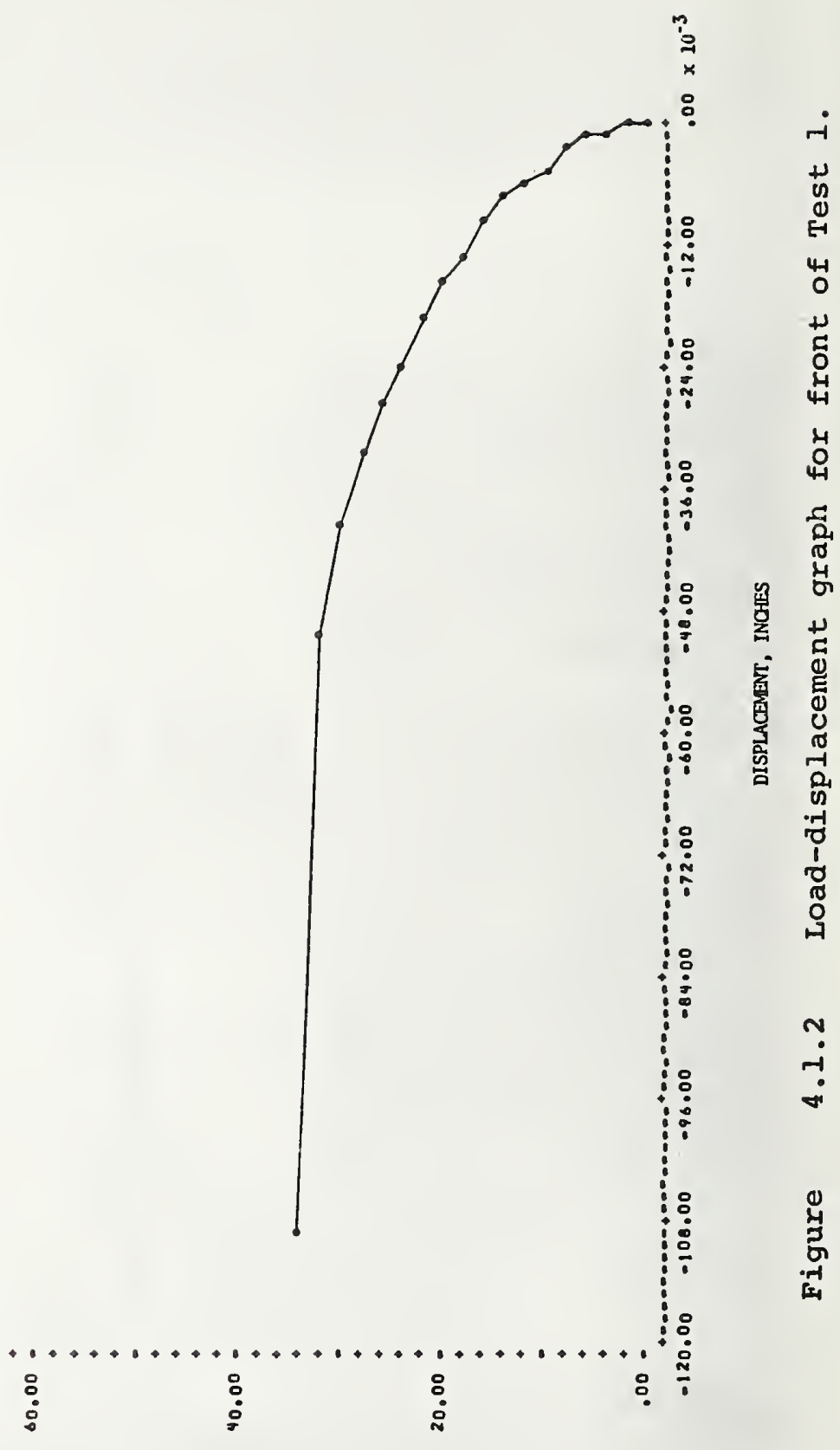

㟧

문

zㅡ

문흠

$z$

웅

$-\sqrt{1}$

章

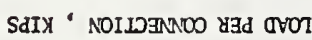




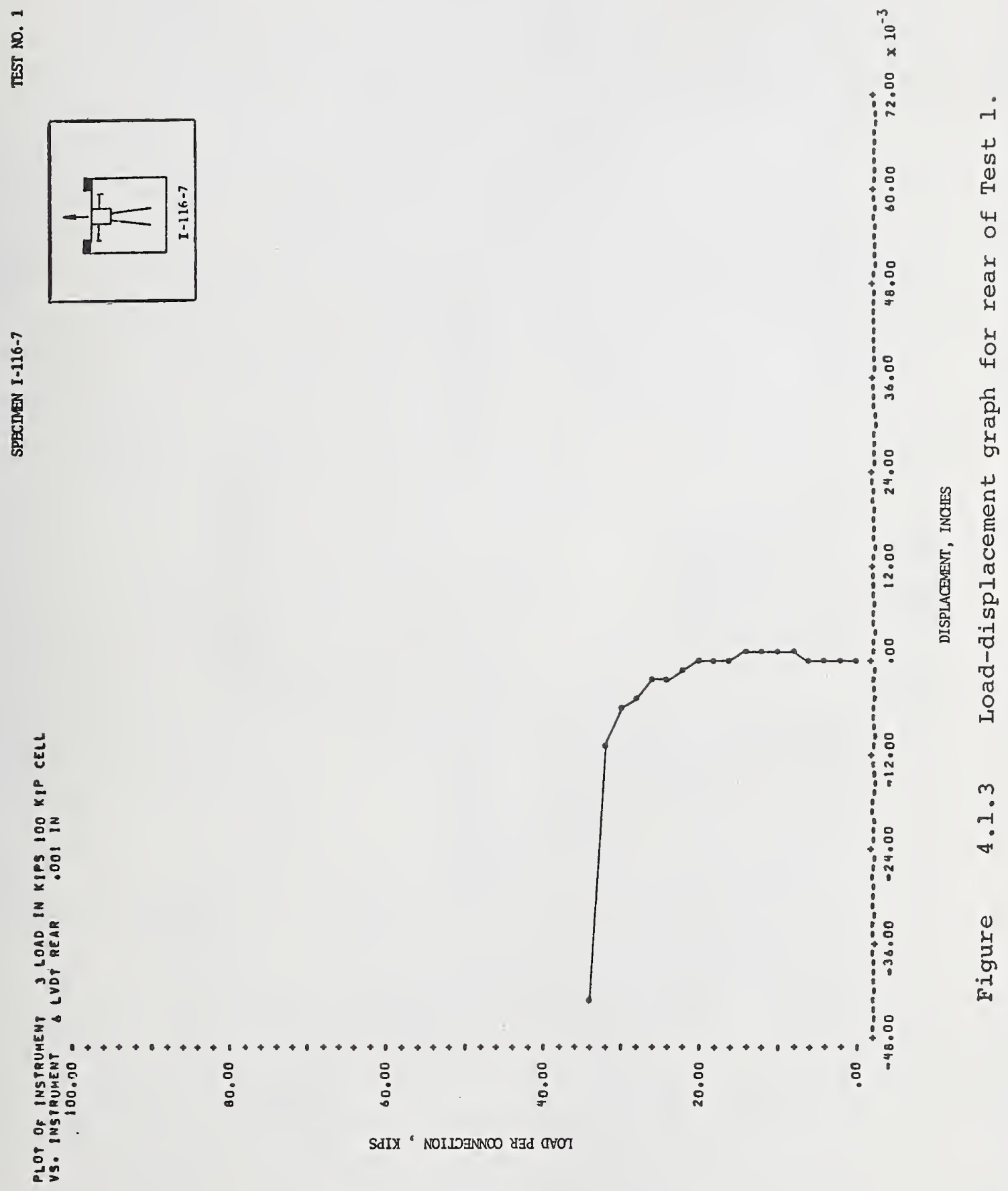




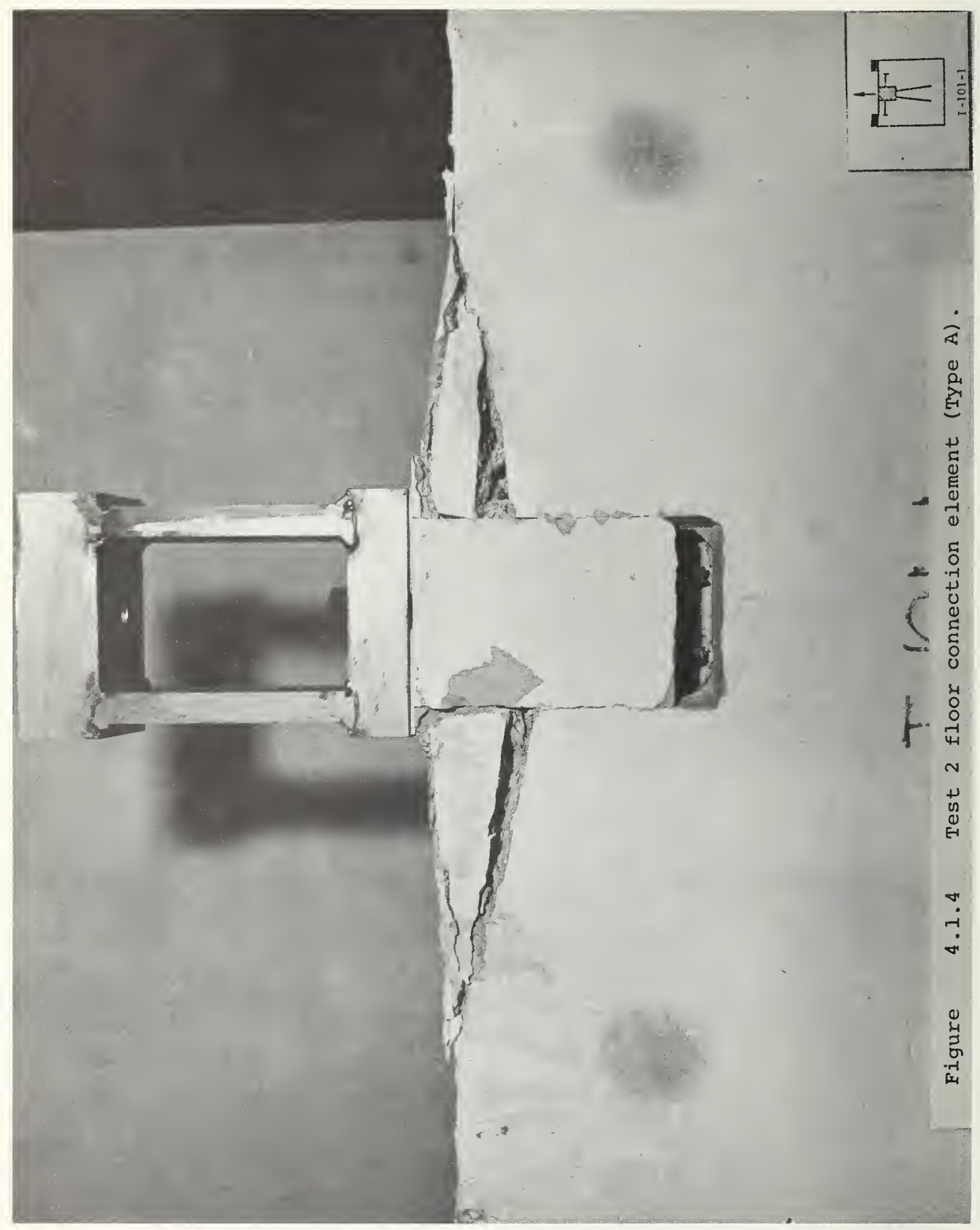




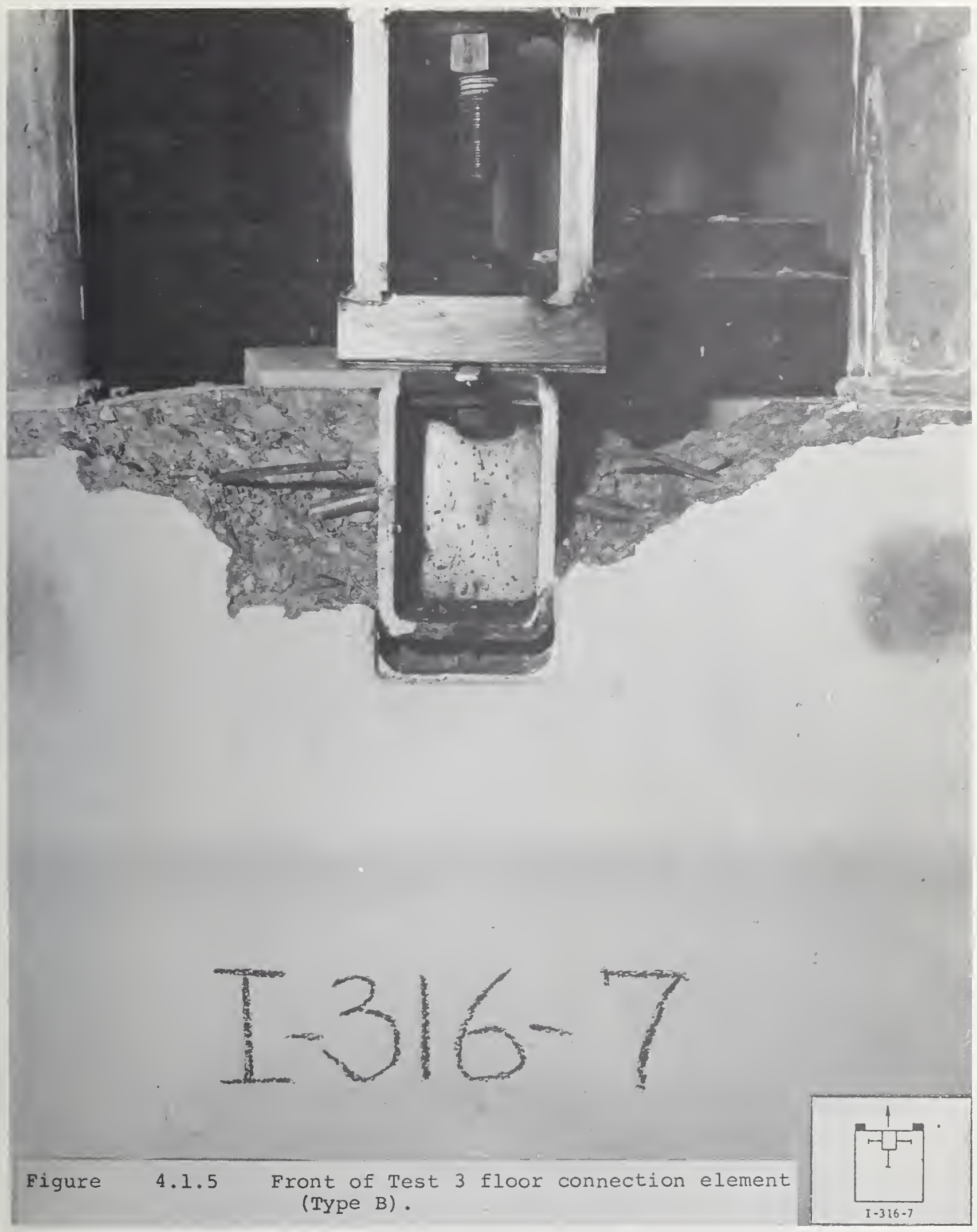




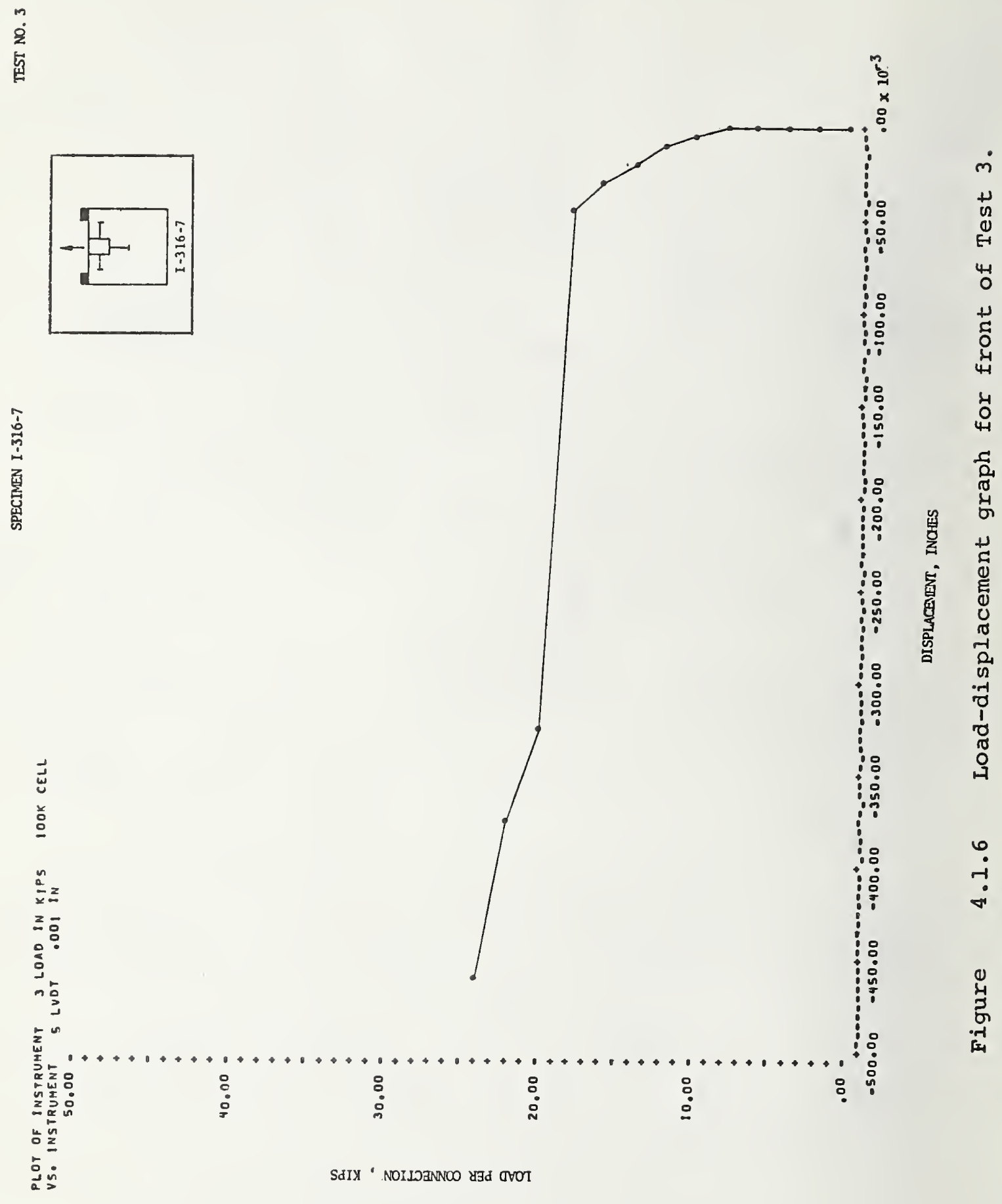




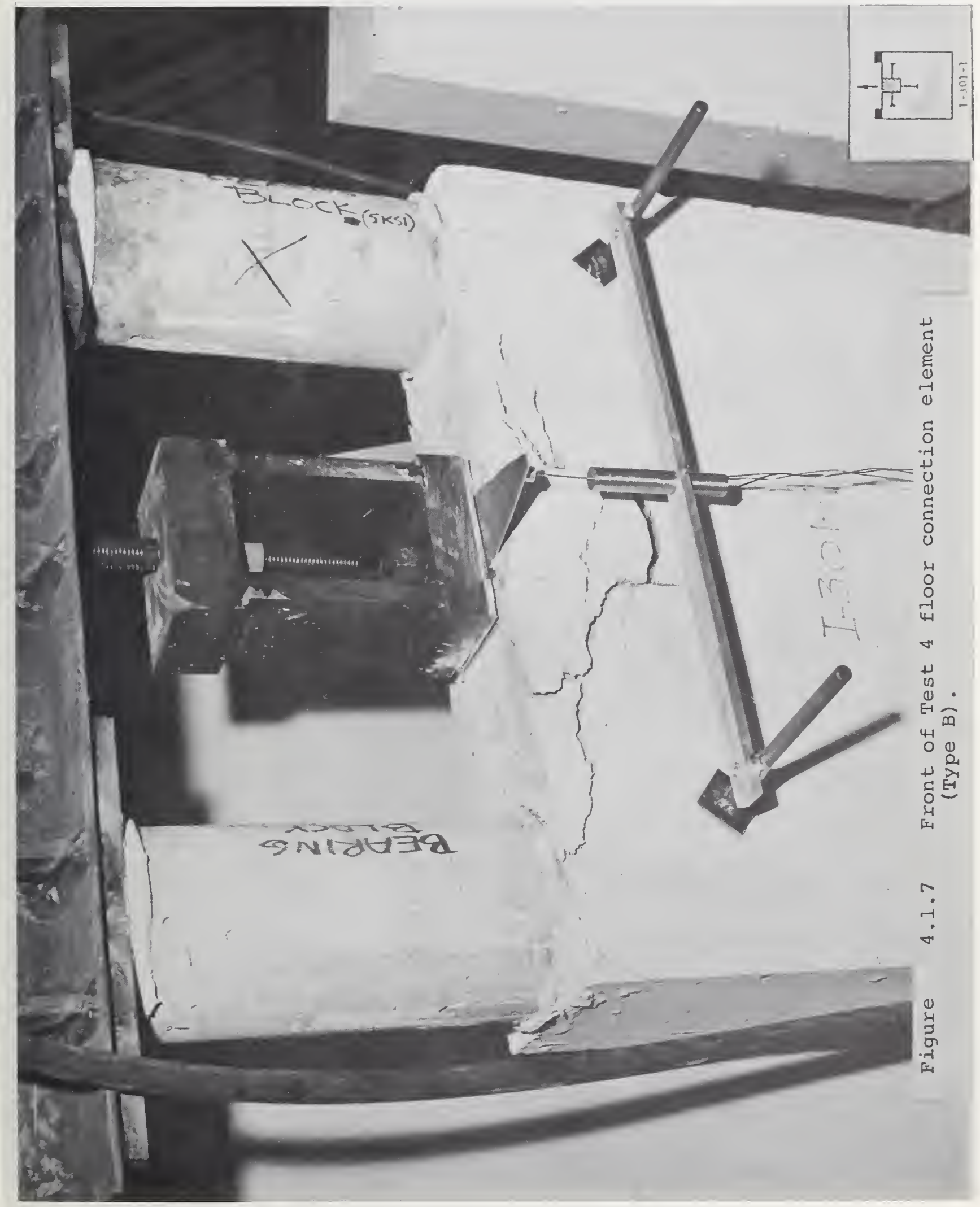







官

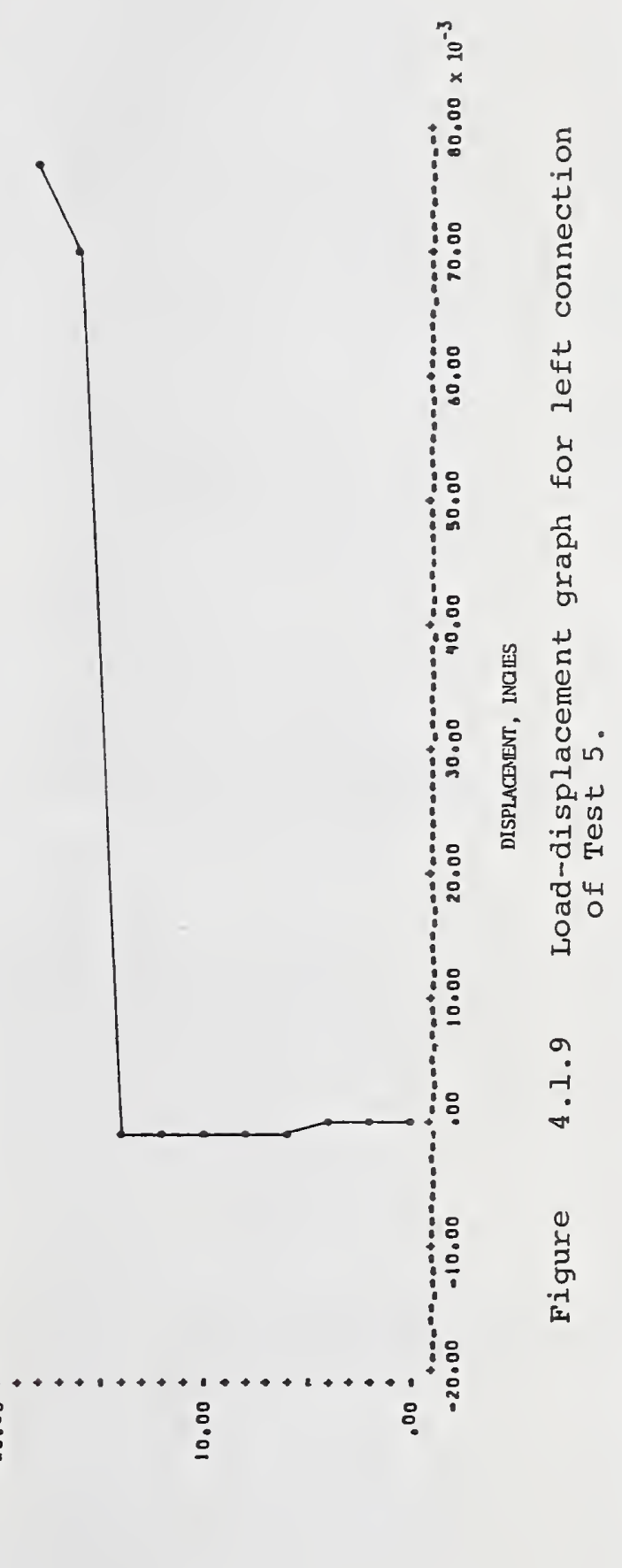




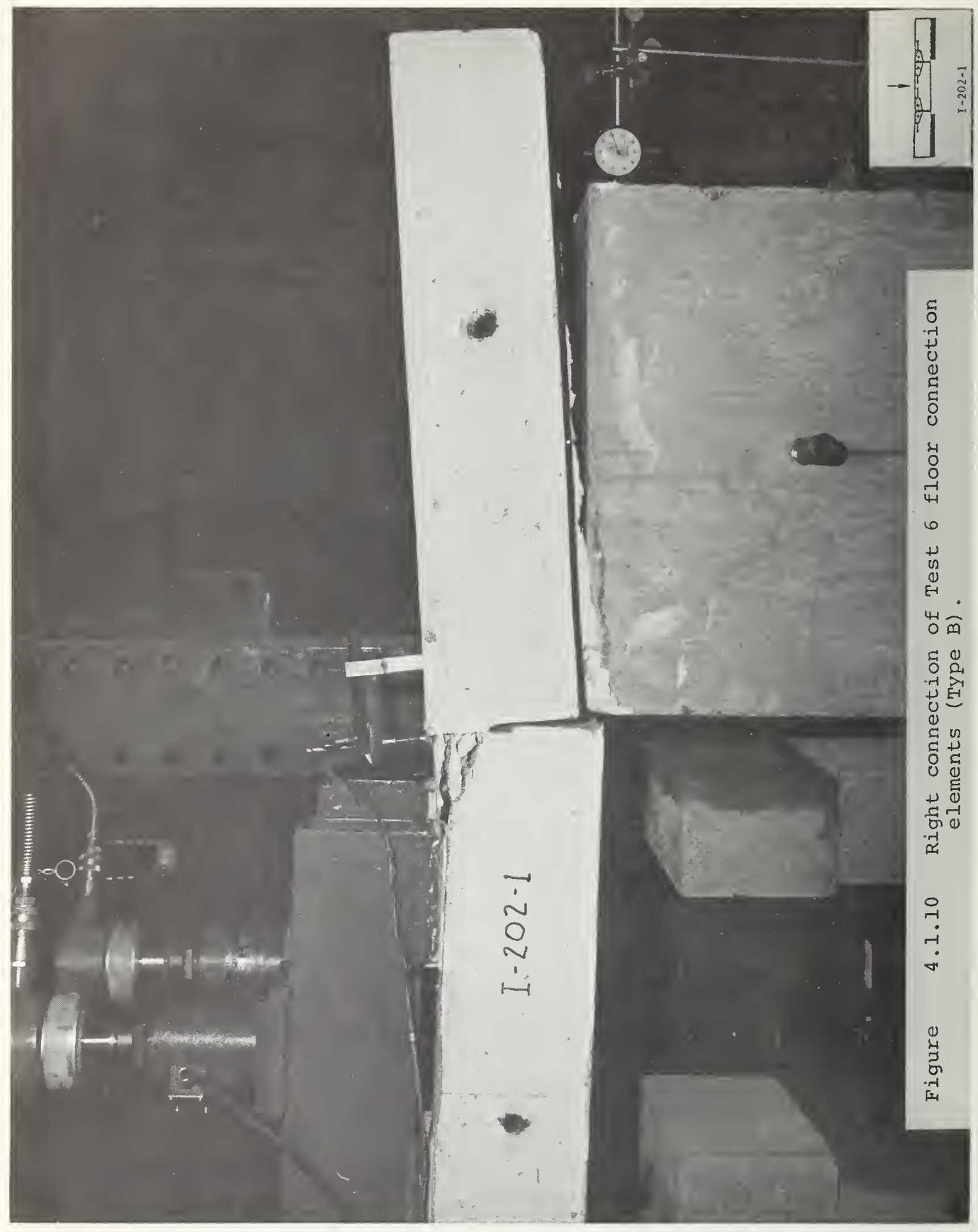




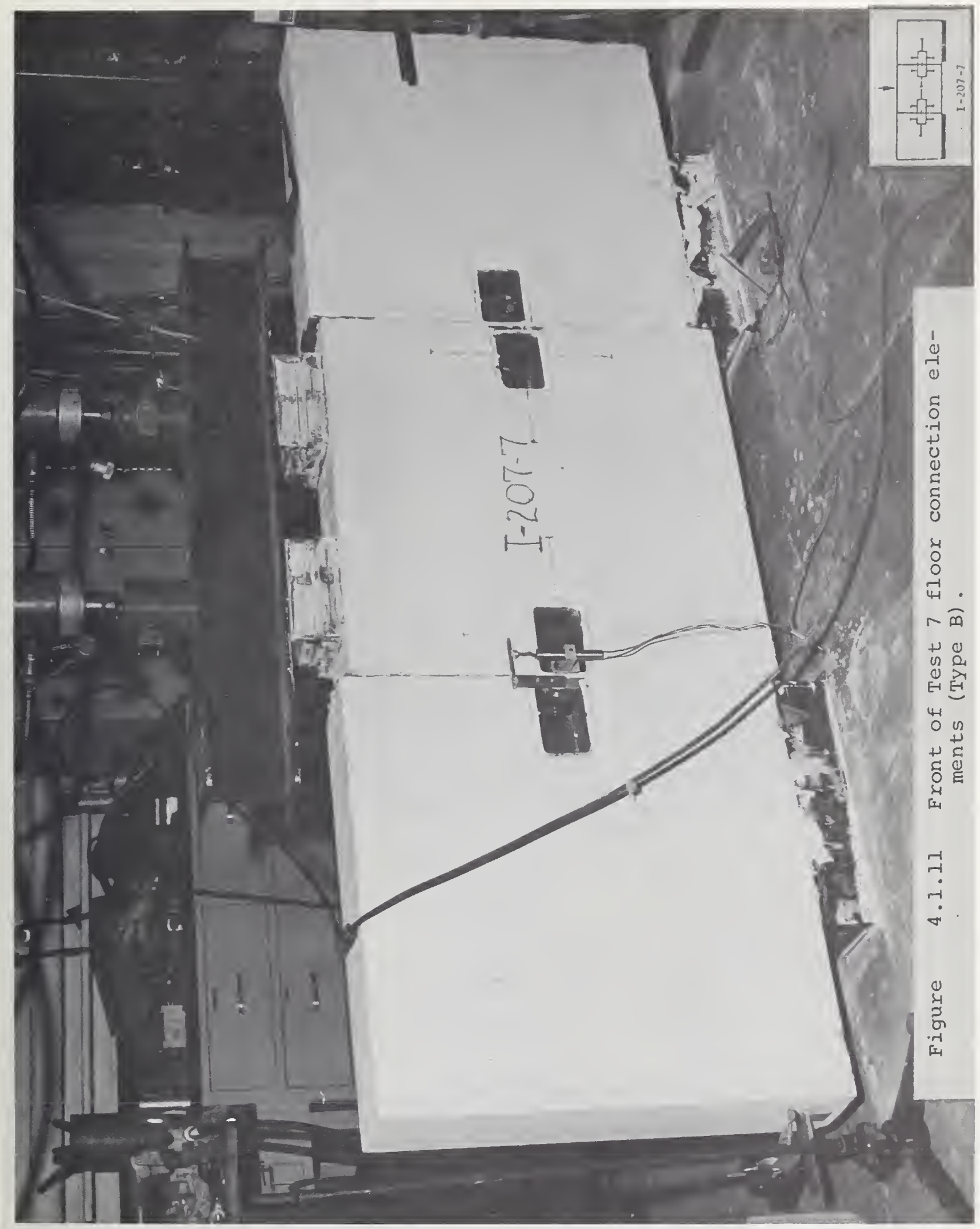



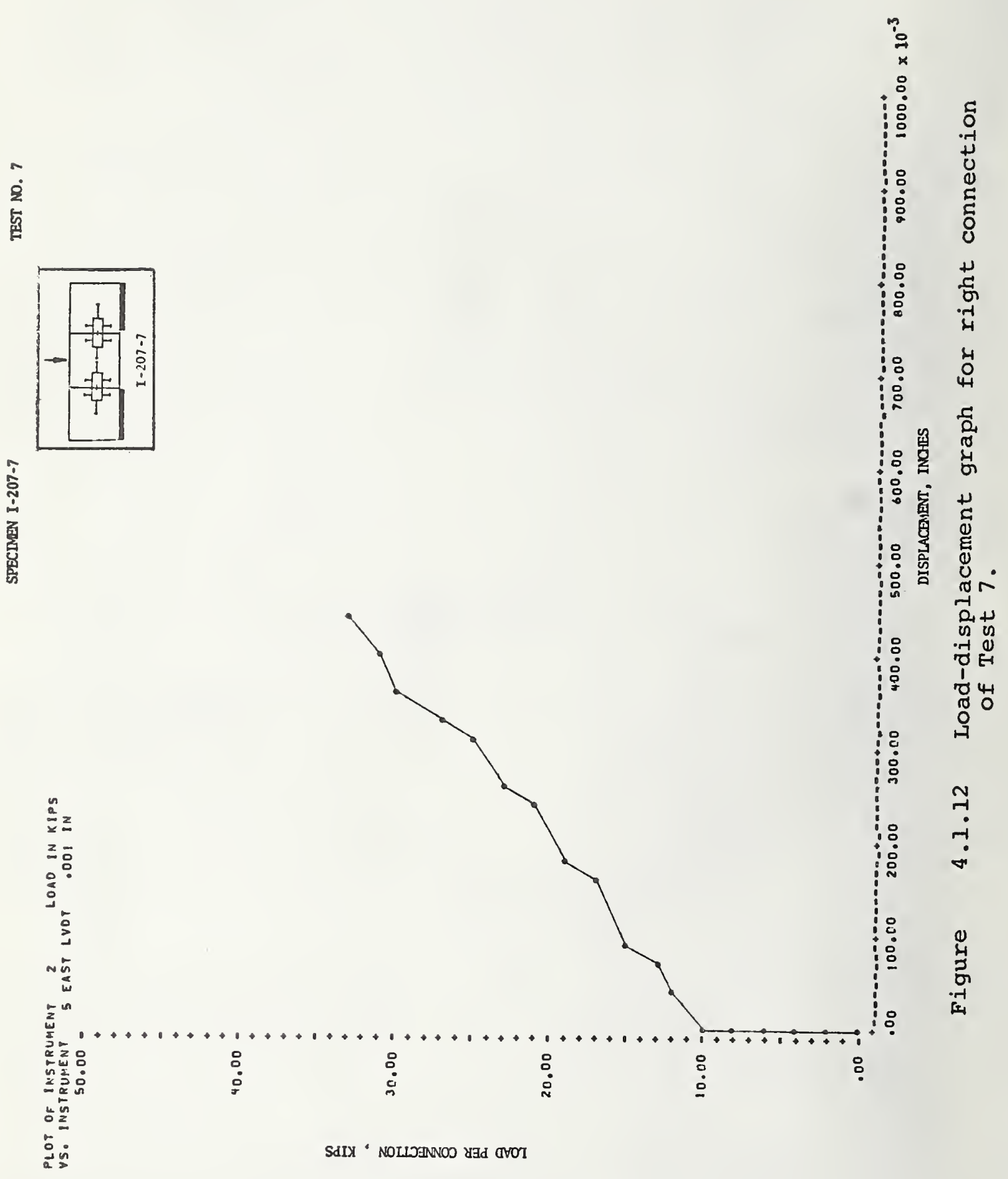


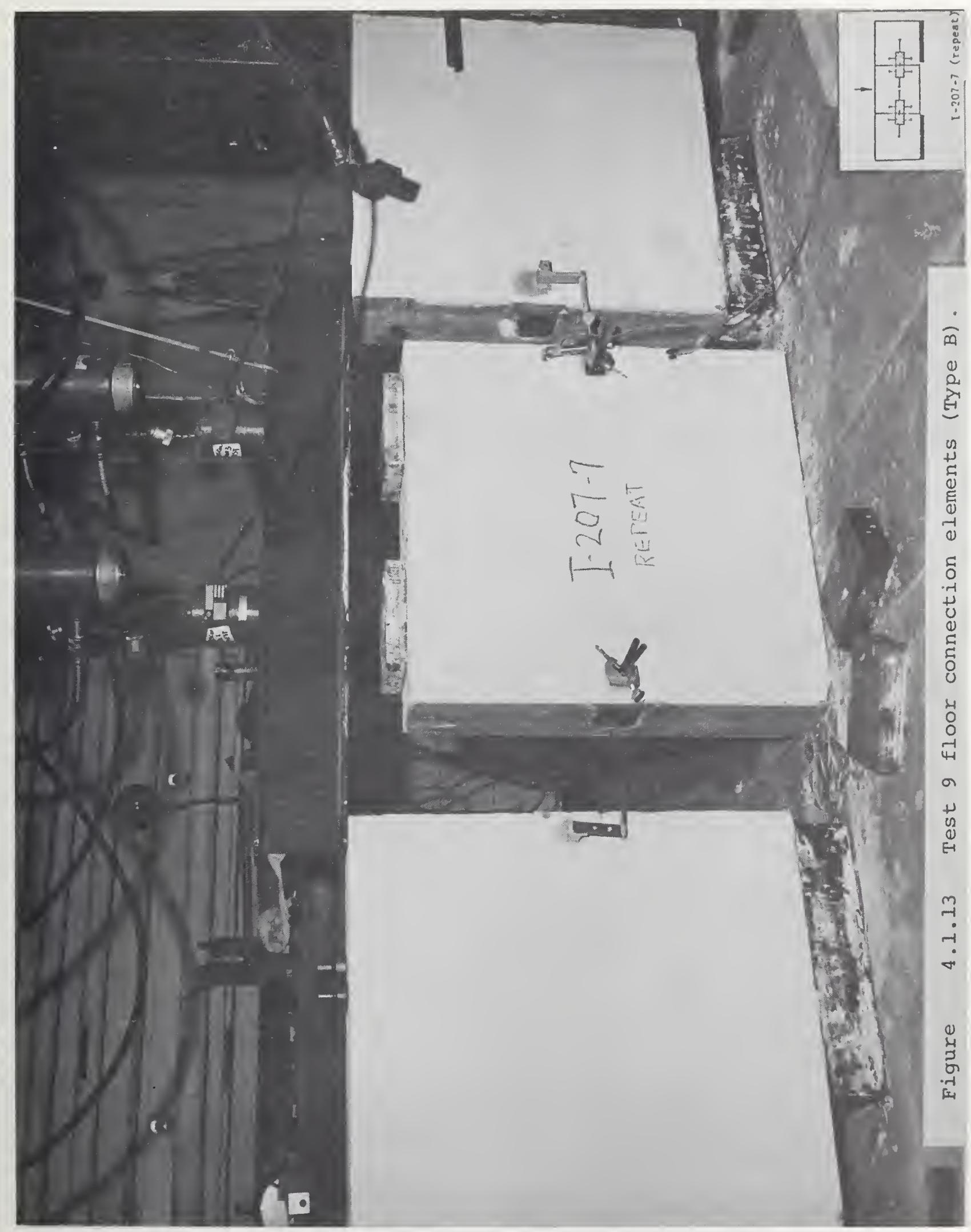




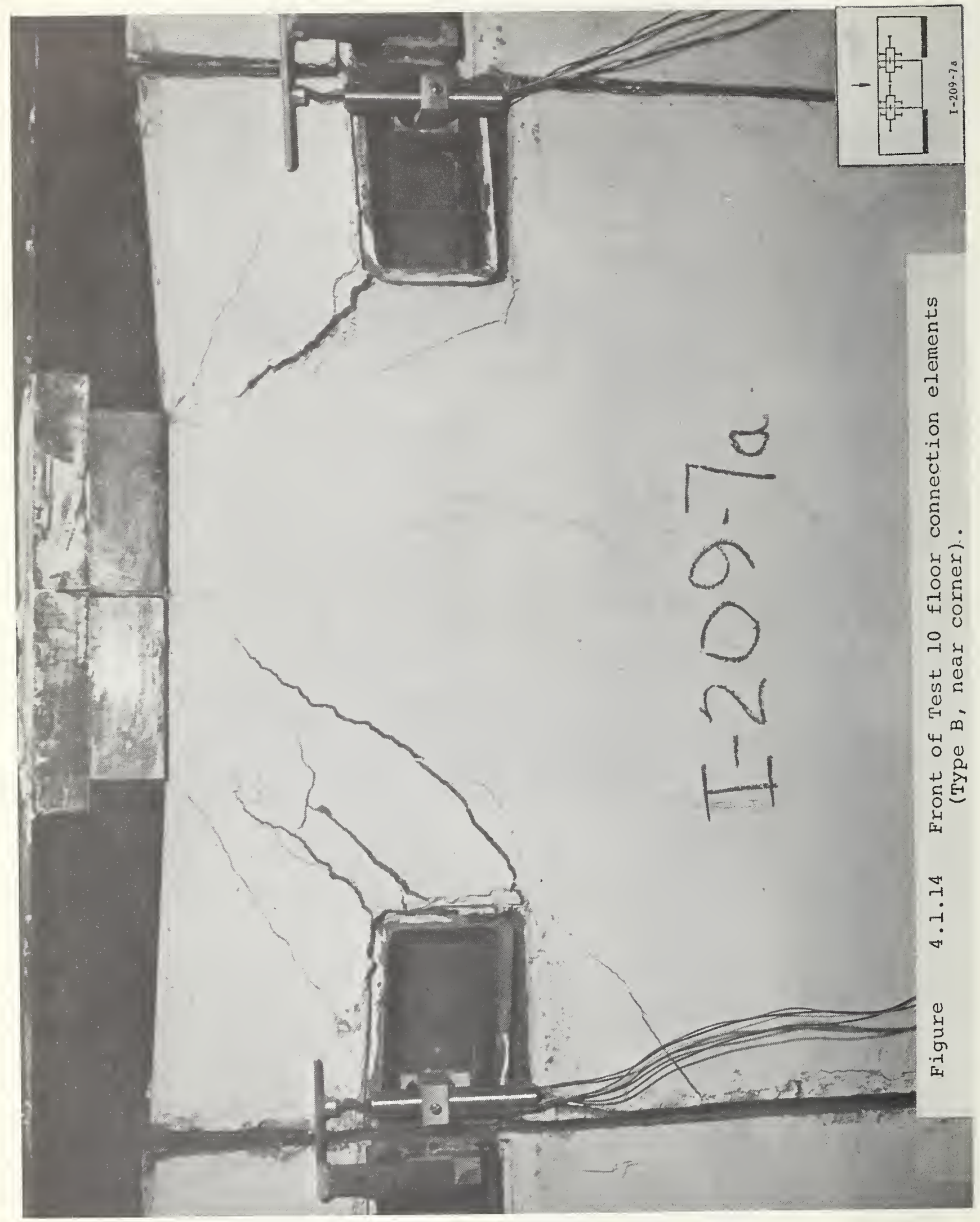




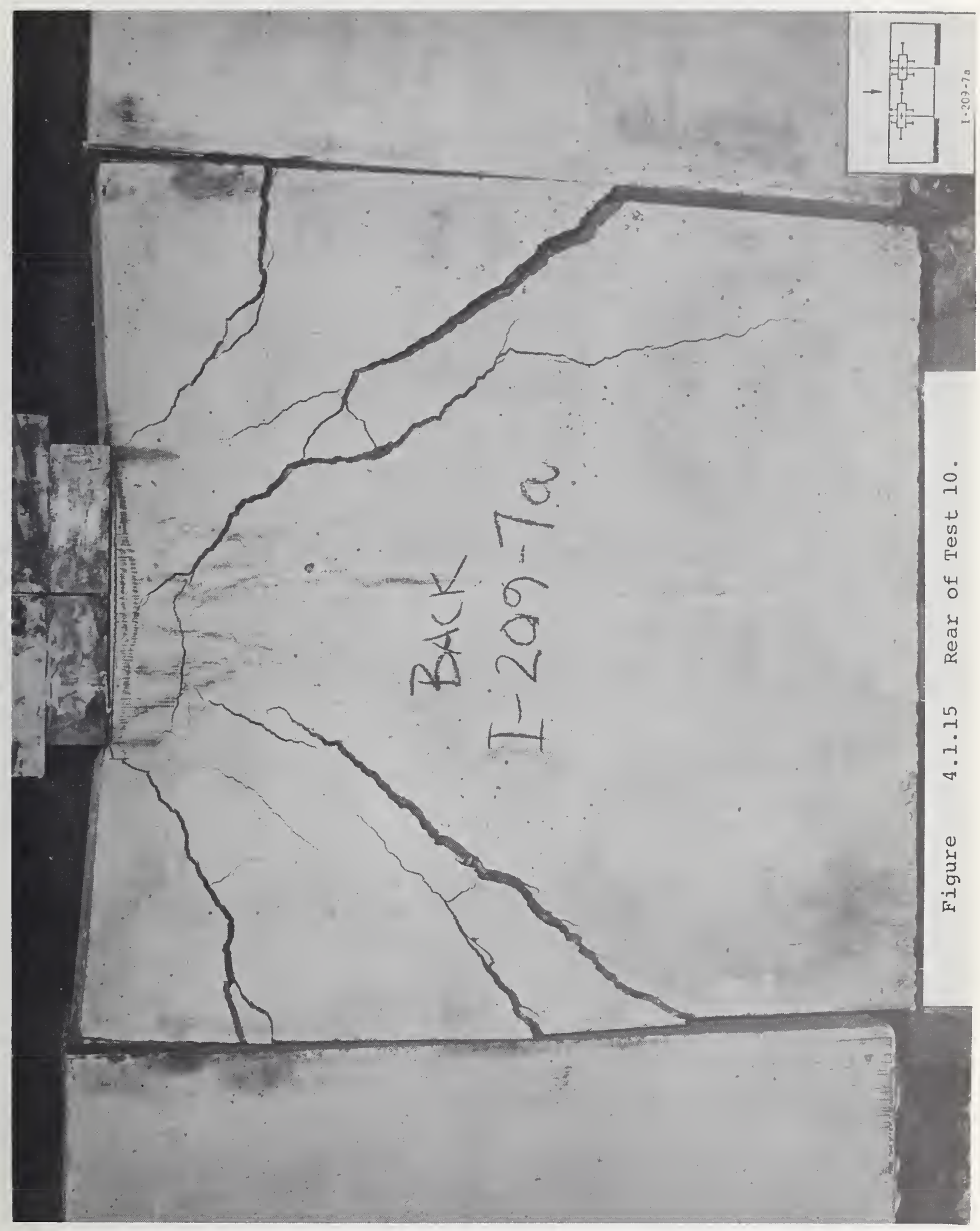




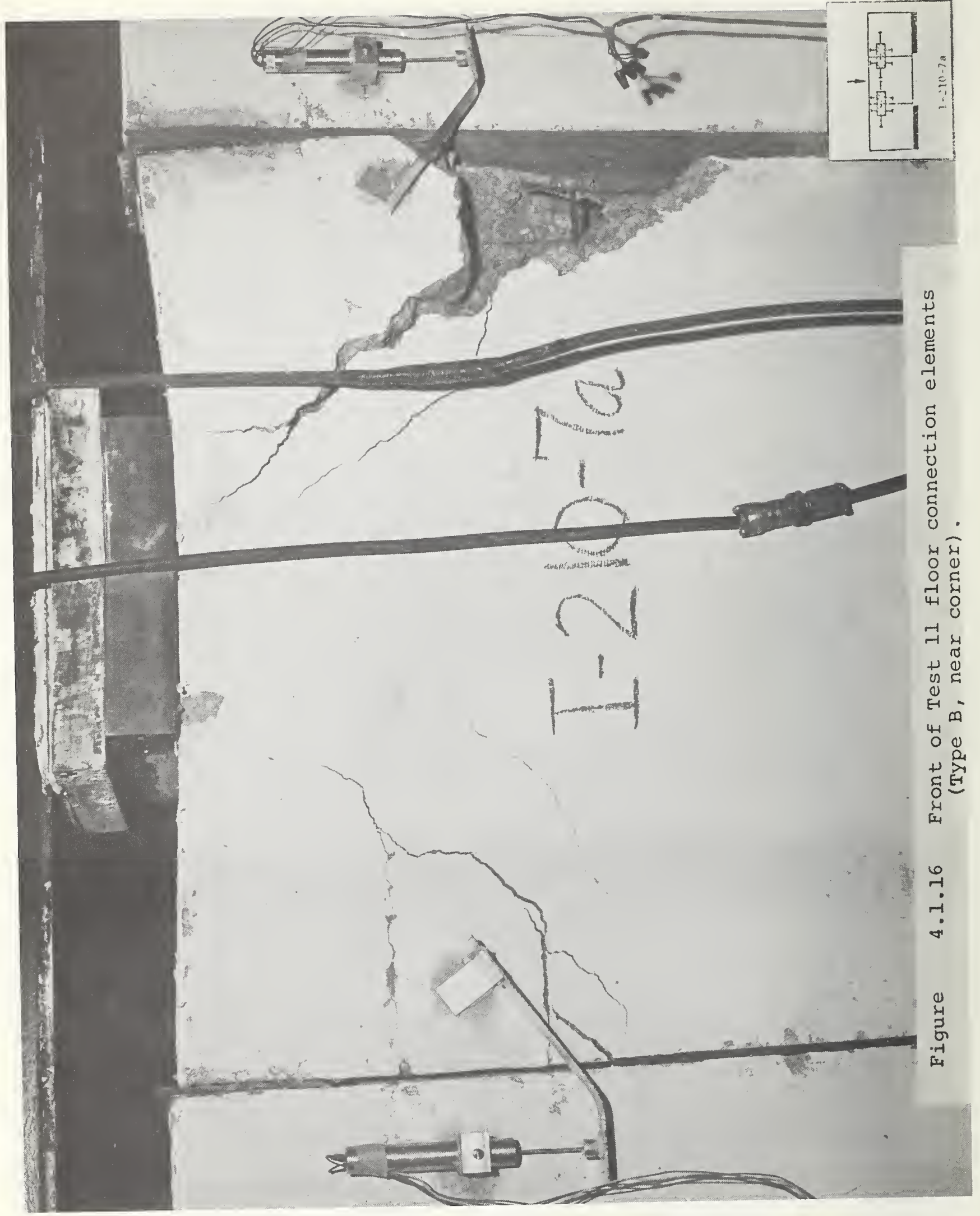




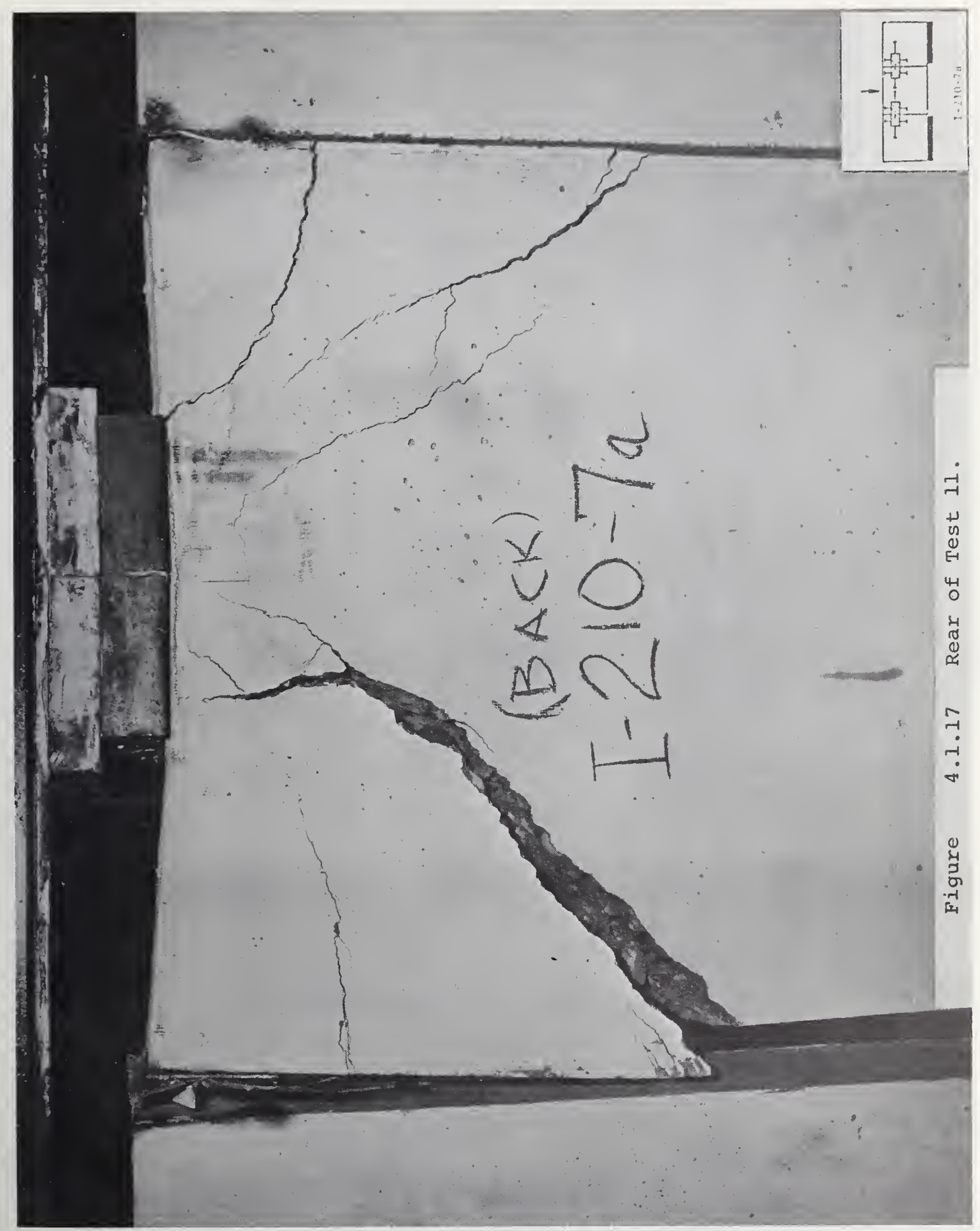




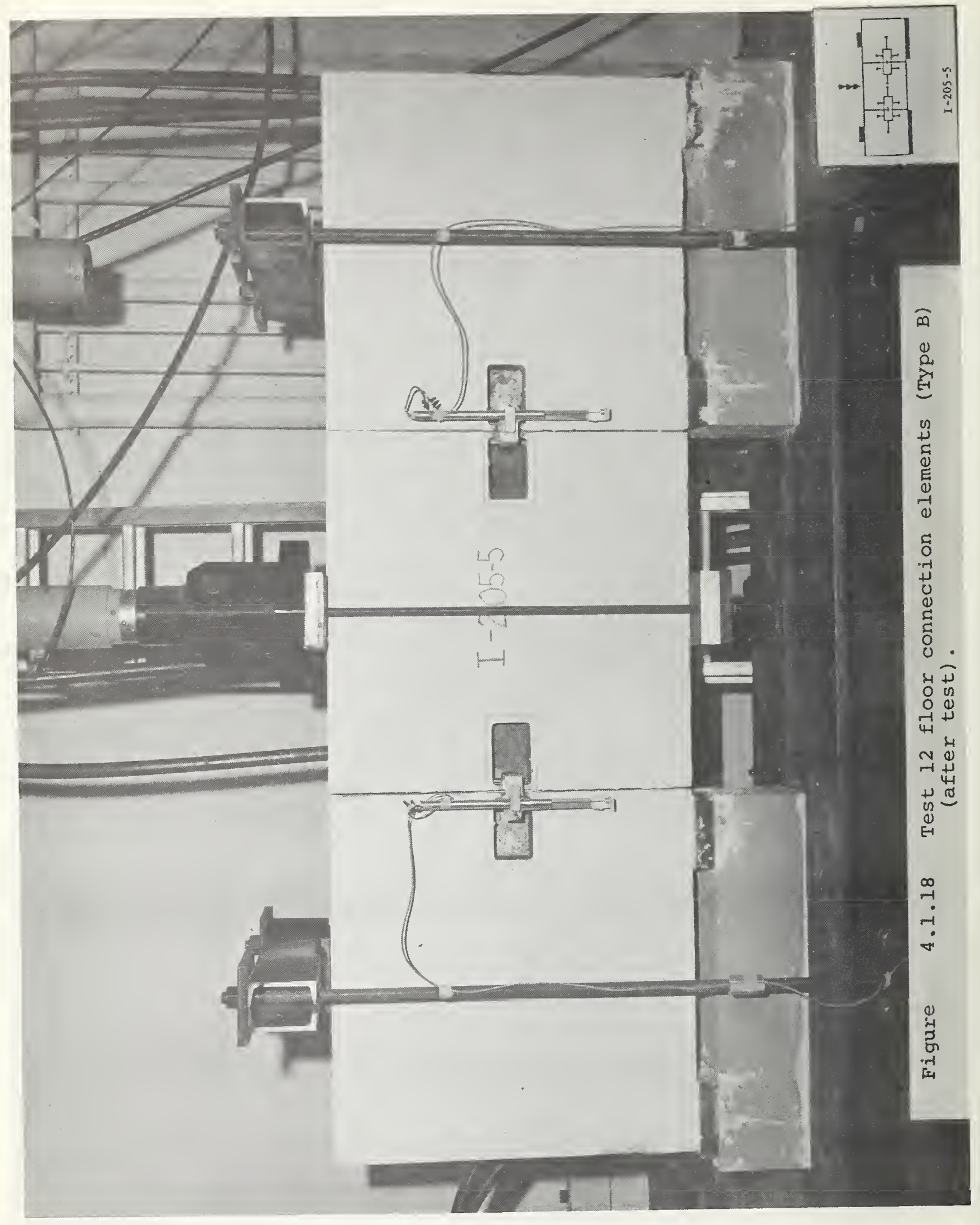




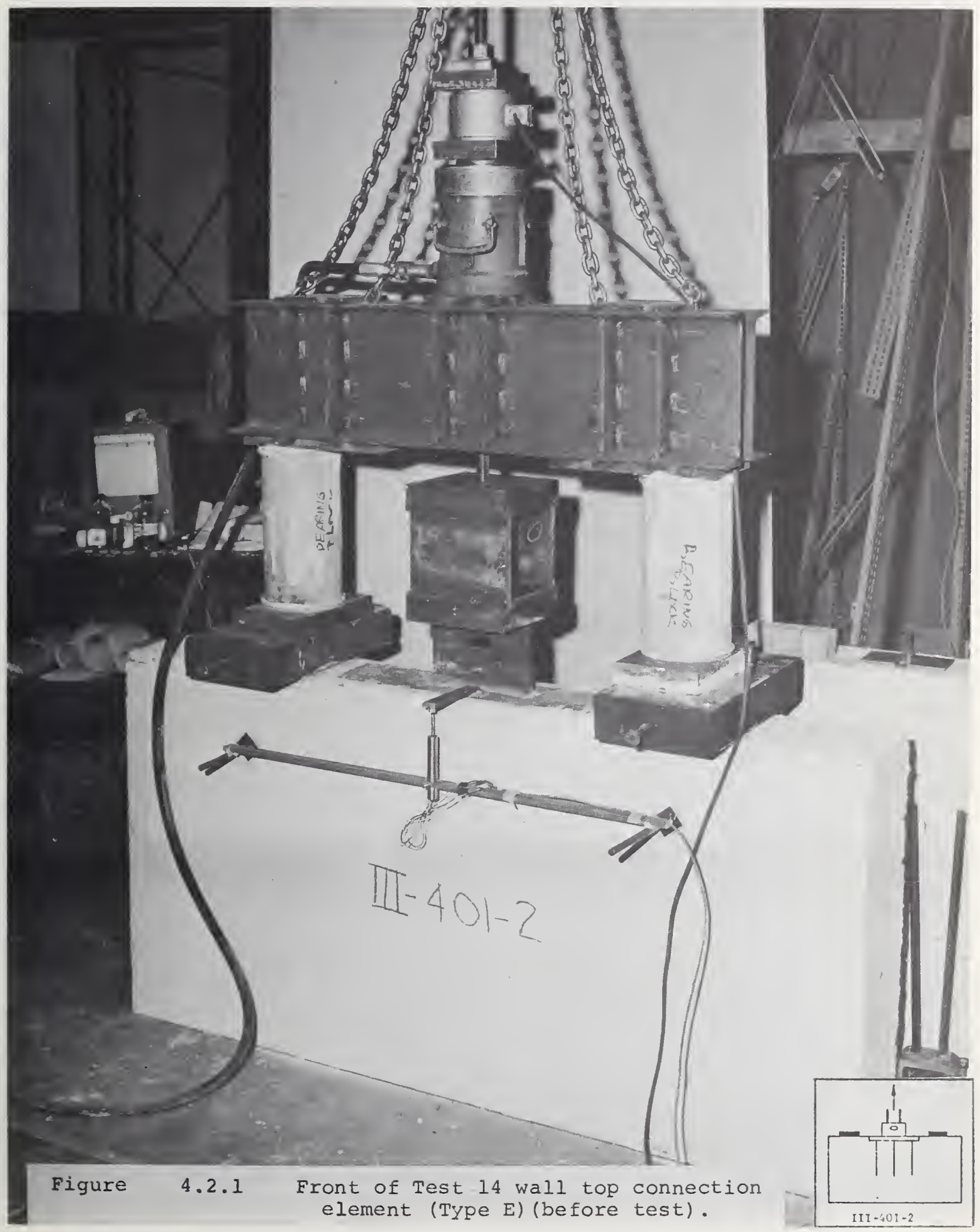




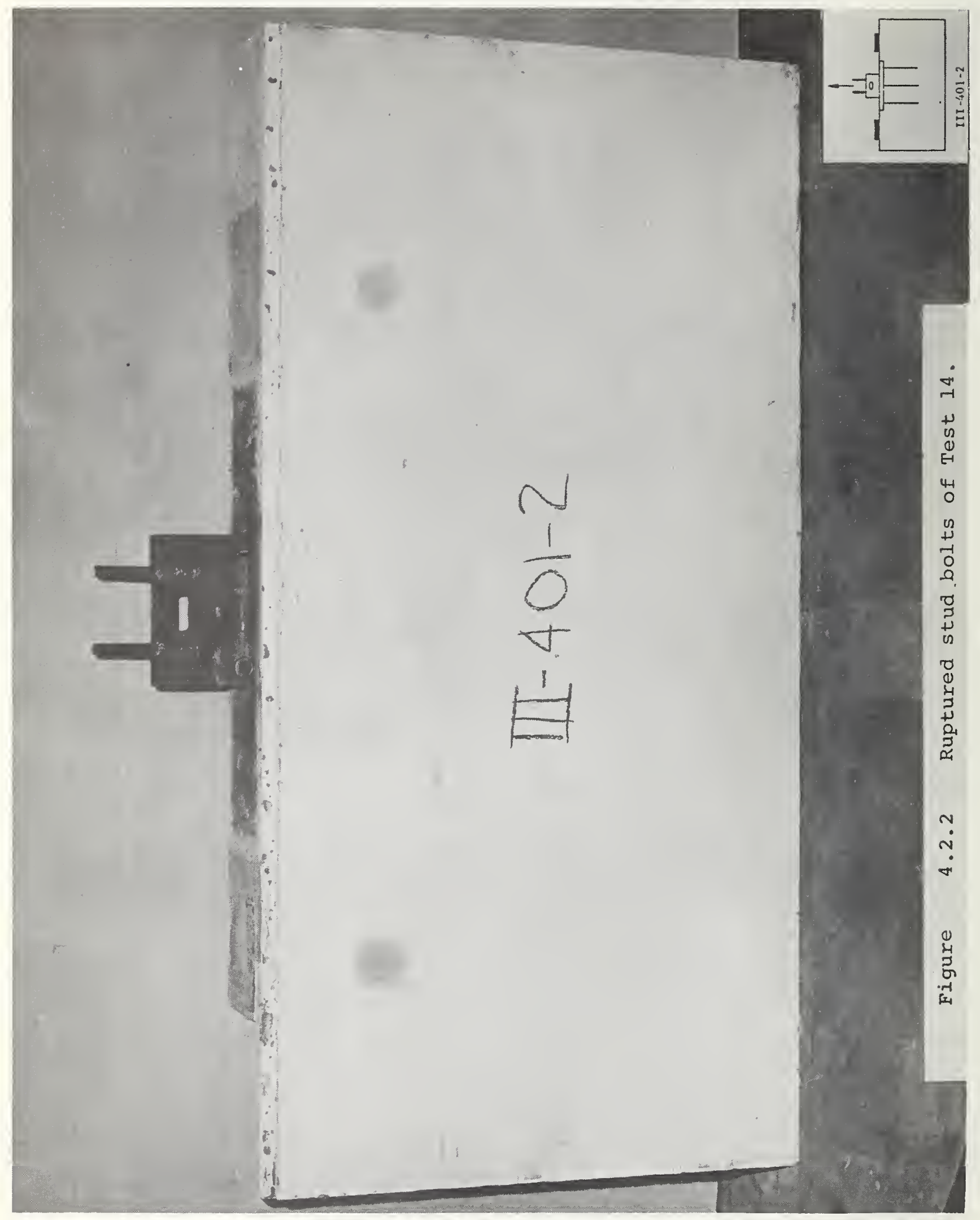




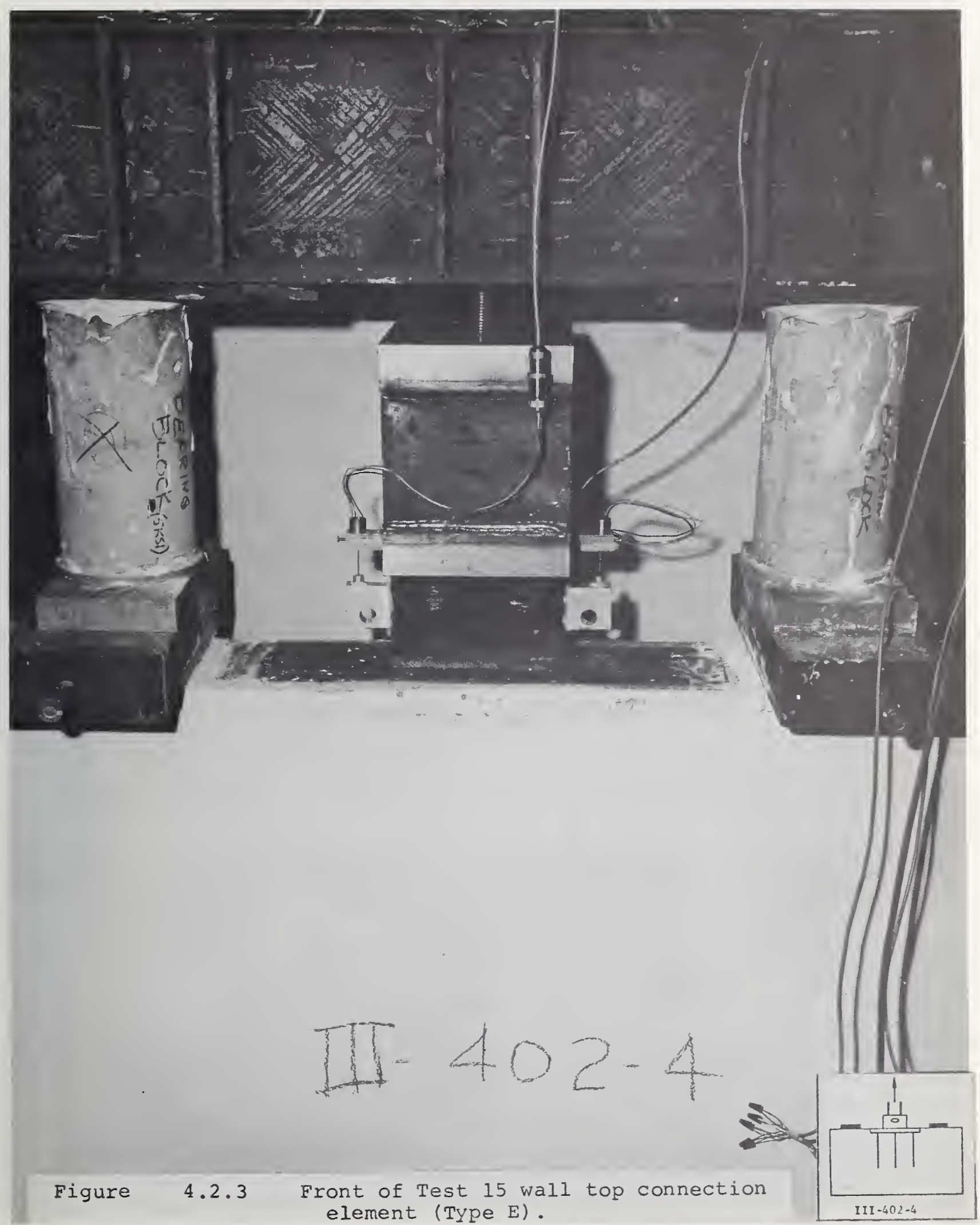




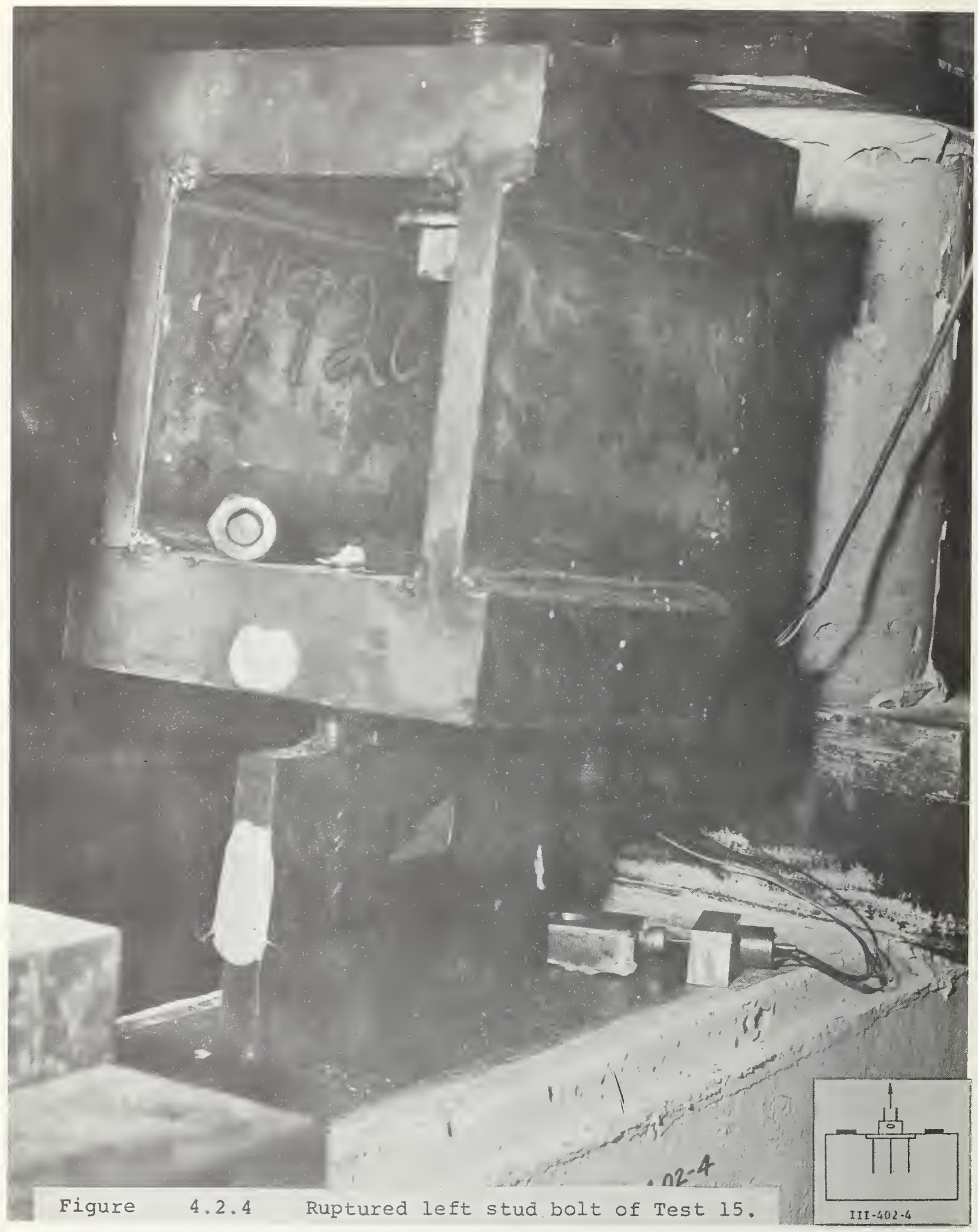




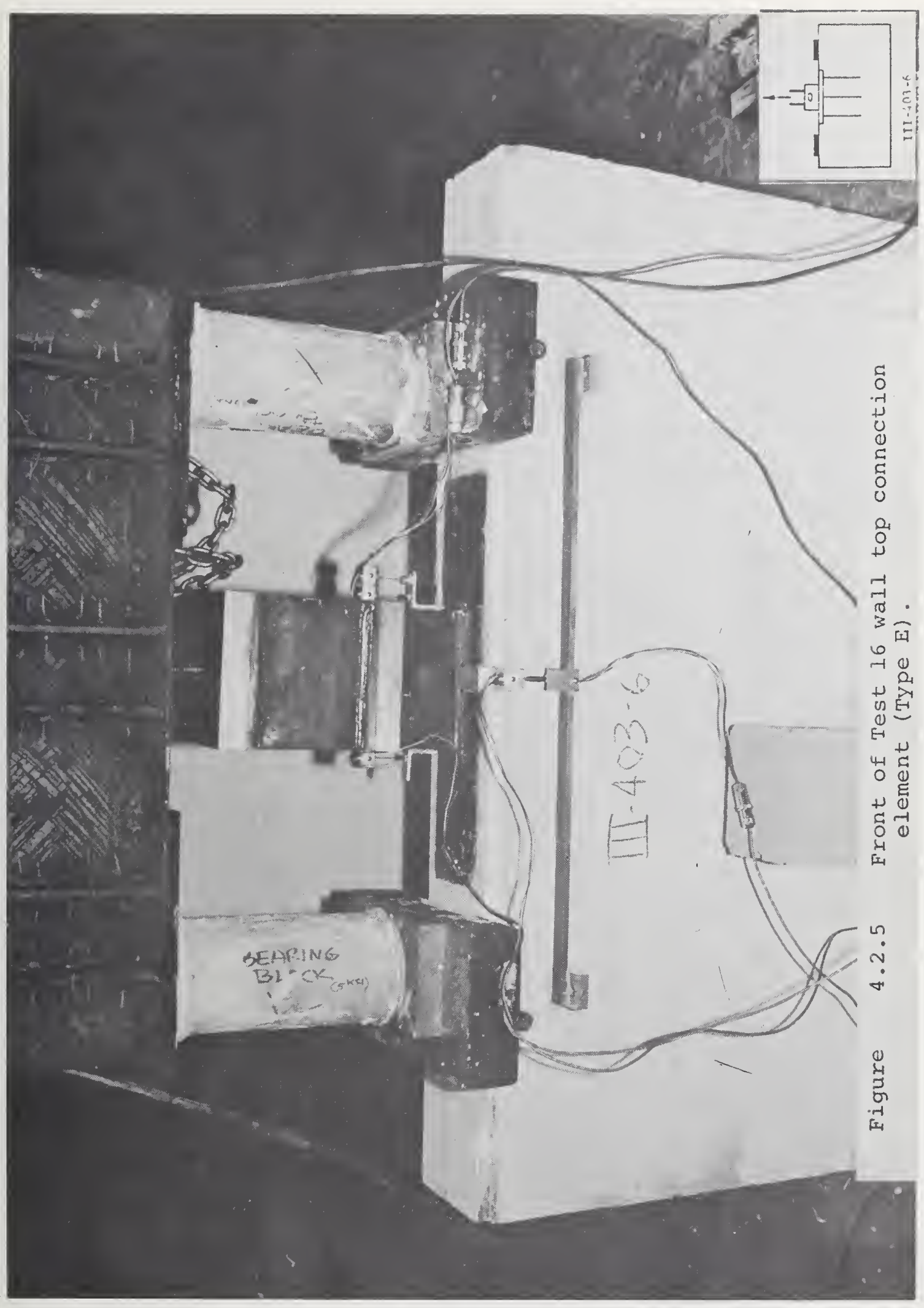




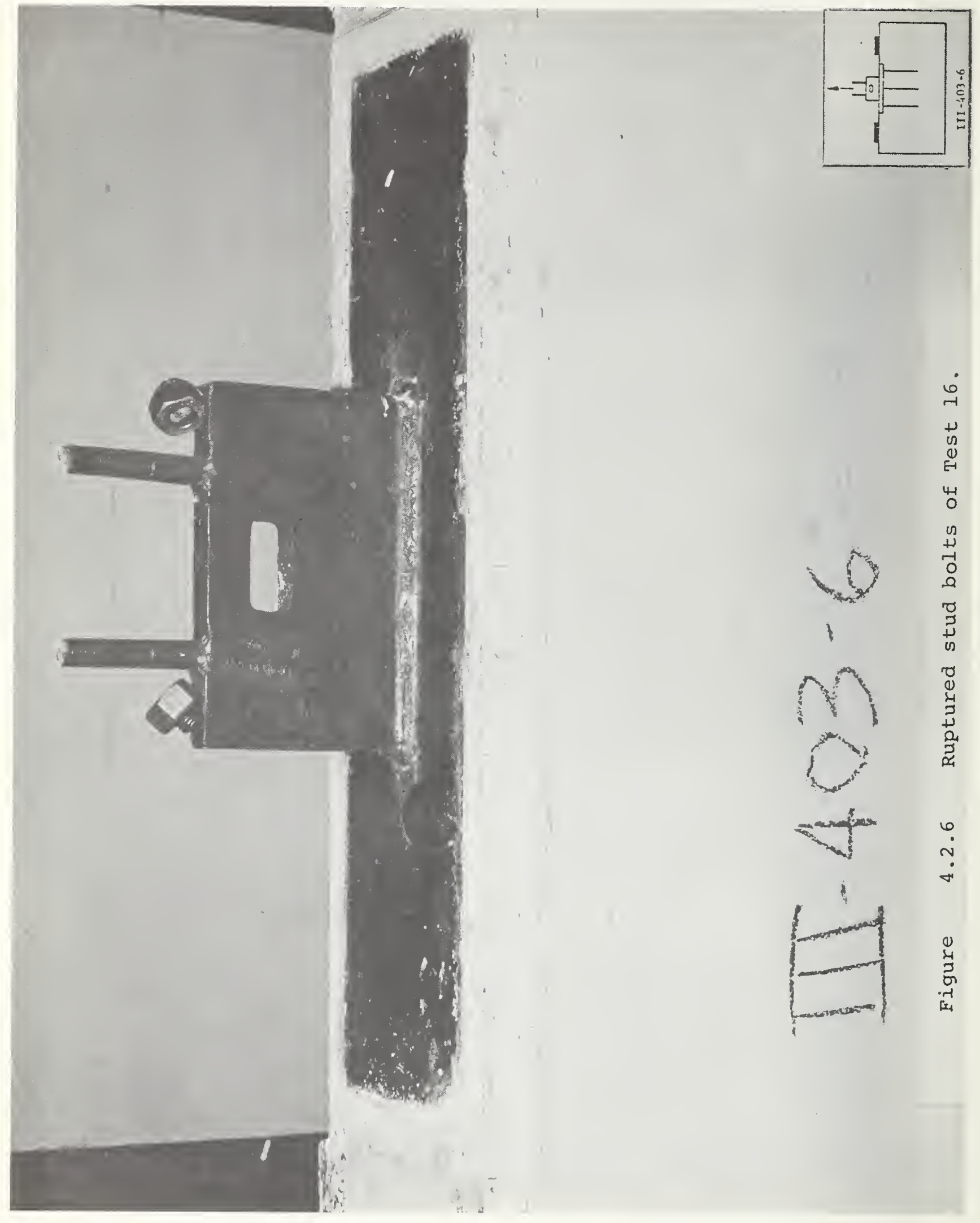




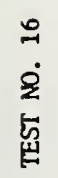

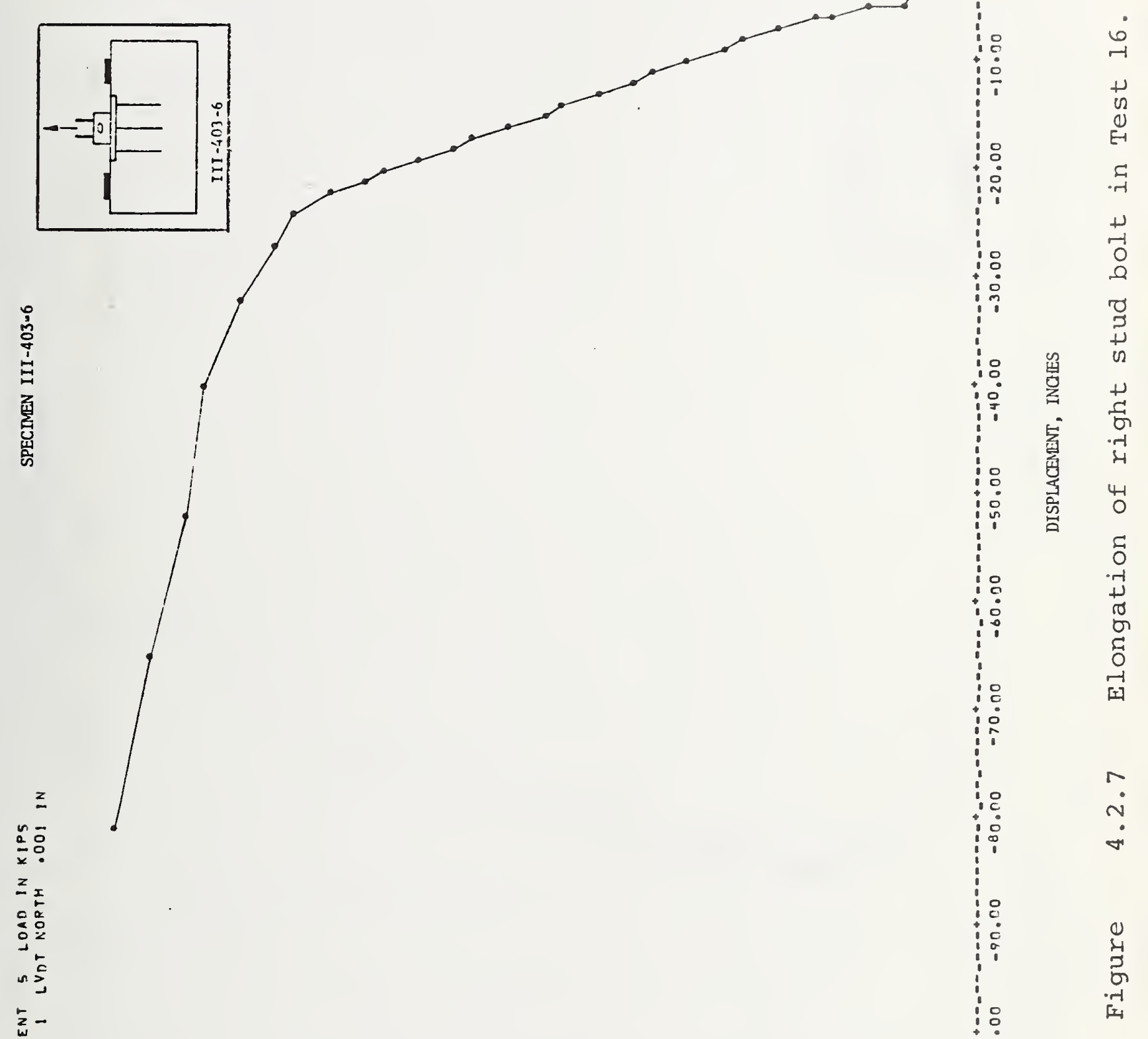


官

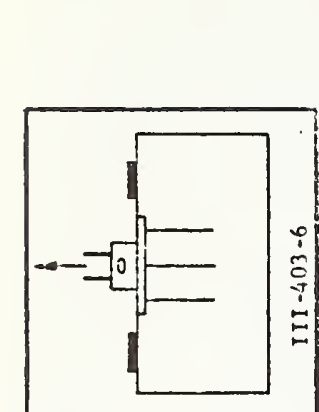

兽

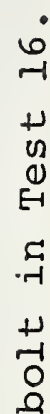

$=$

$z$

焉

ए.

菻

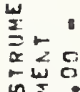

的空:

范

용 
울

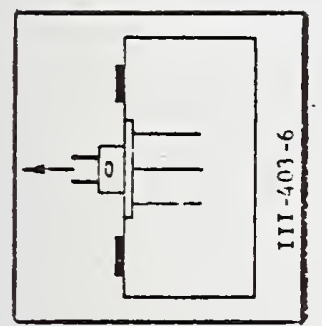

号 


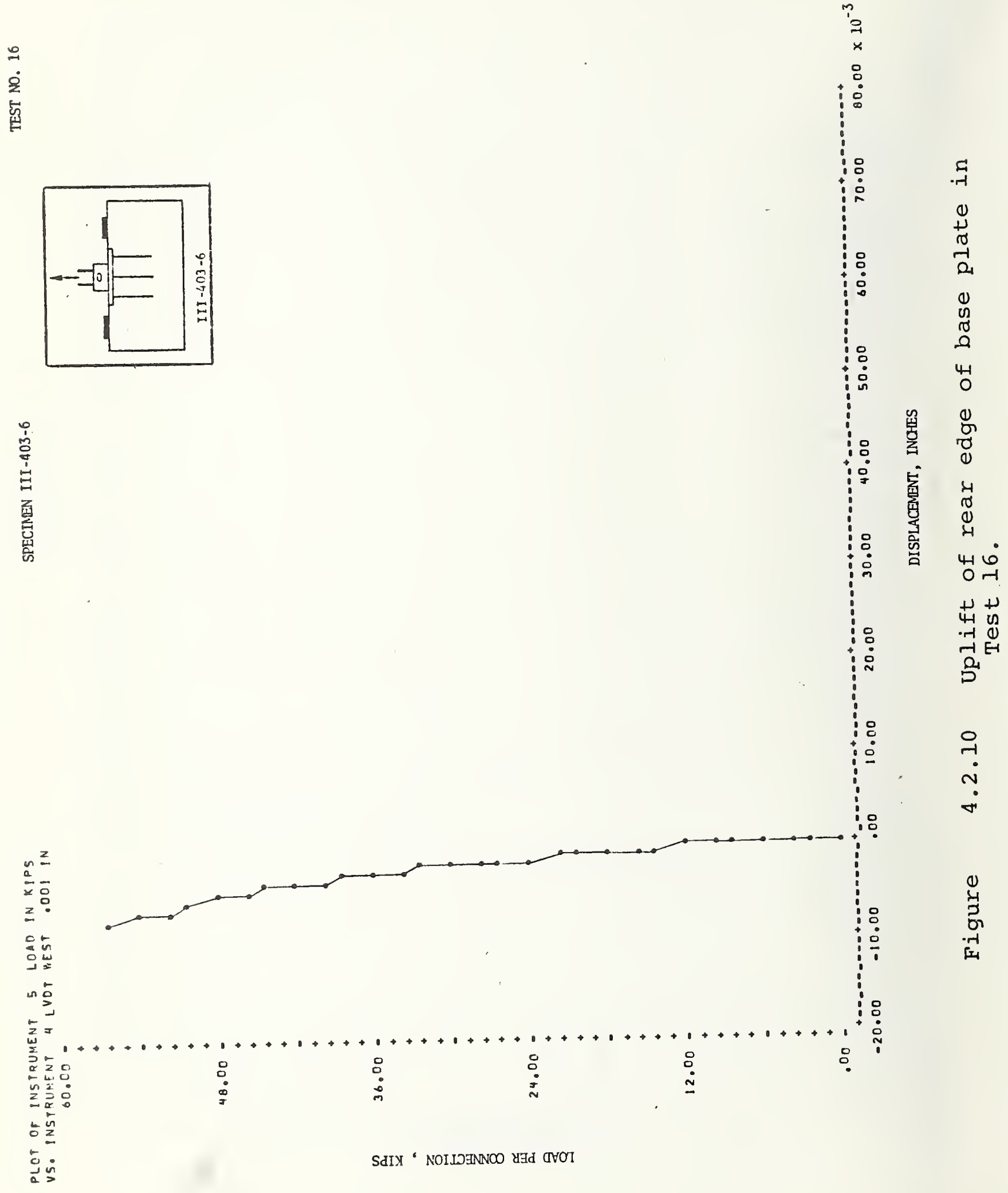




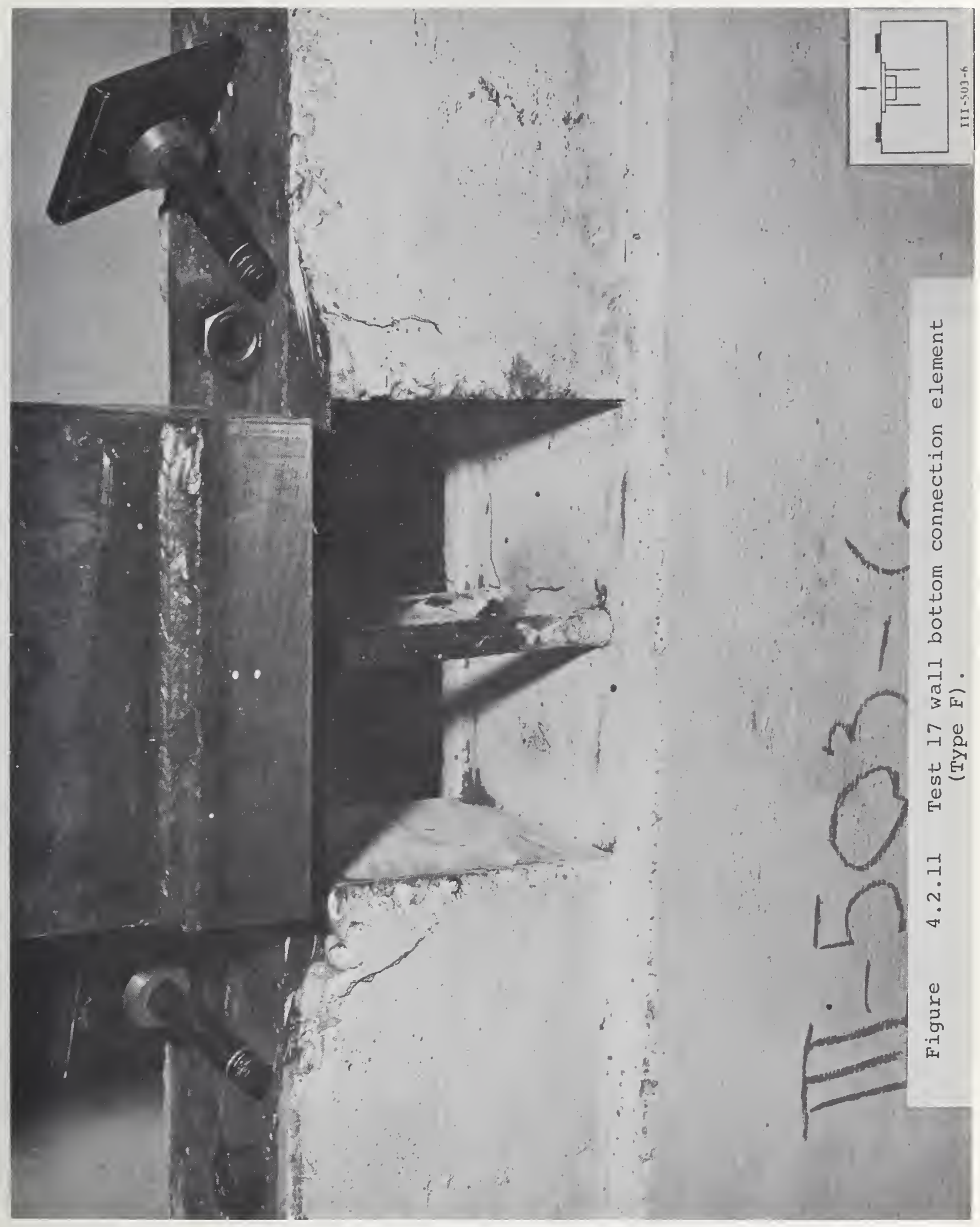




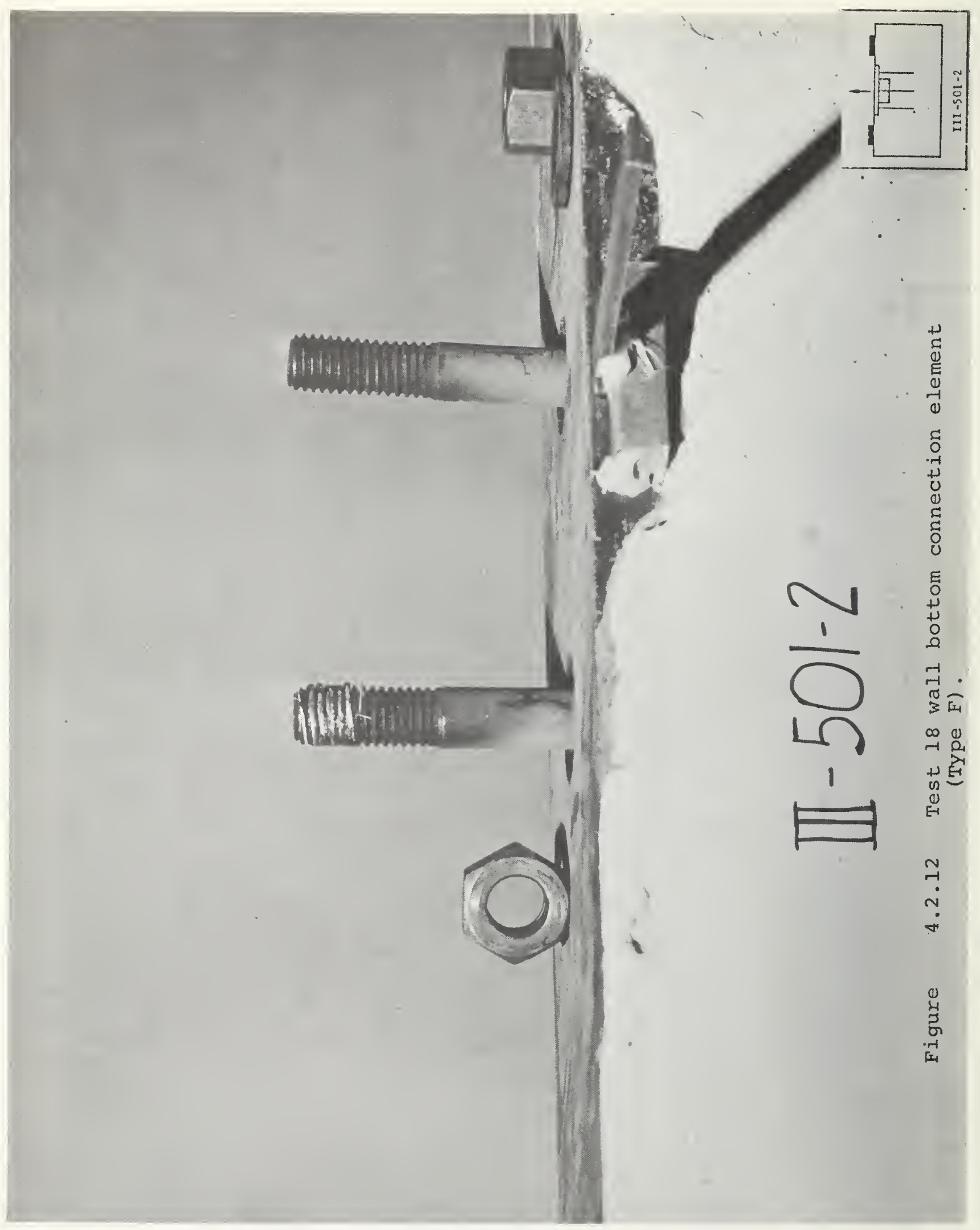




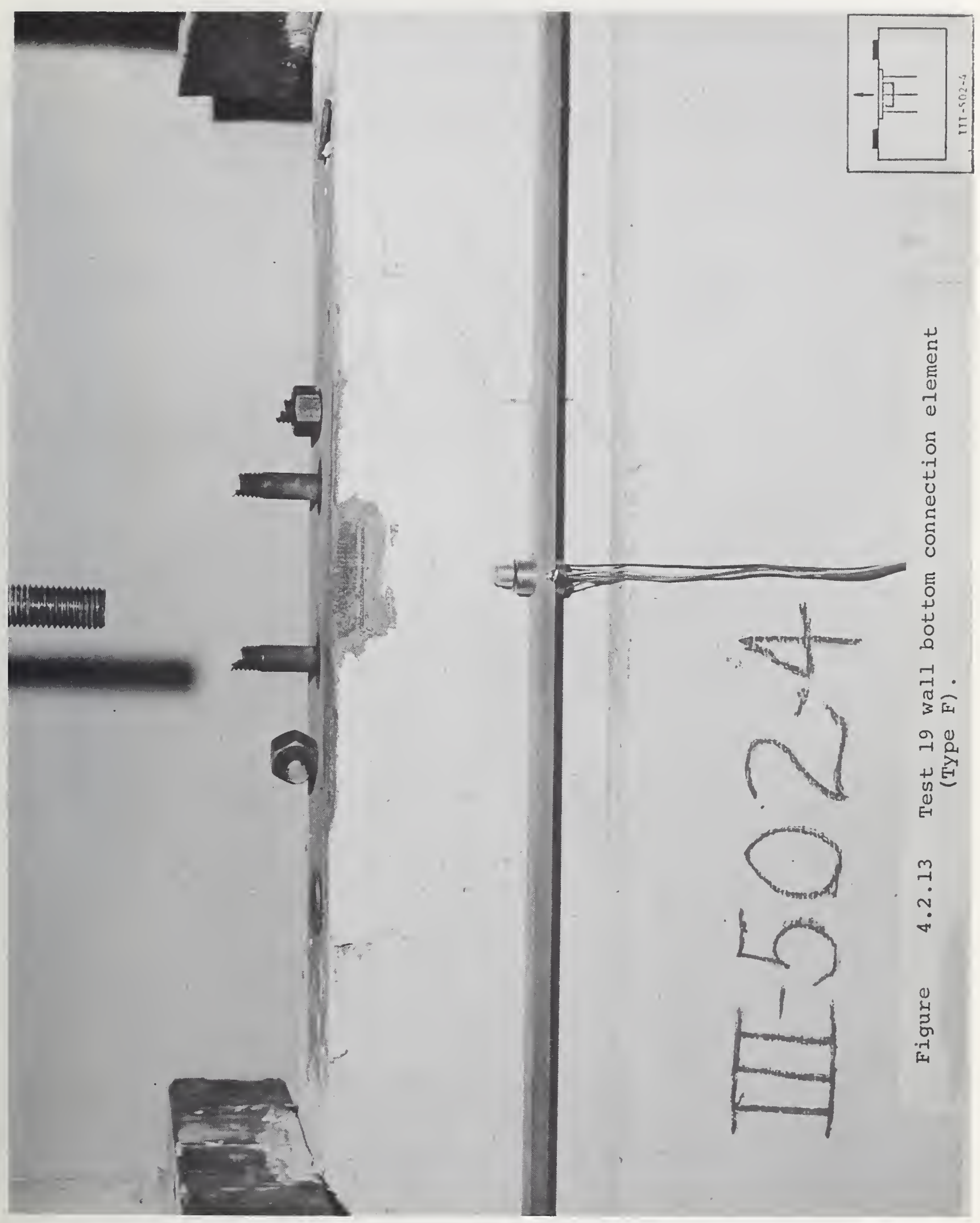




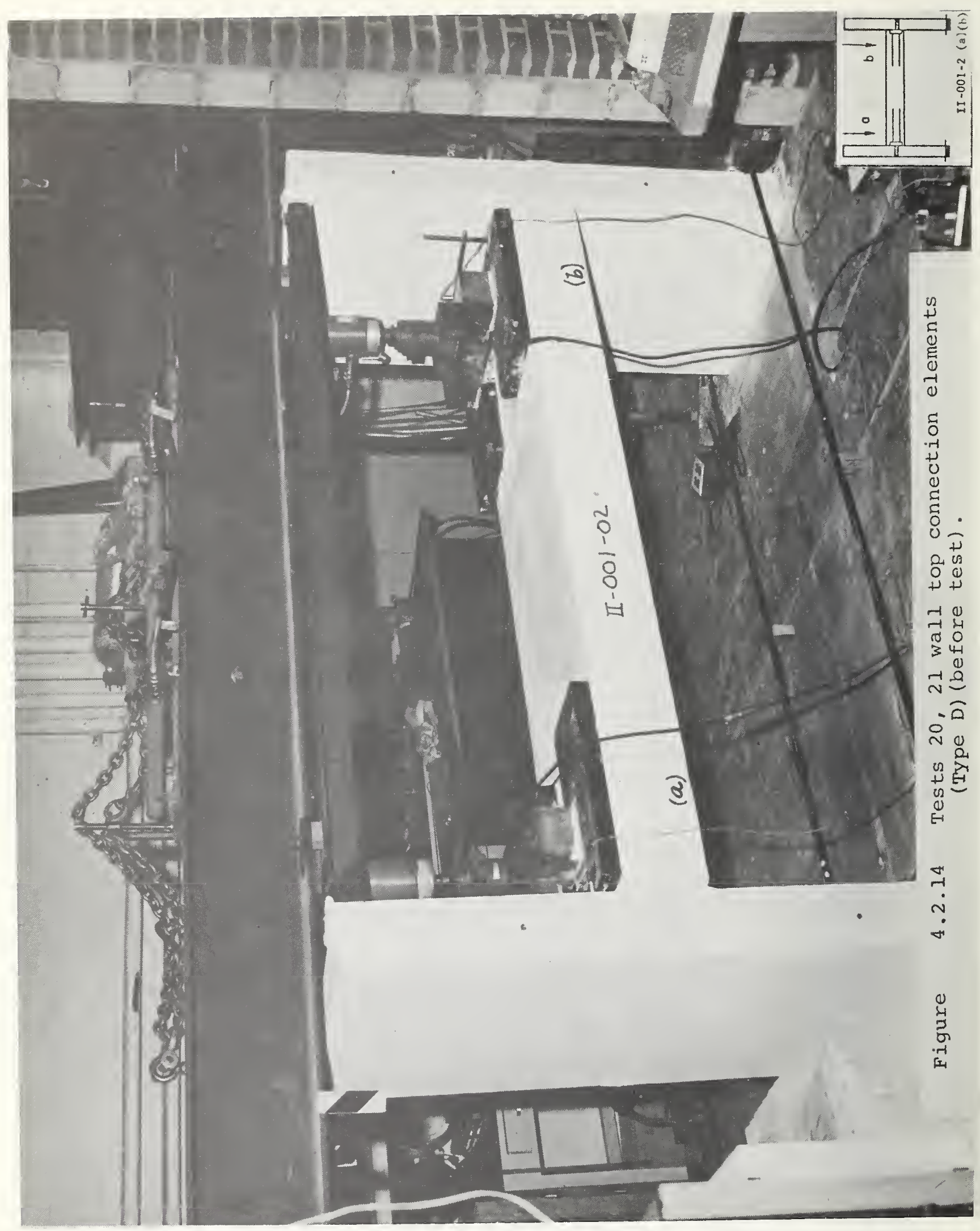




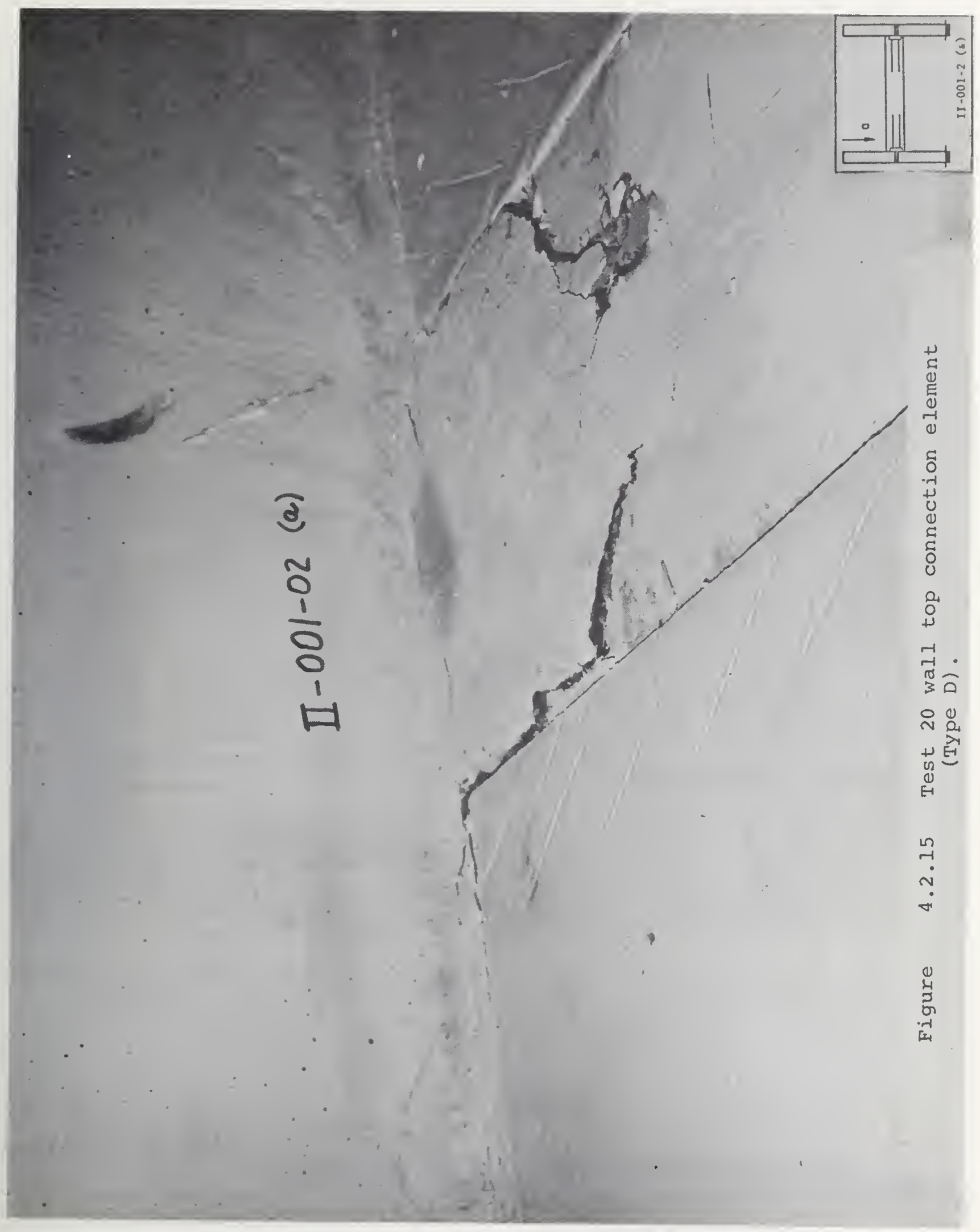




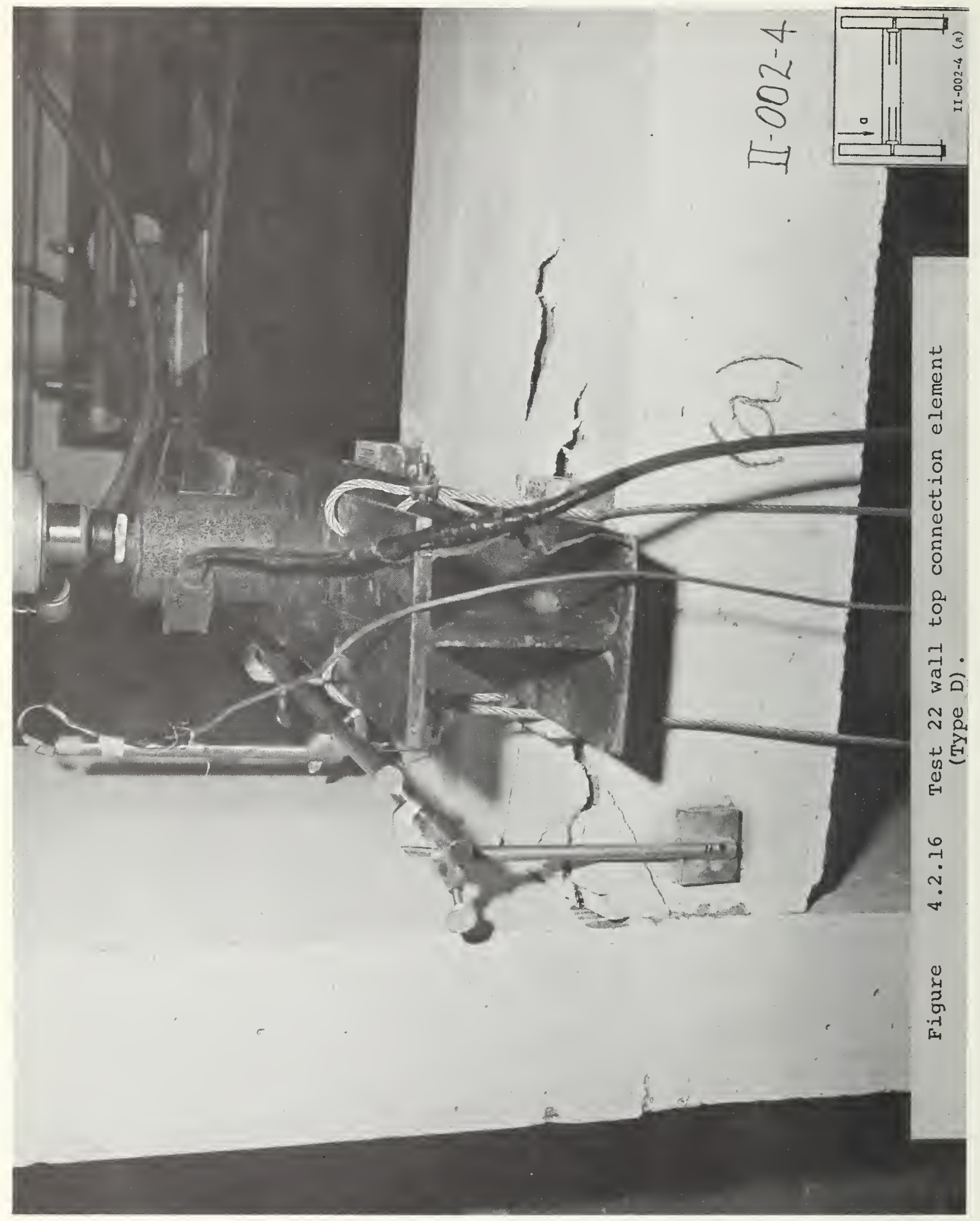




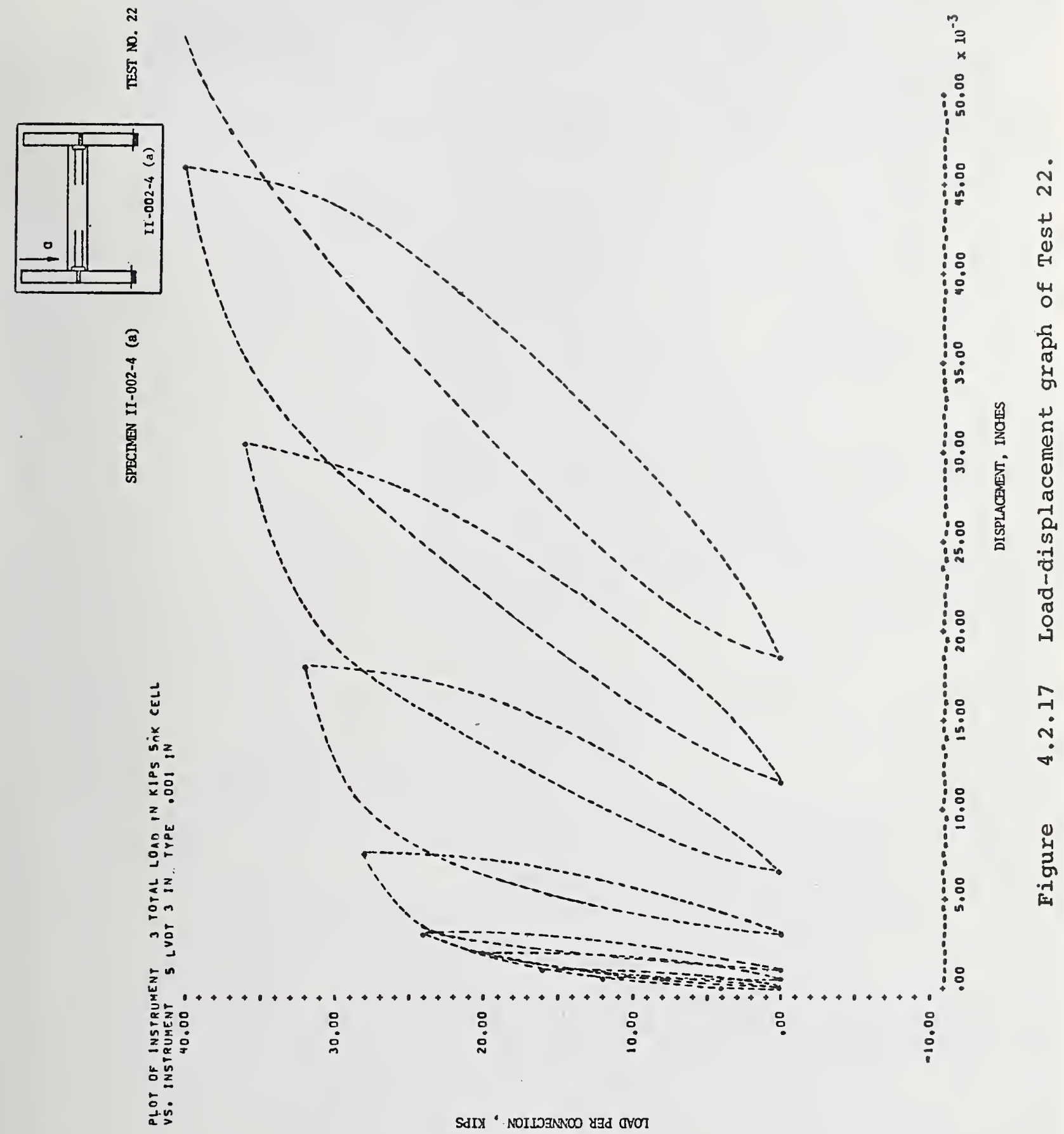




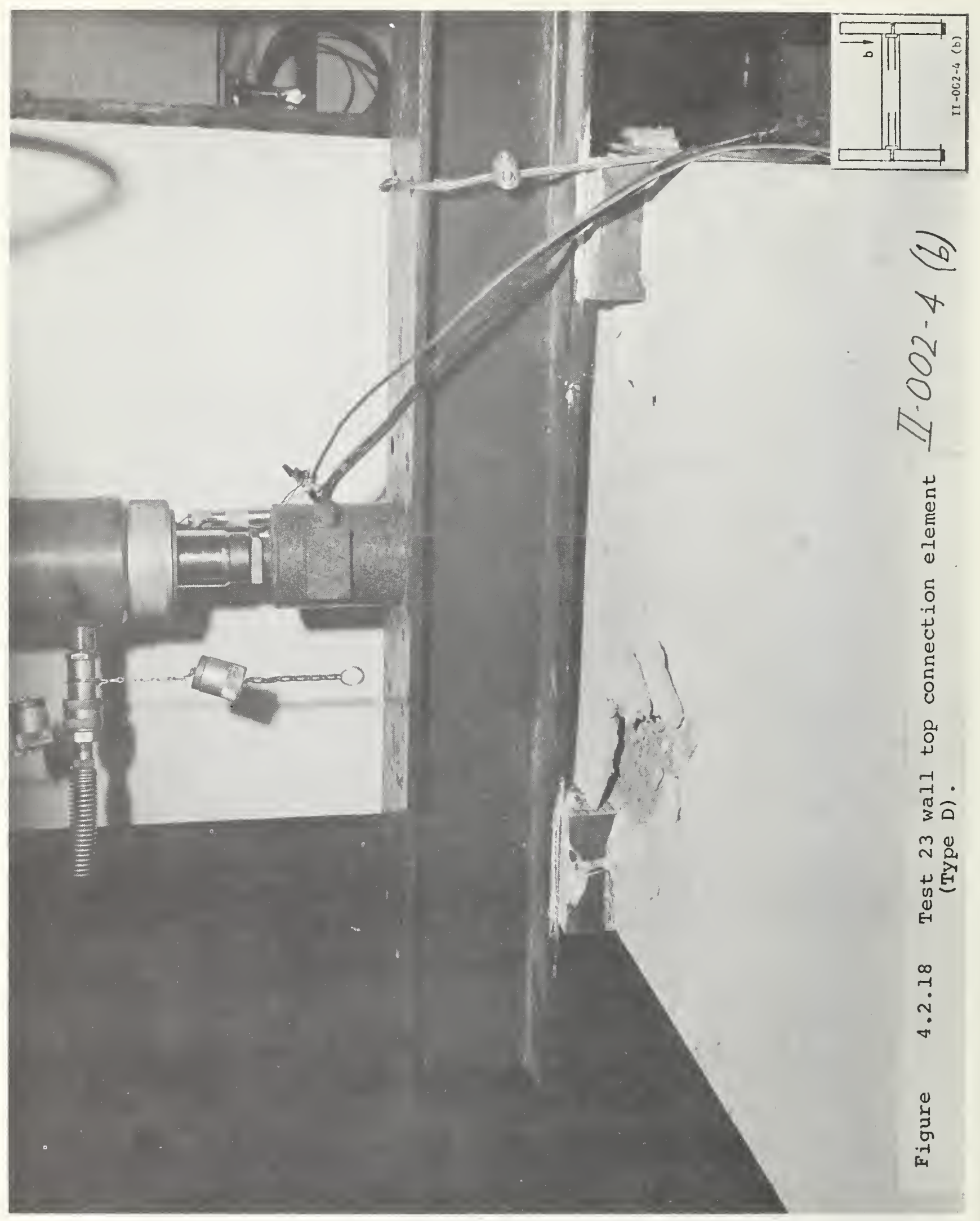




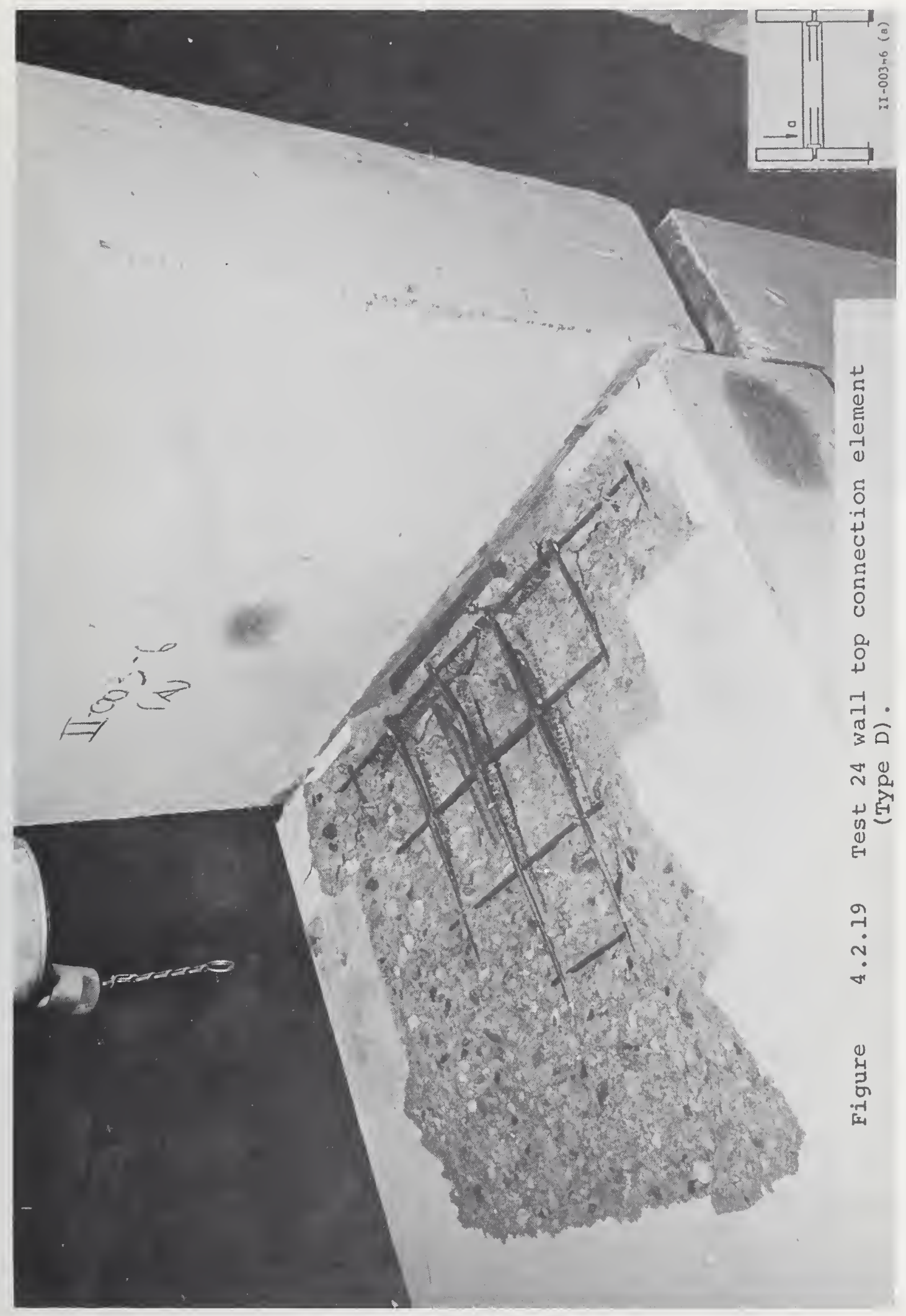




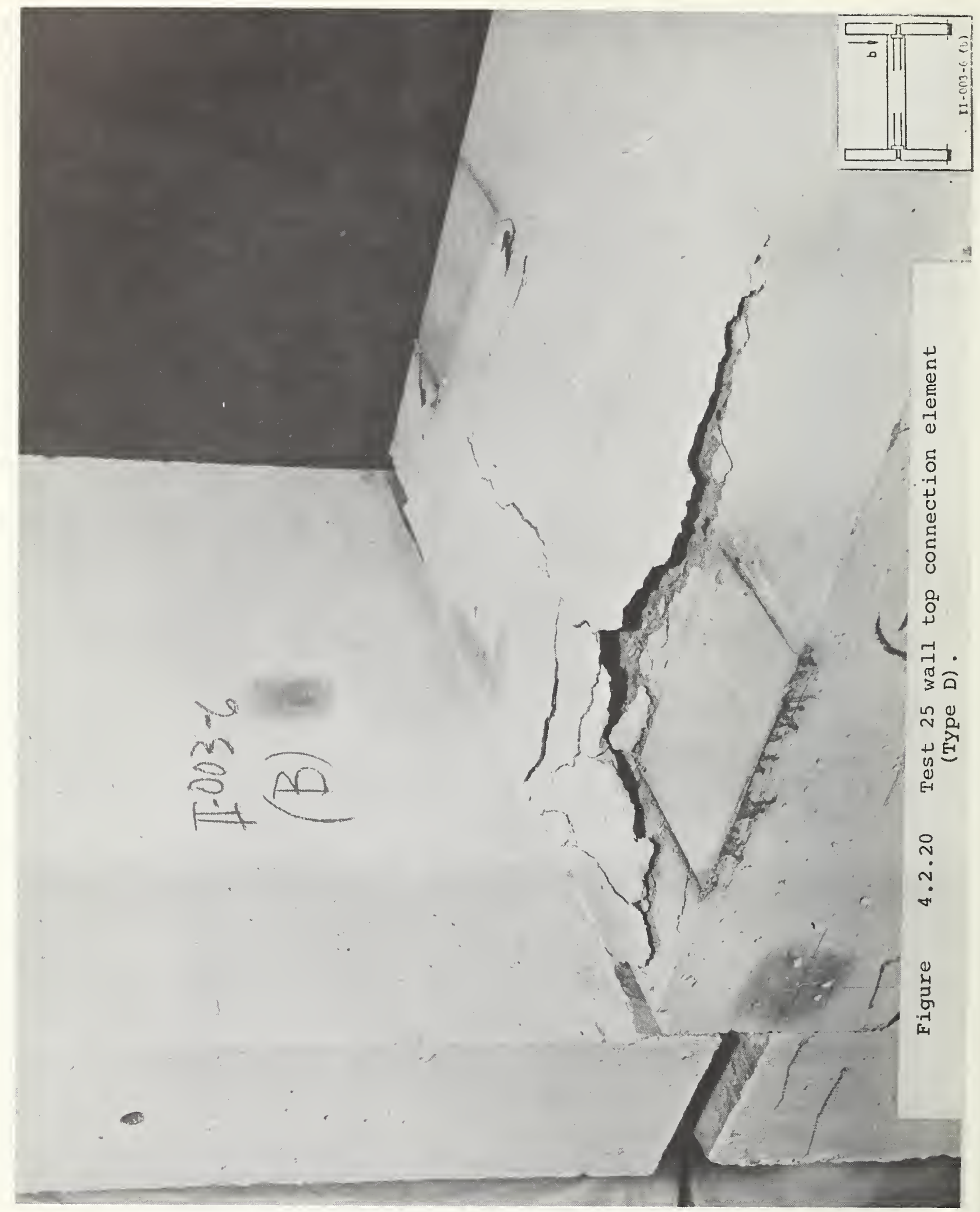


A11 test results and other pertinent test data are shown in table 3.0. Tests are identified by numbers from 1 to 25 and are correlated with specimen identification numbers and illustrative figure numbers given in the same table. Representative load-displacement curves (indicated by ' $g$ ' in table 3.0 ) are presented for one test in each test group.

The tests illustrated by graphs are those having the minimum observed failure load in each group (except Test 16, chosen over Test 15 because the additional instrumentation in Test 16 was more informative). The comments which follow expand on particular test procedures and results not fitted into the Remarks column in table 3.0 .

\section{A.1 Floor Connections}

A.1.1 Floor Connection Element (Type A) - Tension

TEST 1 - Specimen I-116-7 was considered to have failed when there was visible and graphical evidence of cracking deformation developing rapidly at $29.5 \mathrm{kip}$. No distortion of the rectangular insert tube was apparent even when loaded to maximum capacity of 34 kip followed by failure of one anchor bar. The LVDT seen in figure 4.1.1 provided data for the graph in figure 4.1.2. The graph in figure 4.1 .3 was generated by an LVDT similarily mounted on the opposite or rear face of the specimen (floor bottom). The difference in the rates of displacement at the two points of observation is attributed to the 
greater surface area of tube imbedment (hence, more restraint) "below" the connection bolt, i.e., to the rear in figure 4.1.1 (fig. 1.2.2 - elevation).

TEST 2 - Specimen I-101-1 which contained a grout-filled insert failed at 38.7 kip in a manner similar to that of Test 1. Damage to grout visible in figure 4.1 .4 is a spalled surface repair and not evidence of internal grout breakdown. Both tail anchor bars failed at a maximum load of 48 kip. Magnified displacement seen in figure 4.1 .4 was produced to examine tail bar failures.

\section{A.1.2 Floor connection Element (Type B) - Tension}

TEST 3 - Specimen I-316-7 failed at 18.0 kip when cracking deformation gave indication of yielding. No distortion of the insert rectangular tube was observed throughout the test. Maximum capacity (22 kip) was determined by tensile failure of tail stud. After-test displacement (in fig. 4.1.5) was increased by additional pulling to examine stud. Load-displacement curve in figure 4.1 .6 is for front of specimen (top floor surface).

$$
\text { TEST } 4 \text { - Specimen I-301-1 failed at } 30.0 \text { kip in a manner }
$$
similar to that of Test 3. After-test examination showed that the crack across the grouted area (fig. 4.7.7) extended only into the recess of the insert below the walking surface (front) of the floor specimen; grout in the insert tube was not damaged. Tail stud tensile failure occurred at a maximum load of $42 \mathrm{kip}$. 
A.1.3 Floor Connection Element (Type B) - Vertical (Outof-Plane) Shear

TEST 5 - Specimen I-208-7 shown in figure 4.1 .8 after the test, failed at 14.5 kip by initial slip of a friction-type bolt connection. The load-displacement curve in figure 4.1 .9 is for the left LVDT (fig. 4.1.8) mounted to measure relative movement of the two inserts at the left connection. Outer supporting slabs in the test arrangement were fully restrained by hydraulic rams (figs. $3.2 .2,4.1 .8$ ) to introduce a possible severe condition of no rotational accommodation of a transversely (out-of-plane) loaded joint.

TEST 6 - Specimen I-202-1 (seen in fig. 4.1.10 after the test) failed by initial slip at $18.5 \mathrm{kip}$ in the right joint. By contrast, the supporting slabs in this test were unrestrained and were permitted to rotate while the center slab was loaded. A.1.4 Floor Connection Element (Type B) - Horizontal
(In-Plane) Shear

TEST 7 - Specimen I-207-7 is shown in figure 4.1.11 after the test. Spacing of ungrouted joints, for this type of test, was maintained by extra steel shims in the joints at the top of the assemblage. These shims were oiled and interfaced with polyethylene film. Failure occurred by initial slip at 10.0 kip in the right connection followed by similar action in the left one. Continued loading produced increased slip, minor 
detrision of bolt-hole edges in the inserts and shear of the right bolt at 34.5 kip. Figure 4.1 .12 is a load-displacement graph obtained from the right LVDT. Displacement dials placed at the outer ends of the test assemblage indicated very small rotational uplift $(0.017$ in maximum at right end).

TEST 8 - Specimen I-201-1 is not il1ustrated. This test was similar to Test 7 except that the joints and insert tubes were grout-filled. Failure occurred by initial slip in one connection at $33.0 \mathrm{kip}$. This load was not exceeded during continued deformation. Continued loading produced increased slip, marked detrusion of bolt hole edges in the inserts and shearing of one bolt at 33 kip.

TEST 9 - Specimen I-207-7 (repeat) consisted of the component slabs used in Test 7 (reassembled with unused bolts and shims) with only the insert tubes grout-filled. As in Test 7 , ungrouted joint spacing was maintained by oiled shims at the top of the test assemblage. The specimen, after the test, is shown in figure 4.1.13. Failure occurred by initial slip in one connection. at 11.7 kip followed by similar failure in the other. Continued loading produced increased slip, marked detrusion of insert bolt hole edges, apparent bolt bending and shearing of both bolts at 35.5 kip per bolt.

TEST 10 - Specimen I-209-7a failed by initial slip of both connections at 10.0 kip per connection element without any indication of cracking in the concrete. Continued loading pro- 
duced 0.27 in of connection slip and visible cracking at 24 kip per connection element. Further loading to a maximum load of 33 kip per connection element caused 0.5 in of shear cracking deformation and racking of insert tubes (figs. 4.1.14,4.1.15).

TEST 11 - Specimen I-210-7a failed by initial slip of both connection elements at 11.0 kip per connection element. Progress of load-deformation was similar to that of Test 10 except for the absence of racking of the grout-filled insert tubes (which did, however, undergo some rotation under continued loading) (fig. 4.1.16, right connection). Maximum load produced the major diagonal crack at the right connection; shear failure of the bolt followed. The back of the specimen is shown in figure 4.1 .17 .

TEST 12 - Specimen I-205-5 was subjected to simulated repeated wind loading causing an in-plane shear force of 3.8 kip per connection element (figs. 3.2.3,4.1.18). Load was varied (as a haversine function) from 0 to 3.8 kip per connection element for 1000 cycles at a frequency of $0.1 \mathrm{~Hz}$. The oscillograph record of the entire test showed no detectable slip in either connection within the limit of resolution $(0.005 \mathrm{in})$.

TEST 13 - Specimen I-204-3 was subjected to a repeated in-plane shear force of 6.9 kip per connection element. The load was a sine function between the limits of \pm 6.9 kip per connection element for 5 cycles at a frequency of $0.1 \mathrm{~Hz}$. The 
experimental setup is illustrated by the same figures used to illustrate Test 12. The oscillograph record of the entire test showed no detectable slip in either connection within the limit of resolution $(0.005$ in).

\section{A.2 Wall Connections}

\section{A.2.1 Wal1-Connection Element (Type E) - Tension}

TEST 14 - Specimen III-401-2 failed when a maximum total load of 58.0 kip caused tensile rupture of both stud bolts. Relative movement between the insert horizontal base plate and undisturbed concrete was measured by the LVDT shown in figure 4.2.1, as well as by an LVDT mounted on the rear face of the specimen. The base plate uplift of 0.006 in given in table 3.0 is the greater value of the two sides instrumented (front). Tensile failures of the stud bolts were observed not to have experienced any readily apparent reduction in cross section, i.e., necking down (fig. 4.2.2).

\section{TEST 15 - Specimen III-402-4 failed at a maximum total} load of 55.0 kip at which time one stud bolt was ruptured in tension. Average maximum elongation in the studs (in a 2-7/8 in length under tension) was 0.04 in. Maximum elongation in the ruptured stud was 0.09 in; yielding of the ruptured stud permitted the pulling device to rotate and allowed the second stud to recover. Elongation of the studs was measured by LVDT's (fig. 
4.2.3) with reference to the vertical tongue plate of the insert and under-surface of the stud nuts (fig. 4.2.4).

TEST 16 - Specimen III-403-6 failed by tensile rupture of both stud bolts at a total maximum load of 57.5 kip. As shown in figure 4.2 .5 , this specimen was instrumented to measure approximate elongation of the studs on the right and left sides of the insert tongue plate, as well as uplift displacement of the insert base plate with respect to the front and rear faces of the concrete specimen. The extra LVDT at the right side of the tongue was used for test monitoring. The specimen after the test is shown in figure 4.2.6. At failure, the average elongation in $27 / 8$ in of the individual studs (figs. $4.2 .7,4.2 .8)$ was 0.046 in; some recovery occurred in the left stud. The average uplift of the two edges of the base plate (figs. 4.2.9, 4.2.10) was 0.008 in at failure.

\section{A.2.2 Wall Connection Element (Type F) - Tension}

TEST 17 - Specimen III-503-6 and similar ones were tested upside down. Each test of this type was terminated by faiture of the pulling apparatus (5/8 in A-325 nuts and bolts which simulated the stud bolts of a mating Type E insert in practice). The total maximum load of 50.0 kip stripped the threads of both nuts. Insert plate uplift was measured at the front and rear faces as in preceding tension Tests 14 and 16 . Figure 4.2.11 shows the stripped nuts and minor (penciled) cracks in 
the concrete specimen near the ungrouted access block-out. The cracks were observed at $40 \mathrm{kip}$.

TEST 18 - Specimen III-501-2 sustained a total maximum load of 61.0 kip. Failure was by thread stripping of one pul1ing bolt nut (fig. 4.2.12). An audible sound of slip was heard at a 10-kip total load although there was not visible indication of distress. At 38 kip, a vertical hairline crack was observed at the front centerline of the grout fill. At failure, this crack closed and was not visible. Figure 4.2 .12 also shows how a reference fixture for the LVDT core was attached to the edge of the insert plate in a grouted specimen at the front and rear.

TEST 19 - Specimen III-502-4 sustained a total maximum load of $68.0 \mathrm{kip}$. The test was ended by rupture of both pulling bolts. Plate uplift was measured at front and rear. Figure 4.2.13 shows (penciled) cracks in the concrete after the test.

A.2.3 Wa11 Connection Element (Type D) - Horizontal (Out-ofPlane) Shear

The assemblage used in each of these tests provided a symmetrical double specimen. Each half of an H-assemblage ( $a$ and b, in fig. 4.2.14) simulated a T-connection of two floor slabs connected to a bearing wall top (inserts $A$ to $D$ to $A$ ). The position for testing was rotated $90^{\circ}$ from that in actual use. Thus, an artificially double-top-ended test wall panel (fig. 2.2.3; horizontal in fig. 4.2.14) contained a Type D insert at both ends, a and b. In order to subject the Type D 
connection elements to direct out-of-plane shear, i.e., with the floor panels restrained from rotating, steel struts (I-beams) were grouted between the two upper floor panels. Threaded steel tie rods with cross channels were grouted around the two lower panels for the same purpose (fig. 4.2.14). Except for Test 20, subsequently described, each test in this group was one-half of an H-assemblage loaded independently. Observed ram load values were converted to a parallel total equivalent load acting at the "top" edge of the wall panel, i.e., an insert reaction considered to act at the junction of the insert base plate and tongue (figs. 1.2.11,2.2.3). Out-of-plane (transverse) shear failure was considered to have occurred in tests of this group when there was visible shear cracking around the Type $D$ insert and an increased rate of deformation as observed on the load-deflection monitor.

TEST 20 - Specimen II-001-2(a) was for one of two assemb1age halves loaded simultaneously. Transverse shear failure occurred at $30.0 \mathrm{kip}$. The specimen was loaded to a maximum load of 50 kip with a corresponding deformation in excess of $0.28 \mathrm{in.}$ Transverse shear deformation was measured between the wall panel side areas and its central area over the imbedded insert (end b of fig. 4.2.14). Figure 4.2.15 shows the transverse shear failure after testing with the test apparatus removed. Areas to either side of the cracked portion are covered with plate embedment plaster. 


\section{IEST 21 - Specimen II-001-2(b) was tested simultaneously}

with the preceding one as shown in figure 4.2.14. Failure occurred by shear, similar to Test 20 . The two rams used for testing the whole assemblage were operated by a common pump. End (a) yielded more readily than (b). Thus, the deformation at end (b) lagged the maximum load $(0.03$ in at $50 \mathrm{kip})$. End (b) was, therefore, retested independently. In the retest a maximum load of 42 kip was reached at 0.13 in deformation after which the continued loading dropped off to 36 kip at a deformation of 0.46 in. Loading apparatus and instrumentation mounts for the retest (and following tests) were slightly altered to reduce the confinement of the concrete around the Type $D$ insert. Modified loading hardware appears in photos of subsequent tests.

TEST 22 - Specimen II-002-4(a) was tested by static cyclic loading. Each load application was increased by an increment of 4 kip. Apparatus and specimen after testing are shown in figure 4.2.16. Note the smaller, less confining pressure plates and the mounting of the LVDT directly on the wall panel side edges. Transverse shear failure occurred at a load of 23.8 kip. The highest loading cycle reached a maximum of 39.4 kip at 0.08 in deformation, beyond which loading was continued without cycling. A transverse deformation of about 1 in was reached at a diminishing load of $27 \mathrm{kip}$. Figure 4.2.17 shows the computer plot of load-displacement relationship at the ends of each cycle. Data were recorded at zero loads and at each new load increment. 
Lines between plotted points were added to indicate cyclic sequence and do not represent the exact path between points.

TEST 23 - Specimen II-002-4(b) was also tested by cyclic loading similar to that of the preceding test. The apparatus and specimen after the test are shown in figure 4.2.18. Transverse shear failure occurred at a load of 25.0 kip. The last loading cycle reached a maximum of 41.7 kip at 0.12 in deformation, beyond which loading was continued without cycling. A transverse deformation of about 0.8 in was reached at a diminishing load of $27 \mathrm{kip}$. An additional displacement measuring dial was used in this test to observe movement of the wall panel in the vicinity of the insert with respect to the attached (upper) floor panel. A maximum movement of the wall of 0.02 in in the direction of the applied force was observed at maximum 10 ad.

TEST 24 - Specimen II-003-6(a) failed by shear at a load of 25.0 kip. Loading was by 4 kip increments without cycling. Continued loading reached a maximum of 41.2 kip at a shear deformation of $0.14 \mathrm{in}$. Further loading dropped to 29 kip at a deformation of about 0.4 in. Dial-measured displacement of the wall panel relative to upper floor panel near the Type $D$ insert was 0.06 in at maximum load. Figure 4.2.19 shows the specimen cleared of concrete debris after the test. Also visible is the large joint (1-3/4 in) between floor panel edges which was in all test assemblages of this group. The 
joint width was created by two $1 / 4-$ in shims on both sides of the Type $D$ insert tongue to prevent interference of fillet welds (which join tongue to base plate, fig. 1.2.11) with the bearing edge of floor panels.

TEST 25 - Specimen II-002-6(b) was tested by static cyclic loading similar to that of Tests 22 and 23. Failure by shear occurred at a load of $25.0 \mathrm{kip}$. After failure, loading was continued, without cycling, to a maximum of 44 kip at a shear deformation of $0.17 \mathrm{in}$. Loading beyond the maximum was continued to a diminishing load of $40 \mathrm{kip}$ at a deformation of about 0.28 in. Excessive fragmenting of the concrete near the LVDT core prevented further deformation readings. However, figure 4.2 .20 shows evidence of additional deformation ( 0.6 in) caused by further drop-off loading. 
FORM NBS-114A (1.71)

LORM. OEPT. OF COMM BIBLIOGRAPHIC DATA SHEET

1. PUBLICATION OR REPORT NO
NBSIR $73-126$
$-126$

4. TITLE AND SUBTITLE

Structural Tests of Mechanical Connections for Concrete Panels
5. Publication Date

6. Performing Organization Code

\section{AUTHOR(S)}

Louis E. Cattaneo and Felix Y. Yokel

8. Performing Organization NBSIR 73-126

9. PERF ORMING ORGANIZATION NAME AND ADDRESS

NATIONAL BUREAU OF STANDARDS

DEPARTMENT OF COMMERCE

WASHINGTON, D.C. 20234

10. Project/Task/Work Unit No.

\section{2}

11. Contract/Grant No.

$$
\text { IAA }-\mathrm{H}-16-70
$$

12. Sponsoring Organization Name and Address

Office of Research and Technology

Department of Housing and Urban Development

Washington, D.C. 20410

13. Type of Report \& Period Covered

Final

14. Sponsoring Agency Code

16. ABSTRACT (A 200-word or less factual summary of most significant information. If document includes a significant bibliography or literature survey, mention it here.)

Structural evaluation tests were performed on prototype steel insert connectors proposed for joining floor and wall panels of a precast concrete housing system included in Operation BREAKTHROUGH. Descriptions are given of 25 tests conducted with 5 different types of connectors. Specimen connections were laboratory tested under simulated design loading conditions to evaluate their load capacity and ductility.

17. KEY WORDS (Alphabetical order, separated by semicolons) Concrete panels; connections; ductility; floor diaphragms; housing systems; insert connectors; Operation BREAKTHROUGH; precast concrete

18. AVAILABILITY STATEMENT

X UNLIMITED.

FOR OFFICIAL DISTRIBUTION. DO NOT RELEASE TO NTIS.
19. SECURITY CLASS (THIS REPORT)

UNCL ASSIF IED

20. SE CURITY CLASS (THIS PAGE)
21. NO. OF PAGES

UNCL ASSIFIED 

